
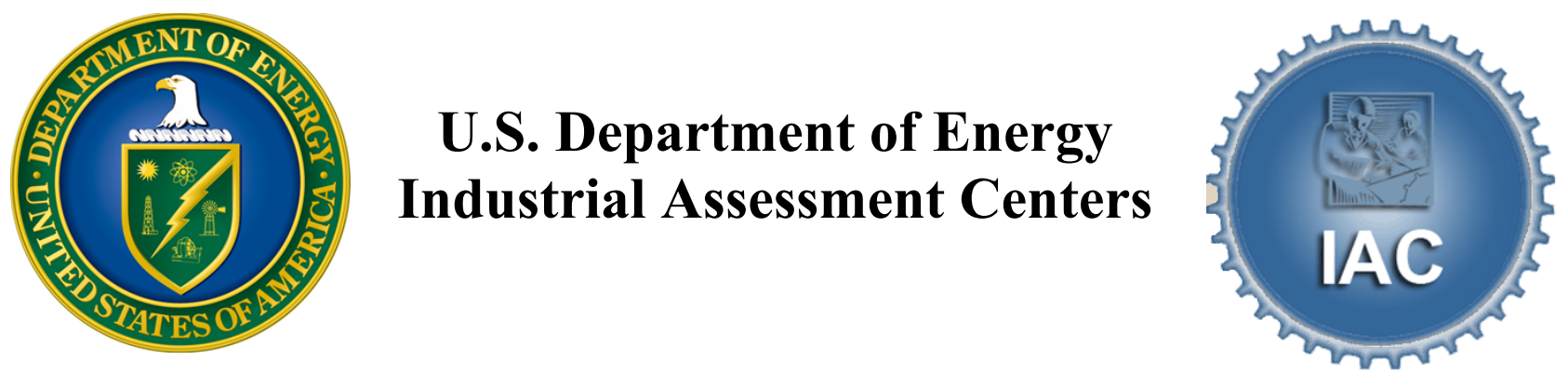

\title{
Industrial Assessment Center (IAC) \\ Operations Manual
}

\author{
Prepared by \\ Industrial Assessment Center, West Virginia University \\ Oak Ridge National Laboratory
}

November 1, 2016 


\section{TABLE OF CONTENTS}

ACKNOWLEDGEMENT .1

ABBREVIATIONS, ACRONYMS, AND INITIALISMS .........................................1

1. OPERATIONAL CHARACTERISTICS OF AN IAC .......................................1

1.1 Introduction ..........................................................................................................1

1.2 Organizational Model and Operations of the IAC ......................................2

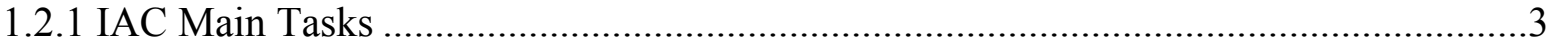

1.2.2 Benefits of the IAC programs ...........................................................................2

1.3 Energy Assessments and Reporting ..............................................................3

1.4 Health and Safety Aspects .....................................................................................7

2. CENTER MANAGEMENT .....................................................................9

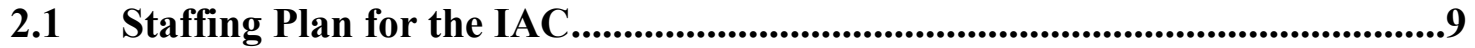

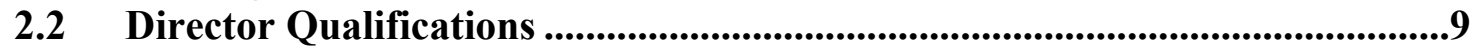

2.3 Interface with Field Manager ...............................................................................10

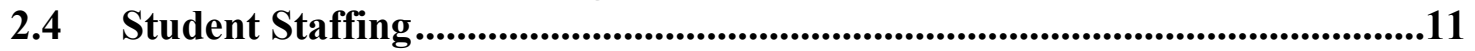

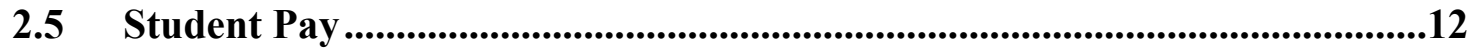

2.6 Student Roles and Responsibilities ........................................................12

2.7 Student Training .......................................................................................13

2.8 Relationship between Curriculum and IAC Operations ..............................14

2.9 “Graduating" IAC Student Competency Measures .....................................15

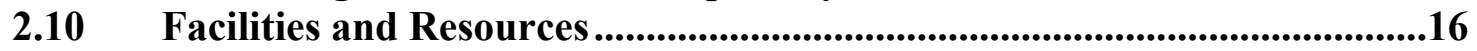

2.11 Continuous Improvement Plan ....................................................................18

3. TYPICAL ENERGY ASSESSMENT ...............................................................19

3.1 The Energy Assessment Process .....................................................................19

3.1.1 Client Selection and Marketing .......................................................................19

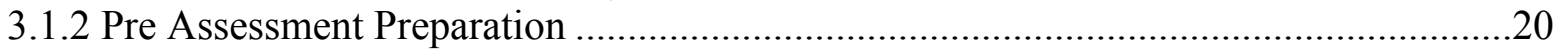

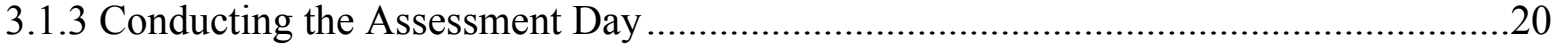

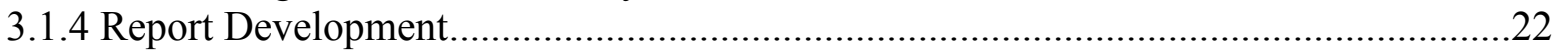

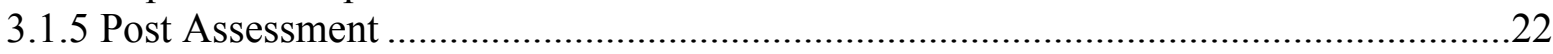

4. ENERGY ASSESSMENT FOR SPECIFIC INDUSTRY SECTORS ...................24

4.1 Glass Manufacturing .................................................................................24

4.2 Plastics Manufacturing...........................................................................................27

4.3 Iron \& Steel Manufacturing.................................................................................29

4.4 Chemicals Manufacturing ................................................................................31

5. CROSSCUTTING TECHNOLOGIES FOR IMPROVED ENERGY

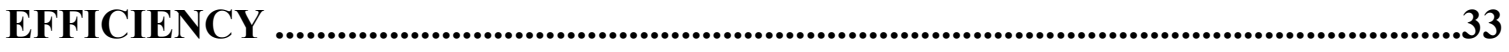

4.5 Process Heating Systems ..................................................................................33

5. TOOLS AND TECHNIQUES ........................................................................................38

5.1 Pressure Profile Monitoring ........................................................................38 


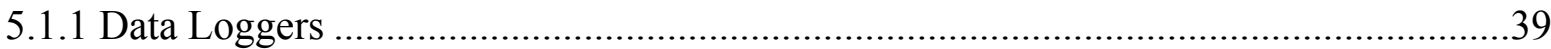

5.2 POWER Consumption Monitoring ................................................................44

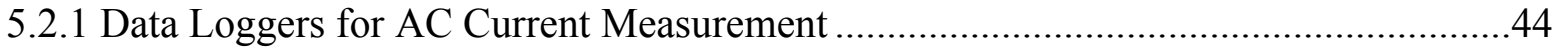

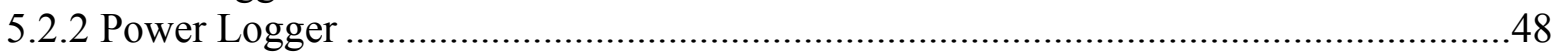

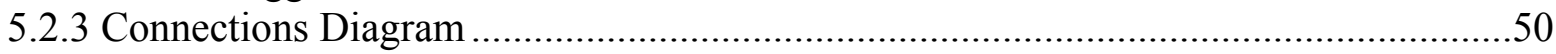

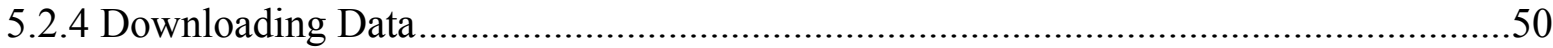

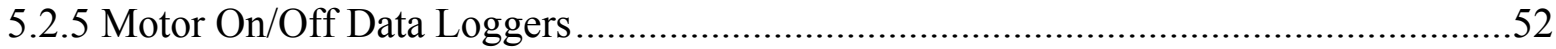

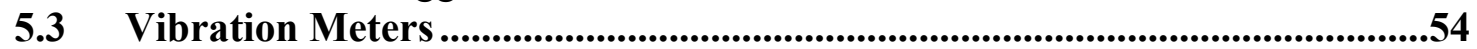

5.4 Ultrasonic Leak Detector.....................................................................................56

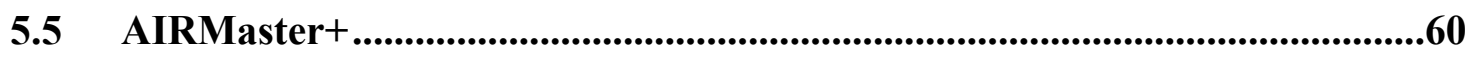

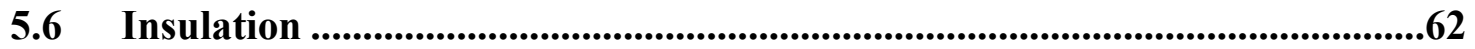

6. APPENDIX ..........................................................................................................................67

6.1 Appendix I: Equipment List .................................................................68

Appendix II: Sample IAC Pre Assessment Questionnaire .......................................93

Appendix III: Sample IAC Assessment Report ........................................................98

Appendix IV: Sample Implementation Survey .........................................................99 


\section{ACKNOWLEDGEMENT}

Bhaskaran Gopalakrishnan of West Virginia University Industrial Assessment Center prepared this report in collaboration with Sachin Nimbalkar and Thomas Wenning of Oak Ridge National Laboratory (ORNL). We would like to acknowledge John Smegal and Andrew Graves of U.S. Department of Energy for providing valuable guidance and management support.

In addition, we wish to recognize the following individuals for their review work and technical advice:

Subodh Chaudhari, West Virginia University Jennifer Travis, Oak Ridge National Laboratory

Kiran Thirumaran, Oak Ridge National Laboratory 


\section{ABBREVIATIONS, ACRONYMS, AND INITIALISMS}

\begin{tabular}{|c|c|}
\hline ABET & Accreditation Board for Engineering and Technology \\
\hline AEE & Association of Energy Engineers \\
\hline AR & Assessment Recommendation \\
\hline ASHRAE & American Society of Heating, Refrigeration, and Air Conditioning Engineers \\
\hline BBtu & billion Btu \\
\hline BPTS & Best Practices Tracking System \\
\hline Btu & British Thermal Units \\
\hline CY & Calendar Year \\
\hline $\mathrm{CD}$ & Compact Disk \\
\hline $\mathrm{CO}_{2}$ & Carbon Dioxide \\
\hline $\mathrm{CHP}$ & Combined Heat and Power \\
\hline CTA & Collaborative Targeted Assessment \\
\hline CWSAT & Chilled Water System Analysis Tool \\
\hline DOE & Department of Energy \\
\hline DC Pro & Data Center Profiler \\
\hline EERE & Energy Efficiency and Renewable Energy \\
\hline EIA & Energy Information Administration \\
\hline EPA & Environmental Protection Agency \\
\hline EPACT & Energy Policy Act \\
\hline FSAT & Fan System Assessment Tool \\
\hline FY & Fiscal Year \\
\hline IAC & Industrial Assessment Center \\
\hline IIE & Institute of Industrial Engineers \\
\hline ITP & Industrial Technologies Program \\
\hline MECS & Manufacturing Energy Consumption Survey \\
\hline MER & Monthly Energy Review \\
\hline MMBtu & million Btu \\
\hline $\mathrm{MMTCO}_{2}$ & million metric tons of carbon dioxide \\
\hline ORNL & Oak Ridge National Laboratory \\
\hline PHAST & Process Heating Assessment and Survey Tool \\
\hline PSAT & Pumping System Assessment Tool \\
\hline PWA & Plant-wide Assessment \\
\hline QS & Qualified Specialists \\
\hline QuickPEP & Quick Plant Energy Profiler \\
\hline RECS & Residential Energy Consumption Survey \\
\hline SENA & Save Energy Now Assessment \\
\hline SEP & Superior Energy Performance \\
\hline SIC & Standard Industrial Code \\
\hline SSST & Steam System Scoping Tool \\
\hline SSAT & Steam System Assessment Tool \\
\hline TBtu & trillion Btu \\
\hline
\end{tabular}




\section{Operational characteristics of an IAC}

\subsection{Introduction}

The Industrial Assessment Centers (IAC) are funded by the Industrial Technologies Program (ITP) within the U.S. Department of Energy's (DOE) Office of Energy Efficiency and Renewable Energy (EERE), provides a unique opportunity to support efficient resource utilization in small to medium-sized manufacturers ${ }^{1}$. The IACs help manufacturers identify opportunities to improve energy efficiency, minimize waste, and improve productivity. Figure 1.1 illustrates the IAC centers in the United States.

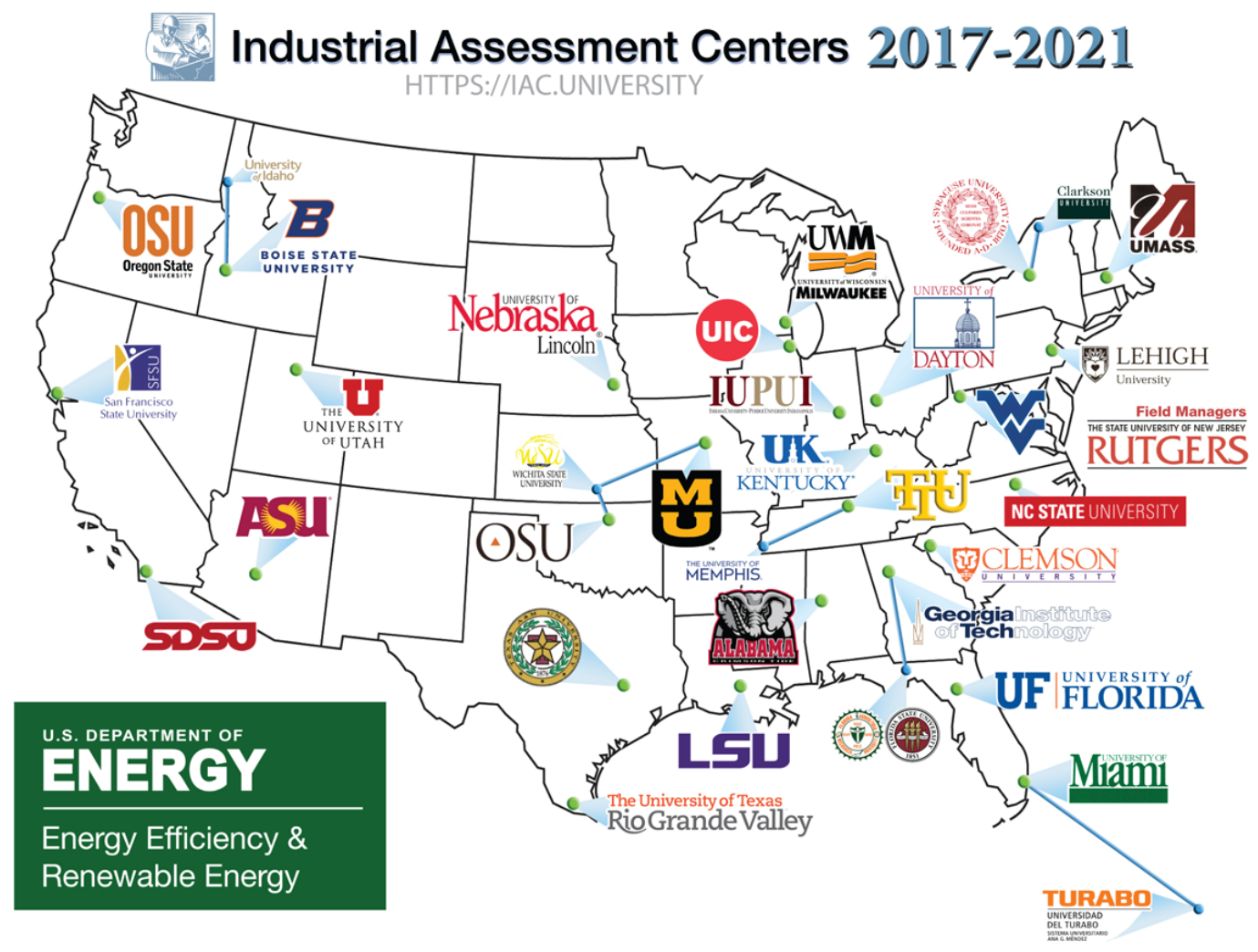

Figure 1.1: Industrial Assessment Centers in the United States

\footnotetext{
${ }^{1}$ Small plants - annual source energy consumption $<26$ billion Btu, Medium plants - annual source energy consumption $>26$ BBtu and less than 500 billion Btu, and Large plants - annual source energy consumption $>500$ billion Btu.
} 
Twenty-Nine Industrial Assessment Centers located within 34 engineering departments at top universities across the U.S. conduct energy assessments for small and medium-sized manufacturers and train the future workforce of energy engineers. IACs provide training to engineering students in the identification and analysis of efficient energy use in each aspect of the manufacturing process and associated supporting elements.

The IACs generate savings through three main activities: 1) energy assessments, 2) assessments conducted by members of the IAC alumni and 3) the popular IAC website which includes a database of nearly 134,000 energy savings opportunities identified from over 17,600 assessments as well as self-assessment manuals and similar resources.

\subsection{Organizational Model and Operations of the IAC}

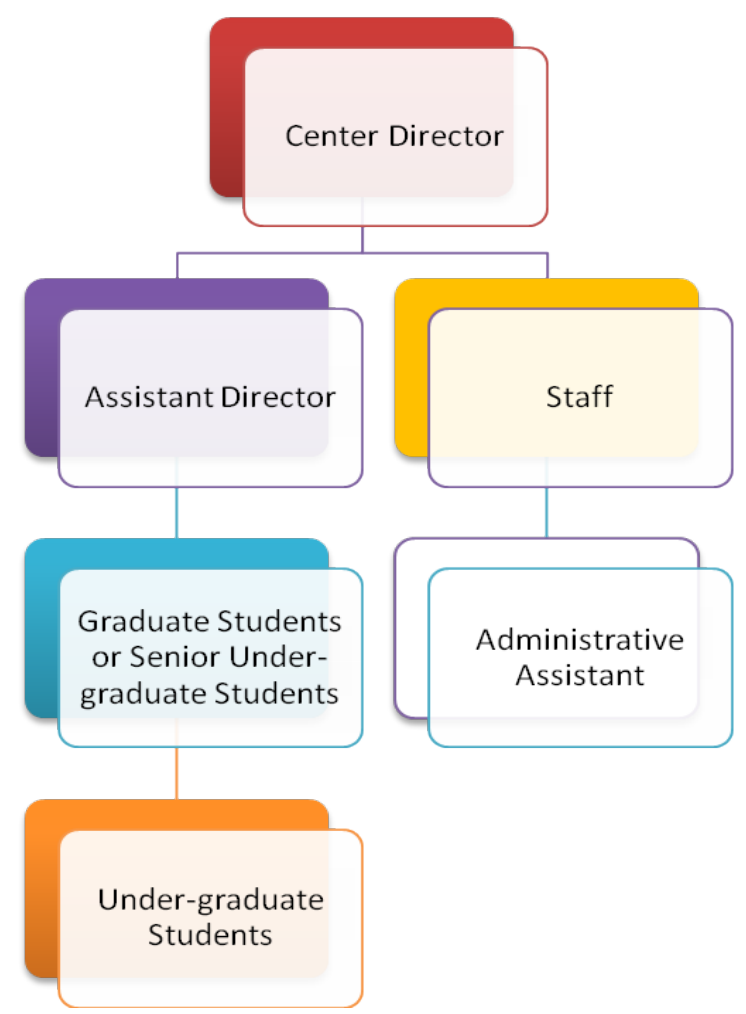

Figure 1.2: Industrial Assessment Center - Typical Organizational Structure

The Director and the Assistant Director of the IACs provide engineering students with practical education, experience, and training in energy engineering. The IACs employ several graduate and undergraduate students and continuously train them on the 
identification and analysis of efficient resource use in each aspect of the manufacturing process and associated supporting elements. The IACs make every effort to promote the training of young engineers in the understanding of the role of energy efficiency and renewable energy practices in basic manufacturing process systems and operations. The IACs enable undergraduate and graduate students to obtain hands-on training in industrial energy, waste, and productivity assessment skills. The IACs employ several engineering students, undergraduates and graduate students. The students are an integral part of the IAC program. Students receive training courses in safety, and then are trained on energy efficiency and the use of related equipment. Each student gains experience as a member of the assessment team and is responsible for participating in on-site energy assessment visits, use of data monitoring equipment, performing energy savings calculations, and writing Assessment Recommendations (AR) on energy, and on waste and productivity aspects that have an energy impact. The students are provided the opportunity to obtain hands-on energy assessment experience, gain competency in the use of the ITP system tools, attend professional meetings, write technical reports, and participate in academic coursework. There are many other tasks, which are accomplished by the IACs, and the students are involved with the Directors in performing them.

\subsubsection{IAC Main Tasks}

IAC work activities can be grouped into four different categories: 1) Management, 2) Pre-assessment, 3) During-assessment, and 4) Post-assessment activities. IAC main tasks are shown in Table 1.1. As students gain experience and knowledge, they are assigned specific responsibilities from the list provided in Table 1.1 such as merging the document, analyzing and writing the energy bill section. Students also attend professional meetings and conferences, as well as participate in the IAC Student Forum, where they can learn more about efficient use of energy and present results of their work. They are also provided with additional training in industrial energy systems, and sent to training courses for ITP Energy System Tools End-Users and Qualified Specialists. Benefits of the IAC program are provided in the next sub-section. 


\begin{tabular}{|c|c|c|c|}
\hline Management & Pre-assessment & During Assessment & Post-assessment \\
\hline $\begin{array}{l}\text { - Identifying potential } \\
\text { clients for scheduling } \\
\text { IAC assessments, } \\
\text { Contact clients and } \\
\text { collect high level plant } \\
\text { data to cross-check the } \\
\text { IAC assessment } \\
\text { criteria, } \\
\text { If IAC assessment } \\
\text { criteria is satisfied, } \\
\text { establish assessment } \\
\text { dates, } \\
\text { Organize and } \\
\text { coordinate weekly } \\
\text { progress group } \\
\text { meetings } \\
\text { Quarterly reporting to } \\
\text { field manager }\end{array}$ & $\begin{array}{l}\text { Create client file, } \\
\text { check energy bills for } \\
\text { completion, } \\
\text { Obtain directions to } \\
\text { the site and } \\
\text { information on } \\
\text { plant's safety } \\
\text { protocol, } \\
\text { Record plant data and } \\
\text { information on IAC } \\
\text { pre-assessment } \\
\text { survey form, } \\
\text { Confirm and } \\
\text { coordinate } \\
\text { assessment visit with } \\
\text { the plant contact } \\
\text { person, and } \\
\text { Check metering } \\
\text { equipment and data } \\
\text { collection documents. }\end{array}$ & $\begin{array}{l}\text { Prepare for and deliver } \\
\text { assessment kick-off } \\
\text { meeting, } \\
\text { Collect general information } \\
\text { about the plant operations, } \\
\text { and production process, } \\
\text { - Conduct plant tour or walk- } \\
\text { through analysis } \\
\text { Develop action plan and } \\
\text { assign different systems to } \\
\text { different team member, } \\
\text { Collect high level system } \\
\text { and equipment data and } \\
\text { develop recommendations } \\
\text { based on careful } \\
\text { observations, } \\
\text { Collect detailed field data, } \\
\text { Prepare close-out meeting } \\
\text { slides and deliver closing } \\
\text { remarks. }\end{array}$ & $\begin{array}{l}\text { - Assign specific } \\
\text { recommendations (ARs) to } \\
\text { IAC team members, } \\
\text { - Complete energy bill } \\
\text { analysis and facility } \\
\text { background sections, } \\
\text { - Complete AR assignments, } \\
\text { - Put together a draft copy } \\
\text { of the assessment report, } \\
\text { - Review assessment report } \\
\text { (Directors and Lead } \\
\text { Student), } \\
\text { Make corrections and } \\
\text { submit the report for final } \\
\text { review (Directors), } \\
\text { Mail electronic and hard } \\
\text { copies of report to the } \\
\text { plant contact, } \\
\text { Upload final report to the } \\
\text { Field Manager's database. } \\
\text { Respond to critiques from } \\
\text { Field Manager on report } \\
\text { Implementation Survey } \\
\text { and Report - Directors, } \\
\text { with help from students }\end{array}$ \\
\hline
\end{tabular}

Table 1.1: IAC Main Tasks 


\subsubsection{Benefits of the IAC programs}

IAC program provides the following benefits to students:

- Hands-on training in diagnostics, data collection, and analysis of energy savings opportunities,

- Opportunities to conduct research and author publications related to technical needs and challenges of industry clients,

- Exposure to a wide range of industries, energy systems and solutions,

- Interactions with plant staff, utility representatives and equipment vendors,

- Direct experience implementing U.S., state and local energy policies,

- Work in a consulting-office structure/environment, while completing undergraduate and graduate engineering degrees,

- Expedited ability to obtain professional licensure and certification,

- Experience high-demand by recruiters from industry, consulting organizations, utilities, and ESCOs.

In addition to providing students associated with the IACs with energy training and experience, the Directors continue to promote training of young engineers by incorporating brief introduction of energy and its efficient use in the academic curriculum at the Universities. This provides students with practical background on energy, which they can use later in their professional work as engineers. Figure 1.2 shows benefits through IAC program for faculty, industry and students. 


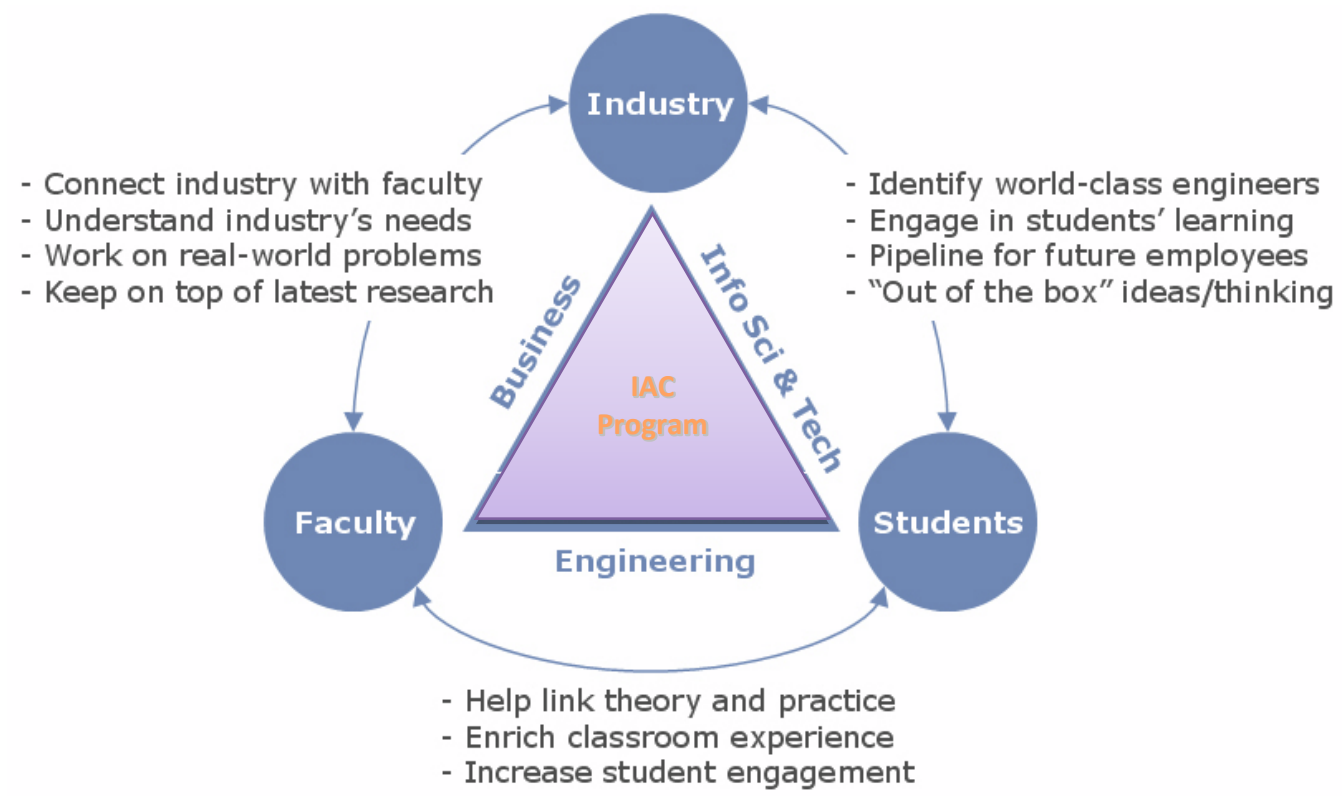

Figure 1.2: Benefits of the IAC program for faculty, industry and students

Figure 1.3 shows how federal government benefits from IAC program.

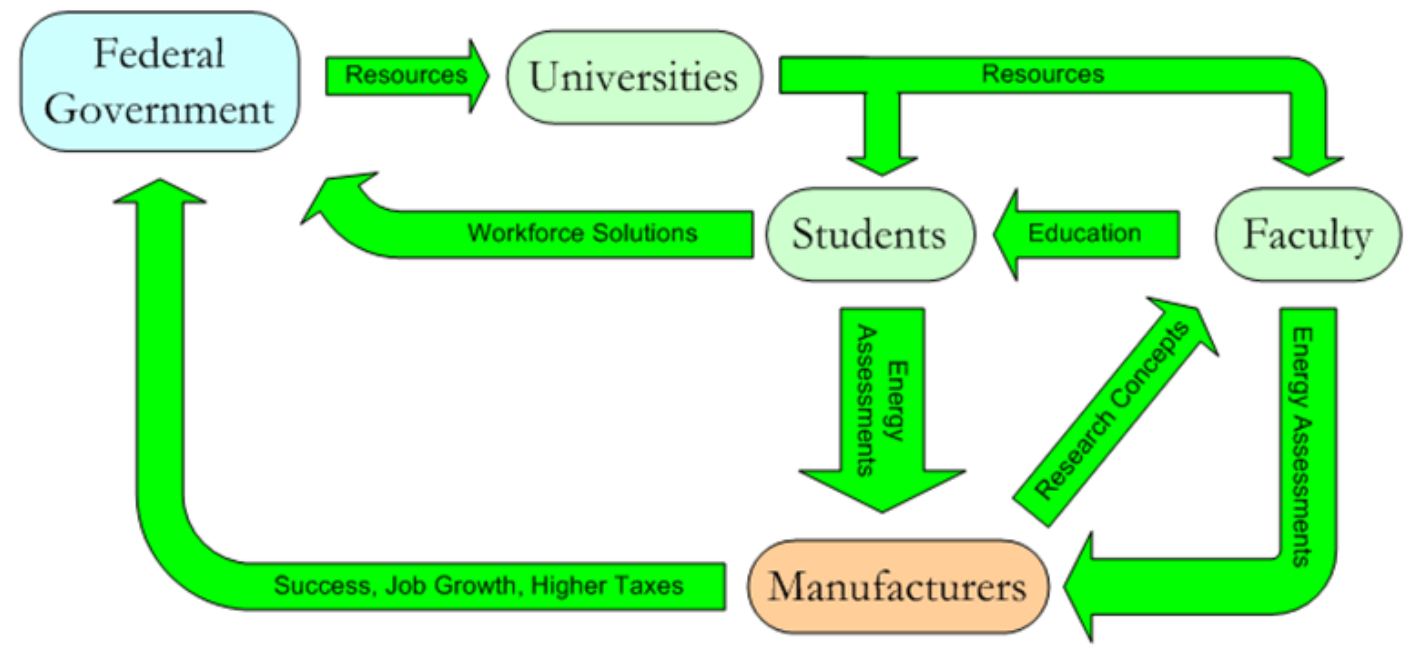

Figure 1.3: Benefits of the IAC program for federal government

\subsection{Energy Assessments and Reporting}

Through the performance of energy assessments, the IACs provide expertise to small and medium-sized plants to reduce their energy usage and costs. Waste minimization and productivity improvement that lead to energy savings are also 
considered. The IACs provide these manufacturers with a comprehensive report that includes all the assessment recommendations, the estimated savings and associated costs, along with their detailed calculations, and the simple payback period. IACs perform energy assessment for varying manufacturing facilities and may focus on crosscut areas with respect to energy systems or devote effort entirely on specific energy systems. The decision in this regard is usually made based upon energy intensity associated with specific energy systems in the facility. For example, if steam system in a facility consumes over $80 \%$ of the energy then it becomes a good candidate for system based energy assessment. During the assessments, the IAC teams also introduce the plant personnel to some of the equipment and Best Practices software used in the assessment, and provides them with limited training. Figure 1.4 illustrates the assessment activities.

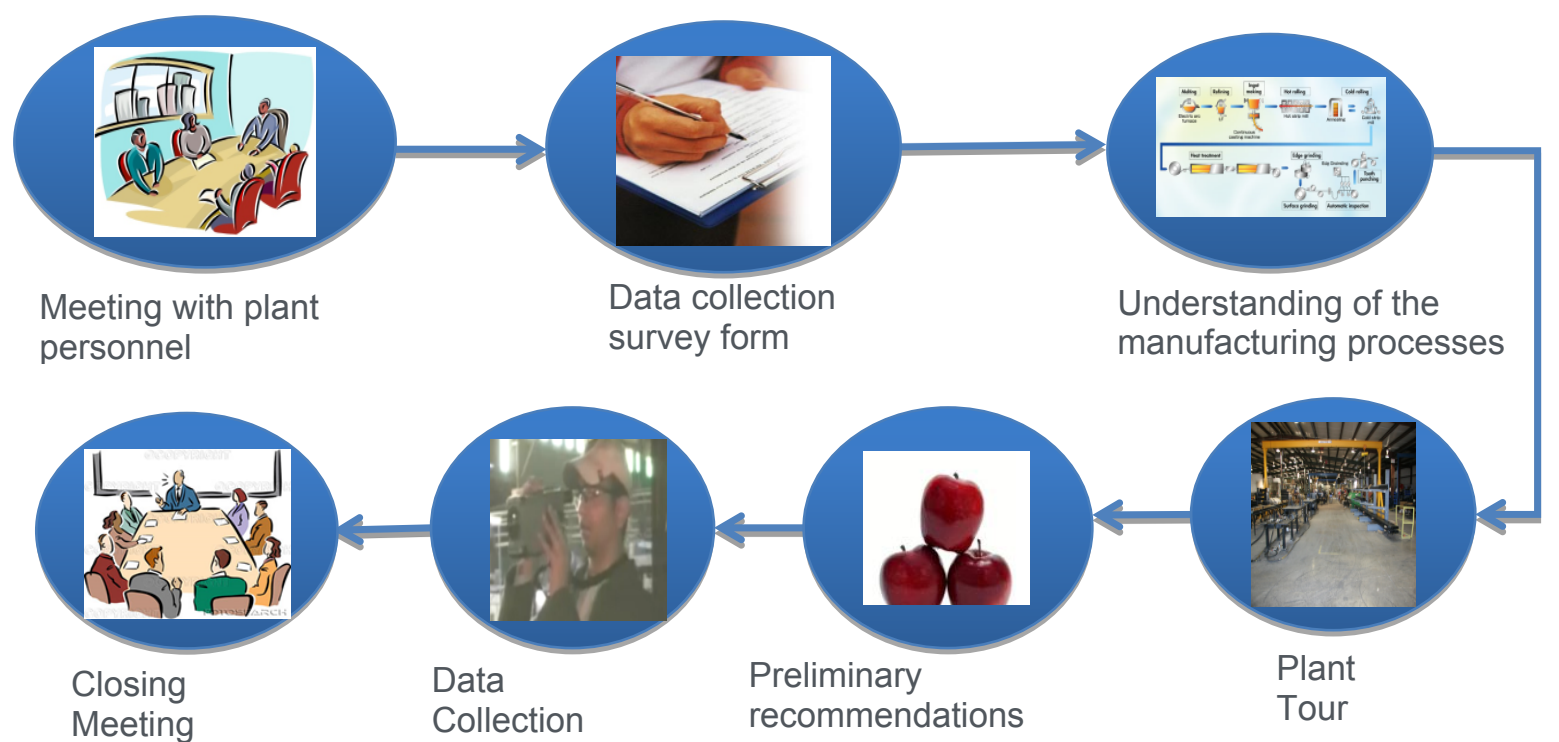

Figure 1.4: Assessment activities

Site visits and comprehensive energy assessments are provided at no cost to the manufacturer. This assistance is provided through effective identification of energy efficiency measures that have a significant impact on energy savings for the manufacturers, cost savings, and payback on investment, pertaining to electricity, natural gas, and other fuels. The pre and post-assessment processes developed by the IACs and their energy efficiency and best practices knowledge, play a major role in delivering and ensuring a continuous energy conservation awareness and policy amongst manufacturers. 
The detailed analysis of the utility bills is an important step towards this process. The utility bills show the energy consumption with respect to time and season and may reveal energy consumption patterns that require attention in terms of electricity, natural gas, and other fuels. The plant tour is an important step towards the identification of energy efficiency measures. The interaction with the plant personnel during the tour often reveals interesting operational characteristics of the energy consuming and process equipment. It also facilitates discussion of any energy efficiency measures that have been attempted in the past by the manufacturing facility. The discussion also clarifies any missing details in terms of process equipment, adopted technologies for operating the process and energy consuming equipment, and the specific methodologies being used in linking the process equipment with other energy consuming equipment. At the end of the plant tour, due to such interaction and close observation of the manufacturing process equipment and other energy consuming equipment, the major focus areas for data measurement and analysis begin to clearly emerge.

The data measurement process is critical, as effective control cannot be achieved without effective measurement. Data logging for electric power consumption, compressed air pressure, motor speeds, temperature, and flow rates are some examples of the effort that will be undertaken to accurately assess the energy consumption "pulse" of the manufacturing facility. The data collected will be subject to a preliminary analysis and validation at the site to discuss any potential anomalies that can be best explained only by the company personnel.

The assessment recommendations developed for the manufacturing facilities, using a process of data logging, monitoring, reference to best practices knowledge, interaction with company personnel, and solid engineering principles, will have a strong potential for implementation. The experience of the IACs certainly aid in the generation of practical and implementation oriented energy efficiency measures that are economically attractive to the manufacturing facilities. In order to be successful, IAC members need to have in-depth knowledge related to functioning of major energy consuming equipment such as air compressor and HVAC units. In section 3 , it is discussed about some of major energy consuming equipment. 
The report produced consists of: (1) the data and other information derived from records and measurements made during the assessment; and (2) the specific recommendations, together with the assumptions used and calculations made. The report includes a detailed description of all manufacturing operations, a plant layout sketch and description, a major equipment list, and an analysis of how energy is used throughout the plant. Each of the energy, waste, and productivity recommendations includes estimates of energy conserved, costs saved, implementation costs, and simple payback periods. The final report and all data that has been collected are kept confidential. All proprietary manufacturing information related to clients is strictly protected. The final report (sample shown in the Appendix II) contains the following:

1. Executive summary of energy savings, cost savings, implementation costs, and payback on investment.

2. Classification of the assessment recommendations into low, medium, and high, in terms of payback on investment for easy review by management.

3. The energy billing summary for electricity, natural gas, and other fuels showing the rates to be used in the energy savings calculation.

4. The assessment recommendations, each detailing the energy savings summary at the very beginning, along with the description of the recommendation, technical formulae used in calculations, assumptions, if applicable, and implementation aspects. The bottom line in terms of payback on investment is shown for each recommendation, along with the annual cost savings, and $\mathrm{CO}_{2}$ emissions saved.

5. Digital pictures of the equipment and specific areas to illustrate the nature of energy saving recommendations, subject to company approval for taking the pictures.

6. The use of DOE Best Practices software tools integrated into the development of appropriate recommendations.

The plant personnel who review the report will see the use of DOE's Office of EERE/ITP Best Practices software incorporated into the generation of many of the energy efficiency recommendations, using the data collected at the plant. This will pave the way for the company personnel to have the interest and motivation to obtain training in some 
of the Best Practices software and utilize them in the continuous energy efficiency process at their facility.

\subsection{Health and Safety Aspects}

The IAC Directors must clearly understand the key health and safety requirements for leading all students on industrial assessments. The assessment process often brings the Directors and the students of the IAC in close proximity to high voltages, high temperatures, corrosive chemicals, molten liquids, high noise levels, slippery floors, obstacles, rotating devices, confined spaces, compressed air and gases, toxic gases, unstable heavy objects, moving vehicles, and other hazardous environments. The safety of the IAC team is dependent on recognizing the hazards posed by each of these aspects. All members of the IAC team understand clearly the types of personal protective equipment that must be used by each team member to address each of these aspects. The Directors of the IACs believe that mitigating the hazard is the key to good safety as this policy has helped the IACs to maintain a $99.99 \%$ accident free record over the years.

The health and safety plan will provide recruited students with comprehensive safety training by one of the Directors as they have participated in numerous assessments and have undergone rigorous safety training themselves through their professional activates. The plan is developed based on the experiences of the Directors as well as input obtained from various health and safety constituents at the universities. The key components of the plan are safe behavior at the facility, Personal Protection Equipment (PPE) to be used, and education on hazards of approaching energized equipment. The focus will be on the use of Personal Protection Equipment that needs to be utilized by every member of the IAC. It is emphasized that some PPE can be obtained at the company while others have to be carried by the assessment team.

The safety training will focus on various aspects of personal protection when working in proximity to industrial energy consuming equipment and infrastructure, and the need to exercise extreme caution when approaching hazardous environments. In addition, the students are taken on a "mock" assessment within the universities facilities that contain energy intensive equipment so as to enable them to understand the fundamentals and importance of proper safety awareness when operating in a 
manufacturing facility. The students will be permitted to go on an assessment only after they have completed the safety training. Prior to the assessment, the Director who will lead the assessment will have a meeting with the students to emphasize and reiterate safety aspects specifically pertaining to the manufacturing facility that will be visited. The students will be informed of the personal protective measures that they must use on the assessment and the importance of "looking out for each other" in terms of safety and health aspects at all times. The students will be informed that they should not collect data during an assessment if safety aspects will be jeopardized in any manner. During the assessment, the Directors will once again discuss safety aspects, and lead by example in being extremely safety conscious during the assessment.

The Directors of the IACs understand that personal protective equipment alone is insufficient for the safety of the IAC team. It is also necessary for the students to understand and be sensitive to how manufacturing operations and material handing are being conducted at the industrial facility. The students are trained to be "aware" of the manufacturing process, movement of materials, motion of the operators, and paths of forklift trucks. The collection of data during an assessment is done subject to the understanding of these aspects. In all cases the company escorts are asked for assistance and advice so as to ensure the safety of the IAC team. 


\section{Center Management}

\subsection{Staffing Plan for the IAC}

The Director and Assistant Director of the IACs are tenure-track Professors who teach graduate and undergraduate courses. Typical teaching loads for the Director and Assistant Director can consume approximately 15 and 8 hours per week respectively. The teaching, research, and administrative duties for each Director are planned in such a manner so as to ensure that at least 2 whole days during each week are available exclusively for assessment purposes. The IAC Directors have published several refereed and conference papers based on the research done in the area of industrial energy saving technology. The papers have provided an effective way to share energy savings techniques, experience, and beyond.

\subsection{Director Qualifications}

The Director of the IAC serves as the strategic leader of the IAC, its primary manager, and mentor for the students. He/she interfaces with DOE and the field manager, and attends the annual Director's meeting. He/she stays current on DOE's current initiatives and BestPractices software tools. The Director makes efforts in integrating the IAC activities and develops collaborations with other partner organizations. He/she works on the long term goals for the IAC to be continued to be recognized as a leader in energy efficiency conservation in the region. He/she is active in publishing work in the energy domain, as evidenced by peer reviewed journal and book publications and conference publications in the domain of energy, manufacturing, and safety. The Director provides the training to the students and is responsible for meeting deadlines for assessments and report submissions. In addition, the director should ensure that submissions are completely in compliance with contract requirements.

$\mathrm{He} / \mathrm{she}$ is an advocate for energy efficiency within the University as well as in the community. He/she interfaces with the U.S. DOE and the IAC Field Manager and others and respond to programmatic requests in a timely fashion, as well as be readily available to interface with industrial clients. The Director makes efforts to stay current on DOE's initiatives including Best Practices software tools and ensures that as many personnel 
within the IAC become Qualified Specialist in at least one Best Practices software tool. The Assistant Director works with and assists the Director on the strategic direction of the IAC. He/she will assist with student recruitment and training and serve in place of the Director when necessary. Some of the IACs utilize the services of professional staff members who are full time employees of the center.

\subsection{Interface with Field Manager}

The IACs realize the importance of effective interaction with the DOE and Field Manager as this impacts the overall effectiveness of the IAC program. The IAC Directors work closely with the Field Manager with respect to the technical and promotional aspects of the program, as indicated herein.

1. Communicate with field managers on a regular basis with respect to center personnel, student utilization, review of assessment reports, accuracy of database input, and reporting requirements for maintaining a quality IAC program.

2. Work closely with the field managers to ensure that special activities initiated by the DOE's Office of EERE and ITP are integrated into the IAC operation in a timely manner.

3. Develop and synthesize material at the request of the field managers so as to facilitate dissemination of energy efficiency information to the concerned stakeholders.

4. Respond to the field manager's request on queries related to specific assessment recommendations and reports so as to improve the quality and integrity of the assessment process and reports.

5. Meet once a year with other IAC Directors, the field manager and his staff, and representatives of the Department of Energy.

6. Cooperate with DOE's Office of EERE and ITP and participate in other EERE/ITP programs and activities, as appropriate.

7. Engage in training and respond to data calls and other activities that may be included in the IAC's workplans.

The IACs believes in effective communication with the field managers to ensure that the quality of the program as well as the reporting requirements is being satisfactorily met. There are several time sensitive tasks that are required to be completed before and 
after the completion of an energy assessment. It is the intention of every IAC to communicate effectively with the field managers so as to resolve queries with respect to these tasks on time. The IACs realize that the IAC program is national in scale and its overall success depends upon its effectiveness as viewed by senior personnel in the U.S. government and the DOE. One example of this is the "Save Energy Now" initiative brought about due to the high escalating costs of natural gas following the hurricanes of 2005. In this context, it is possible that one or more of the special initiatives, that are sensitive to the needs to the industry, be initiated by the DOE's Office of EERE and ITP. The IACs work with the ITP to get involved and play the role to ensure the success of such initiatives.

It is important that the IACs satisfy requests from the field manager from time to time for synthesized energy efficiency and savings data pertaining to the conducted energy assessments for clients. This includes case studies for specific clients protecting proprietary information, which, with the company's permission, can be extremely beneficial in creating energy efficiency awareness in the industrial sector, when published in various media outlets. In developing the case studies, all clients are given an opportunity to review materials that contain information that identifies the plant. One of the most important quality metrics is the technical quality of the assessment recommendations. These recommendations have to be practical, accurate, thorough, and should provide the industrial clients with adequate information to lead to their implementation. The IACs strongly believe that a high implementation rate is key to realized savings, and the centers make every effort to work with the field managers to respond to specific aspects on critiques and feasibility of the assessment recommendations.

\subsection{Student Staffing}

The IACs provide equal opportunity to engineering students in the process of identifying and employing students. The graduate students are usually provided full graduate research assistantships and the undergraduate students are usually on hourly wages. Criteria for student selection include good scholastic achievements, good work habits, good engineering background to perform energy, waste, and productivity 
assessments, and pleasant personalities to work as team members and to deal professionally with the client companies. For example, the undergraduate students selected to work for the IAC should be at least juniors in good academic standing with a GPA of at least 2.5, pursuing a degree in engineering. The graduate students selected to work for the IAC must be pursuing a degree in engineering and must have a GPA of at least 3.0 for M.S. students and 3.5 for Ph.D. students. Some of the students start as sophomores. Each IAC will have its own established criteria for student selection and participation.

\subsection{Student Pay}

Students will be paid based on their level of responsibilities, tenure, and experience. It has been the IACs strategy to hire students on a rational basis so that experienced students can assist in training the newer students. The research assistantships will be a monthly stipend to the graduate students and provide the graduate students a tuition waiver at some of the IACs. Students are paid at a rate so as to attract the best and brightest B.S., M.S., and Ph.Ds typically from the mechanical, industrial, electrical and chemical engineering programs. Graduate students receive a monthly stipend, the amount depending on their academic background and skills. The Lead Student receives a slightly larger stipend. The undergraduate students will be compensated at an hourly rate, the amount depending on their academic background and skills. The students receive pay increases as their tenure and experience increase.

\subsection{Student Roles and Responsibilities}

Only students funded using the IAC resources are permitted to participate in industrial assessments. All students are utilized on the industrial assessments and equal opportunity will be exercised in this regard. IAC Lead Students are selected based on his/her performance and experience and participate in the day-to-day operations of the IAC. The Lead Students maintain the center's student roster in the on-line IAC student registry, and will ensure that all students are registered and that departing students complete the exit interviews. The Lead Students interact with the DOE'S IAC student activities coordinator and with the Field Manager as needed, with the Director's approval. The Lead Student provides direction and assistance to the other students in terms of 
assessment recommendations, report development, computers, and IAC office related aspects. The Lead Student attends the annual student meeting in February hosted by the DOE. He/She also participates in the required training and other activities that are designated for Lead Students. All students are encouraged to attend technical trainings, workshops, and conferences, and to write and present papers on IAC related topics. Many IAC students have attended training sessions in areas such as steam, compressed air, and process heating. Students have the opportunity to engage in professional development and share experiences on a national level through activities such as the annual Lead Student meetings and the IAC student forum website. The students are required to complete exit interviews when they leave the IAC program. They are encouraged to network with other IAC students through the IAC Student Forum website and other opportunities offered by DOE through IAC student activities. The students are eligible to receive certificates from the DOE based on participation on energy assessments. Graduate students are encouraged to adopt energy related research topics towards their thesis, dissertation or problem reports. The IACs also continue to mentor undergraduate senior design projects. The students are encouraged to continue participating in professional society activities such as for ASHRAE, AEE, and IEE. The IACs continue to be committed to producing the next generation of the nation's energy engineers.

\subsection{Student Training}

The first step in training students is to provide them with comprehensive safety training. The students are provided sample utility bills and be trained to understand the billing structure. This enables them to develop the summary data for electricity, natural gas, and other fuels on an annual basis. The students will be required to understand the billing process, the rate structure, and patterns in energy and demand usage. The next step is to emphasize data collection aspects during "mock assessments" on facilities on campus that use a significant amount of energy. The students are trained in the use of each instrument for data collection purposes within the bounds of safe use. The students are exposed to various templates and details of the recommendations that are being proposed to industrial clients on a regular basis. Students are required to develop recommendations based on the data collected during the "mock" assessments. The 
students are trained in the use of DOE's BestPractices tools and software that pertain to these recommendations and will be asked to incorporate the results as part of the recommendations. The IACs utilize AIRMaster+, CWSAT, CHP, FSAT, MotorMaster+, NxEAT, PHAST, PSAT, Steam System Tool Suite, 3E Plus, and ASDMaster in the analysis phase of the development of assessment recommendations. Student training in these and other software tools play a large role in the quality of the IAC reports.

Each recommendation is reviewed thoroughly by the Directors and Lead Students and adequate feedback is provided to the students in terms of feasibility and accuracy. The students are trained in the importance of determining "Best Practices" adopted already by manufacturing facilities nationwide for energy conservation. Detailed training sessions are held by the Directors on this aspect that includes familiarizing the students with the DOE's Office of EERE and ITP information websites and others that describe case studies with respect to Best Practices information. Each student is trained in the "merging" process, where the recommendations developed by many students are integrated into a final report for review by the Director. Each student is also trained in the "uploading" process for reports to the Field Manager. The analysis of critiques of reports from the Field Manager is discussed thoroughly so as the students clearly understand the improvements that can be done to their recommendations. During the assessment process, "new" students are provided "hands on" training by the Directors in terms of utility bill

analysis, safety, data collection, use of instrumentation and professional interface with industrial clients. Feedback is provided to each student on his/her performance.

\subsection{Relationship between Curriculum and IAC Operations}

The Directors teach courses in their expertise topic areas within the field of engineering and make every attempt to educate graduate and undergraduate students on energy aspects. The IACs have often been well integrated into the mission and teaching goals of their respective colleges of engineering and universities. To use the example of an IAC, the Director teaches undergraduate and graduate courses in an engineering discipline, some of which focused on energy systems. The Directors also provide outreach to the community and spend a lot of time in recruiting students for the IAC as well as disseminate IAC experience through conferences and meetings. 
The IACs make efforts to establish a working relationship with the University Media Offices so as to enable the dissemination of industrial energy efficiency information, milestones, DOE's Office of EERE/ITP special initiatives, and success stories as they become available. This aspect is important to publicize the presence of energy efficiency expertise in the University and the regional area. These efforts are done in conjunction with the design and development of a communicative and user interactive website for the IACs as a portal for enabling access to the services provided by the IACs and as an effective outreach arm for the DOE's Office of EERE and ITP program areas and activities.

\section{9 “Graduating" IAC Student Competency Measures}

It is ensured that "graduating" IAC students have a measurable level of competency in the areas of industrial energy assessment and report development. Each "graduating" student has typically participated in at least 10-15 assessments, is able to demonstrate the use of data collection instrumentation during assessments, have attended at least one energy related training session, and has shown demonstrable knowledge in the use of one or more DOE's BestPractices Software and tools. The Directors are responsible to monitor this competency level of "graduating" IAC students. The IACs maintain a strong networking element in the course of their IAC experience. The IACs maintain professional association with the graduated IAC students for mutual benefits. The maintenance of alumni contact information is a key interest aspect for the IACs, each of which will make every attempt to maintain a current database of the IAC students who have exited the program. The IAC students have made several presentations at national conferences. Figure 2.1 shows where the students are headed upon graduation. 


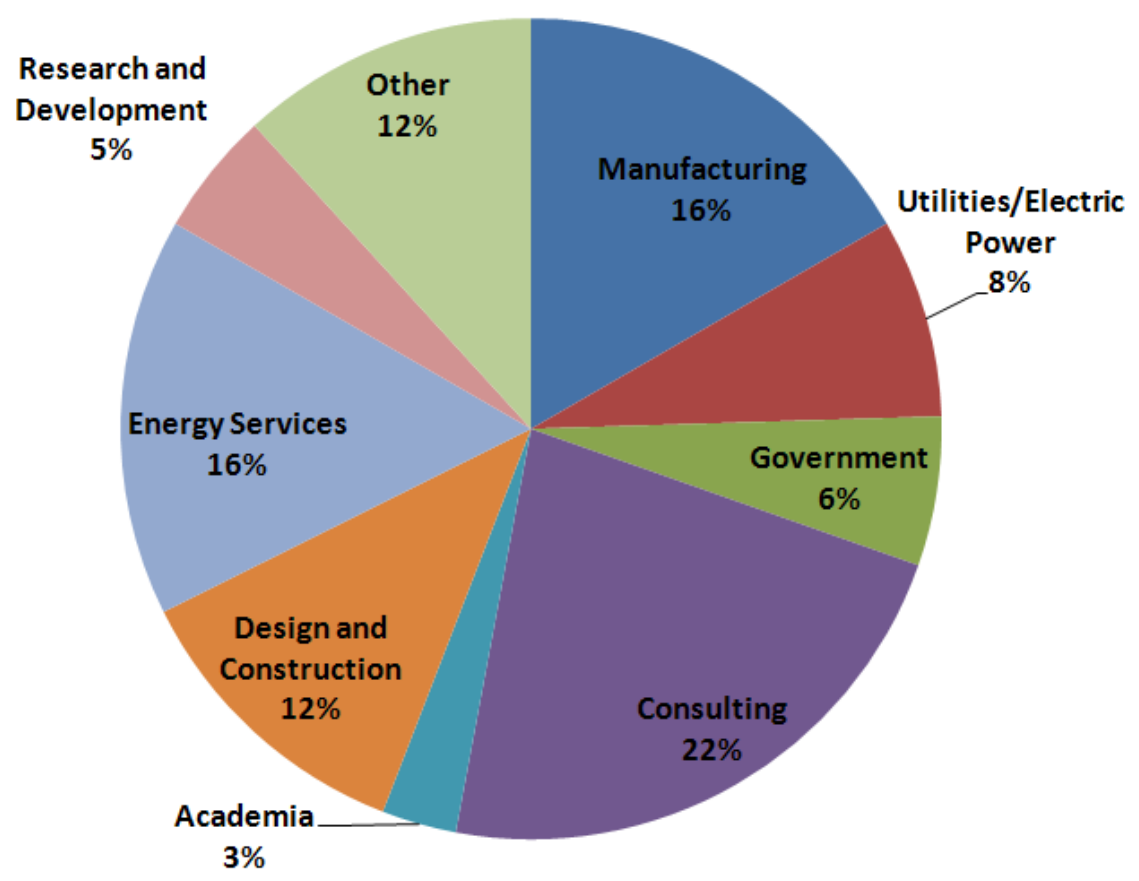

Figure 2.1: where the IAC students are headed upon graduation

\subsection{Facilities and Resources}

The IACs are located in large sized rooms (500 square feet or more) on University campuses and enable many students to work comfortably. The students are required to maintain presence in the IAC office, and the Directors also maintain regular presence. The IAC offices are equipped with telephones, energy analysis and diagnostic equipment (as in Table 2.1 and 2.2), fax machines, scanners, and computers for electronic communication over the Internet and are dedicated only to the IAC. The Table 2.1 and 2.2 shows the typical equipment found in the IACs, with detailed specifications shown in the Appendix I. The instruments, equipment, and computers are subject to regular maintenance and calibration and are also repaired or replaced as soon as possible so as to not disrupt the quality of work being performed at the IACs. The IACs already have relevant energy measurement equipment and data loggers applicable to monitoring parameters on all energy intensive industrial applications, as shown in Table 2.1 and table 2.2 . 
Table 2.1: Office Equipment List typically found in IACs

\begin{tabular}{|l|c|c|}
\hline \multicolumn{1}{|c|}{ Equipment name } & Area of application & No. \\
\hline Computers & Data analysis and report writing & 8 \\
\hline Laptops & Data analysis and report writing & 2 \\
\hline Printers - color & Report generation & 2 \\
\hline Scanners - color & Report generation & 2 \\
\hline Fax Machine & Client/Vendor contact & 1 \\
\hline Phones, Desks, Cabinets & $\begin{array}{c}\text { Client contact, assessment work, report and } \\
\text { equipment storage }\end{array}$ & 10 \\
\hline
\end{tabular}

Table 2.2: Assessment Equipment List typically found in IACs

\begin{tabular}{|l|c|c|}
\hline \multicolumn{1}{|c|}{ Equipment name } & Area of application & No. \\
\hline Combustion Analyzers & Boiler/Furnace/Oven & 3 \\
\hline Ultrasonic Guns & Air leak/Stem trap & 3 \\
\hline Thermo-Anemometers & Air speed/Air temperature & 2 \\
\hline Power logger & Power analyzer & 1 \\
\hline AC Clamp-on Ammeters & Power analyzer & 2 \\
\hline Light Meters & Lighting & 3 \\
\hline Digital Illuminometer & Lighting & 1 \\
\hline Pressure Data Loggers & Compressed air & 16 \\
\hline Digital Pressure Gages & Compressed air & 2 \\
\hline Pressure Transducers & Compressed air & 16 \\
\hline Digital Thermometer & Temperature sensing & 1 \\
\hline Vacuum Leak Detector & Vacuum & 1 \\
\hline Light Intensity meter & Lighting & 1 \\
\hline Flexible Current Transducers & Power analyzer & 2 \\
\hline Digital Thermometer/ Pyrometer & Air/Liquid temperature & 1 \\
\hline Digital Lux HI Tester & Lighting & 1 \\
\hline Stroboscope & Motors & 1 \\
\hline Camera & Process/Equipment pictures & 1 \\
\hline Infrared Temp Guns & Boiler/Furnace/Oven/Other hot surfaces & 2 \\
\hline Temp Gun & Boiler/Furnace/Oven/Other hot surfaces & 1 \\
\hline Airflow Instrument & Boiler/Furnace/Oven & 1 \\
\hline Portable Digital Manometer & Boiler/Furnace/Oven & 1 \\
\hline Light Ballast Tester & Lighting & 1 \\
\hline Thermal Camera & Digital pictures & 1 \\
\hline Digital Camera & & 1 \\
\hline
\end{tabular}

The rooms also have high quality printers, scanners and house large sized central desks for meeting with the students. The rooms have adequate-sized storage space for the storage of reports and energy measurement equipment. The IAC students and Directors 
are the only personnel who are provided access to the IAC room. The computers are state of the art with expanded storage and speed capacities and are connected to the Internet. The rooms also have shelves to store literature on industrial energy efficiency for reference purposes. The IACs also have in their position various reference manuals from organizations such as ASHREA and AEE.

\subsection{Continuous Improvement Plan}

The IACs strive to continuously improve their operations. As mentioned earlier, the IAC students and Directors attend training sessions and attempt to become Qualified Specialists in specific areas, subject to availability of funds. These activities strengthen the efforts to integrate the DOE's Office of EERE and ITP Best Practices with the IAC activities and reports submitted to industrial clients. These activities also lead to the development of new assessment recommendations, help in increasing the savings expected from the proposed recommendations as well as the implementation ratios, enhance the quality of the reports, and lead to the publication and presentation of work in this domain by the Directors and students. 


\section{Typical energy assessment}

\subsection{The Energy Assessment Process}

The IACs usually have two tenure-track faculty members from Engineering Departments at US Universities. The Directors are in charge of the day to day operations of the center working closely with the students, with the final responsibility for the quality of the IAC being with the Director. One or both of the Directors will lead the energy assessments at all times.

\subsubsection{Client Selection and Marketing}

The IACs continue to follow the guidelines set by DOE's Office of EERE and ITP for the selection of firms to receive assessments. These will be small to mediumsized industrial firms within the manufacturing sectors, or suppliers to, or customers for these sectors. In many instances large sized manufacturing facilities subject to energy assessment by IACs. In this case, the assessment could be done over multi day period and focus on energy incentive processes and systems. The Directors schedule the industrial assessments by working with the regional manufacturers' directories, participating in meetings of professional organizations, and using industrial contacts developed as a result of their experience. The plants are located within a reasonable distance from the University campus and satisfy at least three of the criteria set by DOE's Office of EERE and ITP in regard to annual utility costs (Energy bills, in excess of $\$ 100,000$ per year, but no more than $\$ 2.5$ million per year), annual sales (Gross sales less than $\$ 100$ million per year), number of employees (a maximum of 500 employees at a particular plant), and professional in-house energy expertise (a lack of in-house personnel trained in energy use and energy conservation). The assessments are performed in a wide geographical region within approximately 200 miles from the University campuses where each IAC is located. The IACs generally have no difficulty in visiting industrial clients beyond this range, as the Directors understand that the IAC program is national in scope and will require the assistance of the centers in delivering the program goals and priorities.

State Manufacturing Directories are an important source for identifying clients. These directories list all manufacturing facilities grouped by city within a particular state. Some of the IACs also solicit potential clients by interacting with local utilities, through 
its web site on the internet, and receive referrals from past clients who recommend their services to their colleagues in other companies, and receive leads from conferences, seminars, and the U.S. DOE's Office of EERE and ITP. The IACs have maintained quality web sites detailing their services and these web sites are frequently modified to reflect the updates in activities in the domains of assessments, students, and Directors.

\subsubsection{Pre Assessment Preparation}

After pre assessment preparations to identify a potential client a telephone contact is made and an appropriate person identified as the company's representative, typically the plant manager, maintenance manager, or engineering manager. Prior to the plant site visit, the company's representative is asked to provide the IAC with a copy of the 12 most recent months of energy bills, including electricity, natural gas, fuel oil, and any other fuel that is used to provide energy for the facility. The company is also asked to provide the IAC with relevant data on waste disposal quantities that may have an energy impact, and their associated costs. The company is encouraged to send a brochure and other descriptive information about its products and operations. A questionnaire is sent to the company requesting information in detail about the operational characteristics and data on product, process, and systems parameters as well as utility cost and usage. (Appendix IV) A team is formed at the IAC to visit the plant. This team consists of the IAC director or the assistant director as the team leader, and three to five students as team members. Prior to the site visit, the team meets and discusses the operations of the plant, and the members review the information obtained from the company and analyze its bills. One student usually has the responsibility of checking, before the visit, all the energy measurement and monitoring equipment and preparing the standard assessment packet which includes brochures, questionnaire, Best Practices CD, data collection forms, etc., needed for the assessment. The IAC students use the IAC database and case studies to enable the preliminary identification of energy saving recommendations for similar plants.

\subsubsection{Conducting the Assessment Day}

The IAC assessment team will plan to arrive at the industrial facility sufficiently early to discuss the energy bills and to observe the operation of process and energy 
consuming equipment, and the flow of production from raw materials to finished product. The assessment plan for the development of potential energy assessment recommendations utilizes various energy measurement equipment and data loggers. At the plant, the assessment will start with an opening meeting with appropriate plant personnel, during which the assessment process, DOE/ITP services, DOE sponsorship, confidentiality of information, implementation aspects and the reporting process will be explained to the client. The information collection process then moves into high gear as data are gathered about the operations and manufacturing processes of the company, the types of equipment used in the facility such as air compressors, heating/air conditioning units, boilers, chillers, other significant energy consuming equipment, and the information on the types of waste generated by the plant and productivity information that may have an energy impact. The opening meeting is followed by a plant tour, which is conducted in the order of the production process from raw material storage to shipment of finished goods. During this plant tour each IAC team member will observe and record his/her ideas for potential recommendations. While performing this activity, the team members will be required to act in a professional manner and follow their safety training. After the tour, the assessment group will meet and discuss the opportunities that were found, and have a brainstorming session to develop additional ideas. Members of the group will determine the best opportunities for savings, and then organize to collect the required information using the appropriate instrumentation and data sheets. The IAC team will collect pertinent information by returning to the plant floor to take measurements where needed, ask questions of plant personnel when appropriate, observe the operation, and collect data. The IAC Director or Assistant Director will be in charge and will coordinate the team's efforts. The entire group will then meet again to discuss and document the potential assessment recommendations. A closing meeting will be held with the client representatives to explain the recommendations that will be explored. It will be explained that they will receive their assessment report within 60 days, plus calls to check on their implementation progress. At this time as well as during the morning meeting, the IAC Directors will discuss the DOE's Office of EERE and ITP programs and activities with the plant personnel to enable them to understand that partnering and participating in these activities will be part of a continuous energy assessment and 
improvement process at their organization. The $\mathrm{CD}$ containing the Best Practices software tools will be given to each industrial client along with a demonstration on the computer of one or more of the tools in operation.

\subsubsection{Report Development}

The assessment report assignments will be distributed among the IAC student members. The assignments include an executive summary, description of plant operations, plant layout, energy bills analysis, new technologies to consider, QuickPEP energy profiling, preparation of data gathered during the assessment to be placed in the report as graphs, charts and images, and assessment recommendations including energy, and waste and productivity that have an energy impact. The Directors and the Lead Students will assign each student the assessment recommendations to develop, and will state a deadline for the draft report to be sent to the Directors for review. Weekly meetings are held to enable discussion of assessment recommendations and for any necessary modifications based on students' and Directors' input. These weekly meetings are also be a forum for the Directors to interact with the students and try and incubate ideas for the development of new assessment recommendations or modification to existing recommendations for improved technical quality. The draft report is reviewed by the Lead Students and Directors at least twice before being merged into a final report. The final draft is sent to the client within 60 days following the completion of the assessment. Within 60 days, the report will also be electronically transferred to the main program database. The IAC will provide additional technical assistance when requested by the industrial client, as long as the level of assistance is within the time and budget limits of the IAC's contractual agreement.

\subsubsection{Post Assessment}

After sending the report, a call will be made, or an e-mail will be sent, to ensure that the company has received it and understands its contents. If necessary, more or modified information pertaining to the report will be sent to the industrial client. After about six months from mailing the assessment report, a telephone implementation survey will be conducted for each company. A survey form will be used (sample found in the Appendix III), listing the ARs included in the assessment report, and information will be 
collected concerning implementation of each AR or the reason for not implementing it. The survey form will be used to obtain additional information about the clients' estimates of the energy saved, cost savings, and cost for each AR that was implemented. The implementation of assessment recommendations will be summarized in the implementation report and will be uploaded to the field manager's database system. The implementation report will be uploaded within 9 months of the dates of the assessment report submission. A follow up contact with companies, beyond the contact made for the implementation analysis, will be made to determine whether additional energy savings were realized due to replication within other facilities or due to additional implementation of recommendations. The additional energy savings metrics will be reported to the field manager. 


\section{Energy assessment for specific industry sectors}

Various types of industries have implemented energy efficiency measures to improve efficiency of their existing operations. This is especially true for manufacturing industries that have high energy intensity in their operations. These include manufacturing plants in glass manufacturing, plastics manufacturing, primary metals manufacturing and chemical manufacturing industries. Some of the case studies that reveal typical energy saving opportunities that existed in this industry segment and savings realized as a result of a particular measure are discussed here.

\subsection{Glass Manufacturing}

The manufacturing activities carried out in the glass manufacturing facilities range from glass decorating using purchased glass to manufacturing glass from basic raw materials using the hand blown or machine based processes. Four factors which characterize the manufacturing facilities are energy consumption, the plant size, the number of employees, and the annual sales. The industrial assessments conducted at the glass manufacturing facilities revealed a variety of ARs. The manufacturing variety for glass was as follows; hand blown glass, machine made glass, pressed glass, flat glass, glass bending, cut glass, glass fabric production, window manufacturing, decorative glass manufacture, hermetic seal production, and marbles. Significant relationship exists between the annual energy usage and the plant size. The reason that floor area is sometimes strongly correlated with energy usage is because manufacturing processes are usually laid out based on lean manufacturing principles, hence the energy usage is well distributed on the shop floor.

A list of ECOs was recommended for each plant assessed. The energy conserved was reported for each ECO. The ECOs were selected for each plant based on the percentage of energy savings they contributed with respect to the total energy savings recommended for that plant. In general, for each plant, ECOs which had energy savings of twenty percent or higher with respect to total recommended energy savings were selected for this list as they were considered to be the most significant. The ECOs found in the glass manufacturing facilities were adjusting air to fuel ratios, preheat combustion intake air, heat recovery and distribution, insulation of hot surfaces, replace motors with energy 
efficiency motors, modify chiller operation, modify heat output in process, improvement in compressor operation, and reduce infiltration and space heating loads. A total of 280,000 MMBtu or 295,416,800 Megajoules of energy savings were recommended at the thirty two glass manufacturing facilities as a result of these energy efficiency measures. Table 4.1 presents the top 10 energy saving recommendations (by \% savings) in glass manufacturing. 
Table 4.1: Top 10 Energy Saving Recommendations (by \% savings) in Glass Manufacturing ${ }^{2}$

\begin{tabular}{|c|c|c|c|c|c|c|c|}
\hline $\begin{array}{l}\text { Top Ten Frequently Recommended Opportunities } \\
\text { (IAC - } 2006 \text { to 2010) }\end{array}$ & ARC Code & $\begin{array}{l}\text { Frequenc } \\
\quad y\end{array}$ & $\begin{array}{l}\text { Average Source } \\
\text { Energy Savings } \\
\text { (MMBtu/Yr) }\end{array}$ & $\begin{array}{l}\text { Average \% } \\
\text { Source Energy } \\
\text { Savings }\end{array}$ & $\begin{array}{c}\text { Average } \\
\text { Energy } \\
\text { Cost } \\
\text { Savings } \\
(\$ / Y r)\end{array}$ & $\begin{array}{l}\text { Average \% } \\
\text { Cost Savings }\end{array}$ & $\begin{array}{c}\text { Average } \\
\text { Payback } \\
\text { Period (Yr) }\end{array}$ \\
\hline $\begin{array}{l}\text { USE WASTE HEAT FROM HOT FLUE GASES TO } \\
\text { PREHEAT COMBUSTION AIR }\end{array}$ & 2.2411 & 11 & 32,099 & $9.6 \%$ & $\$ 271,262$ & $9.7 \%$ & 1.4 \\
\hline INSULATE BARE EQUIPMENT & 2.2511 & 17 & 18,246 & $1.5 \%$ & $\$ 27,358$ & $1.4 \%$ & 0.7 \\
\hline RECOVER HEAT FROM OVEN EXHAUST / KILNS & 2.2432 & 9 & 16,416 & $3.0 \%$ & $\$ 111,069$ & $5.8 \%$ & 1.7 \\
\hline $\begin{array}{l}\text { ELIMINATE OR REDUCE COMPRESSED AIR } \\
\text { USED FOR COOLING, AGITATING LIQUIDS, } \\
\text { MOVING PRODUCT, OR DRYING }\end{array}$ & 2.4232 & 18 & 11,252 & $2.4 \%$ & $\$ 48,395$ & $2.2 \%$ & 2.2 \\
\hline $\begin{array}{l}\text { USE MULTIPLE SPEED MOTORS OR AFD FOR } \\
\text { VARIABLE PUMP, BLOWER AND COMPRESSOR } \\
\text { LOADS }\end{array}$ & 2.4141 & 11 & 2,801 & $2.9 \%$ & $\$ 21,009$ & $2.6 \%$ & 2.1 \\
\hline $\begin{array}{l}\text { UTILIZE HIGHER EFFICIENCY LAMPS AND/OR } \\
\text { BALLASTS }\end{array}$ & 2.7142 & 76 & 2,620 & $2.2 \%$ & $\$ 16,240$ & $1.2 \%$ & 2.1 \\
\hline TURN OFF EQUIPMENT WHEN NOT IN USE & 2.6218 & 10 & 2,466 & $4.1 \%$ & $\$ 16,712$ & $2.8 \%$ & 0.3 \\
\hline INSULATE STEAM / HOT WATER LINES & 2.2131 & 12 & 1,878 & $1.1 \%$ & $\$ 14,243$ & $1.1 \%$ & 0.6 \\
\hline $\begin{array}{l}\text { ELIMINATE LEAKS IN INERT GAS AND } \\
\text { COMPRESSED AIR LINES/ VALVES }\end{array}$ & 2.4236 & 67 & 1,701 & $1.5 \%$ & $\$ 9,422$ & $18.1 \%$ & 0.4 \\
\hline $\begin{array}{l}\text { USE OPTIMUM SIZE AND CAPACITY } \\
\text { EQUIPMENT }\end{array}$ & 2.4323 & 13 & 1,024 & $2.8 \%$ & $\$ 26,019$ & $2.5 \%$ & 9.3 \\
\hline
\end{tabular}

\footnotetext{
${ }^{2}$ http://iac.rutgers.edu/database/topten/, Extracted for any center and any time on Dec 19, 2010
} 


\subsection{Plastics Manufacturing}

Energy assessment at a leading plastics manufacturer done by an IAC has helped the company save nearly $\$ 100,000$ per year in energy costs. The company is one of the largest plastic packaging specialists in Europe and is expanding into the U.S. market. The plant manufactures injection-molded, rigid containers with open tops. The facility measures 187,000 square feet or 17,372 square meters in size and operates continuously, 7 days per week. Energy costs before the implementation of energy efficiency measures at the plant, totaled approximately $\$ 760,000$ per year, most of which is for electricity and the remainder for natural gas. Of the total 12 opportunities found feasible after study by assessment team, six were implemented at the manufacturing plant within first year. The implemented energy efficiency measures are briefly listed here. It was found that some bare surfaces of molding machines were radiating significant energy due to lack of insulation. However, by insulating these surfaces, the machines' heaters will operate less frequently, which will reduce energy consumption. USDOE developed MotorMaster+ software was suggested to be used for motor management system. This software helped company in evaluating economic decisions about buying new premium efficiency motors and rewinding or replacing a motor. Compressed air is used significantly in the plant. To help the company improve compressed air system energy efficiency, the assessment team suggested the company to reduce the compressor pressure to a safe minimum required by the system, repair compressed air leaks and install engineered nozzles to reduce air consumption. As a result of the energy efficiency study, and recommendations made by assessment team, the company is able to save 2.3 million $\mathrm{kWh}$ or 7,950 MMBtu annually. This translates into significant amount of energy costs savings of nearly $\$ 100,000$.

Table 4.2 presents the top 10 energy saving recommendations (by \% savings) in plastic manufacturing. 
Table 4.2: Top 10 Energy Saving Recommendations (by \% savings) in Plastic Manufacturing ${ }^{3}$

\begin{tabular}{|c|c|c|c|c|c|c|c|}
\hline $\begin{array}{l}\text { Top Ten Frequently Recommended Opportunities (IAC } \\
\qquad-2006 \text { to 2010) }\end{array}$ & ARC Code & Frequency & $\begin{array}{c}\text { Average Source } \\
\text { Energy Savings } \\
(\mathrm{MMBtu} / \mathbf{Y r})\end{array}$ & $\begin{array}{l}\text { Average \% } \\
\text { Source Energy } \\
\text { Savings }\end{array}$ & $\begin{array}{c}\text { Average } \\
\text { Energy Cost } \\
\text { Savings }(\$ / Y r)\end{array}$ & $\begin{array}{l}\text { Average } \\
\% \text { Cost } \\
\text { Savings }\end{array}$ & $\begin{array}{c}\text { Average } \\
\text { Payback } \\
\text { Period (Yr) }\end{array}$ \\
\hline USE / PURCHASE OPTIMUM SIZED COMPRESSOR & 2.4226 & 19 & 3,534 & $2.1 \%$ & $\$ 23,916$ & $2.0 \%$ & 1.3 \\
\hline $\begin{array}{l}\text { USE COOLING TOWER OR ECONOMIZER TO } \\
\text { REPLACE CHILLER COOLING }\end{array}$ & 2.2614 & 12 & 3,470 & $2.2 \%$ & $\$ 23,645$ & $2.0 \%$ & 1.2 \\
\hline INSTALL TIMERS AND/OR THERMOSTATS & 2.7261 & 17 & 3,309 & $2.5 \%$ & $\$ 30,197$ & $3.0 \%$ & 0.7 \\
\hline INSULATE STEAM / HOT WATER LINES & 2.2131 & 22 & 3,002 & $2.6 \%$ & $\$ 29,629$ & $2.5 \%$ & 0.4 \\
\hline $\begin{array}{l}\text { USE MULTIPLE SPEED MOTORS OR AFD FOR } \\
\text { VARIABLE PUMP, BLOWER AND COMPRESSOR } \\
\text { LOADS }\end{array}$ & 2.4141 & 49 & 2,282 & $2.8 \%$ & $\$ 14,846$ & $2.3 \%$ & 1.9 \\
\hline $\begin{array}{l}\text { UTILIZE HIGHER EFFICIENCY LAMPS AND/OR } \\
\text { BALLASTS }\end{array}$ & 2.7142 & 161 & 2,020 & $2.5 \%$ & $\$ 12,806$ & $2.3 \%$ & 2.5 \\
\hline $\begin{array}{l}\text { ELIMINATE LEAKS IN INERT GAS AND } \\
\text { COMPRESSED AIR LINES/ VALVES }\end{array}$ & 2.4236 & 131 & 1,983 & $1.5 \%$ & $\$ 10,617$ & $1.2 \%$ & 0.4 \\
\hline INSULATE BARE EQUIPMENT & 2.2511 & 73 & 1,895 & $1.7 \%$ & $\$ 13,317$ & $1.5 \%$ & 0.6 \\
\hline USE MORE EFFICIENT LIGHT SOURCE & 2.7143 & 57 & 1,843 & $0.9 \%$ & $\$ 10,993$ & $0.9 \%$ & 1.7 \\
\hline $\begin{array}{l}\text { INSTALL COMPRESSOR AIR INTAKES IN } \\
\text { COOLEST LOCATIONS }\end{array}$ & 2.4221 & 55 & 746 & $0.6 \%$ & $\$ 5,318$ & $0.6 \%$ & 0.6 \\
\hline
\end{tabular}

\footnotetext{
${ }^{3}$ http://iac.rutgers.edu/database/topten/, Extracted for any center and any time on Dec 19, 2010
} 


\subsection{Iron \& Steel Manufacturing}

An energy efficiency study carried out at a leading steel manufacturer in state of West Virginia has helped the company survive the market slowdown. The company recycles scrap steel from adjacent areas to produce steel sections, channels and structural beams that are used in fabrication of frames, grousers and welded frames for heavy equipment. The plant is approximately 40 acres in size and is in operation since 1906. The plant approximately operates $8,160 \mathrm{hrs}$ annually. The energy consumption of the plant before energy assessment was 1,216,753 MMBtu/yr or 1,283,747,420 Megajoules/yr or $\$ 10,029,682 / y r$. The assessment team found following feasible energy efficiency measures at the time of assessment. The list includes ladle preheat energy reduction, hand-held cutting flame torches energy reduction, reduce infiltration in doors on furnace openings, preheat combustion air in ceramic recuperator, motor management, downsize motors, variable speed drives in several applications, cogged belt drives, improve power factor, insulate the furnaces and tundish dryer, synthetic lubricants, repair air leaks, outside air, lighting efficiency. The assessment recommendations made by assessment team helped company save an estimated 139,843 MMBtu/yr or 147,542,756 Megajoules/yr. The total energy cost savings were approximately $\$ 1,034,547 / \mathrm{yr}$.

Table 4.3 presents the top 10 energy saving recommendations (by \% savings) in metals manufacturing. 
Table 4.3: Top 10 Energy Saving Recommendations (by \% savings) in Iron \& Steel Manufacturing ${ }^{4}$

\begin{tabular}{|c|c|c|c|c|c|c|c|}
\hline $\begin{array}{l}\text { Top Ten Frequently Recommended Opportunities (IAC } \\
\qquad-2006 \text { to 2010) }\end{array}$ & ARC Code & Frequency & $\begin{array}{c}\text { Average Source } \\
\text { Energy Savings } \\
\text { (MMBtu/Yr) }\end{array}$ & $\begin{array}{l}\text { Average \% } \\
\text { Source Energy } \\
\text { Savings }\end{array}$ & $\begin{array}{c}\text { Average } \\
\text { Energy Cost } \\
\text { Savings (\$/Yr) }\end{array}$ & $\begin{array}{l}\text { Average } \\
\% \text { Cost } \\
\text { Savings }\end{array}$ & $\begin{array}{c}\text { Average } \\
\text { Payback } \\
\text { Period (Yr) }\end{array}$ \\
\hline $\begin{array}{l}\text { USE WASTE HEAT FROM HOT FLUE GASES TO } \\
\text { PREHEAT COMBUSTION AIR }\end{array}$ & 2.2411 & 23 & 26,436 & $4.3 \%$ & $\$ 216,662$ & $6.1 \%$ & 1.5 \\
\hline ADJUST BURNERS FOR EFFICIENT OPERATION & 2.1133 & 11 & 17,441 & $4.9 \%$ & $\$ 108,172$ & $3.7 \%$ & 0.6 \\
\hline PREHEAT COMBUSTION AIR WITH WASTE HEAT & 2.2442 & 12 & 8,959 & $4.0 \%$ & $\$ 52,129$ & $2.2 \%$ & 1.4 \\
\hline UPGRADE CONTROLS ON COMPRESSORS & 2.4224 & 15 & 7,786 & $2.3 \%$ & $\$ 37,316$ & $1.6 \%$ & 0.6 \\
\hline COVER OPEN TANKS & 2.2514 & 14 & 5,072 & $3.2 \%$ & $\$ 30,930$ & $2.5 \%$ & 0.8 \\
\hline TURN OFF EQUIPMENT WHEN NOT IN USE & 2.6218 & 14 & 3,913 & $1.4 \%$ & $\$ 30,363$ & $1.3 \%$ & 0.3 \\
\hline $\begin{array}{l}\text { USE MULTIPLE SPEED MOTORS OR AFD FOR } \\
\text { VARIABLE PUMP, BLOWER AND COMPRESSOR } \\
\text { LOADS }\end{array}$ & 2.4141 & 24 & 2,848 & $1.7 \%$ & $\$ 20,196$ & $2.0 \%$ & 2.1 \\
\hline USE / PURCHASE OPTIMUM SIZED COMPRESSOR & 2.4226 & 16 & 2,616 & $1.7 \%$ & $\$ 22,716$ & $2.4 \%$ & 1.6 \\
\hline $\begin{array}{l}\text { ANALYZE FLUE GAS FOR PROPER AIR/FUEL } \\
\text { RATIO }\end{array}$ & 2.1233 & 16 & 2,550 & $1.3 \%$ & $\$ 21,555$ & $1.5 \%$ & 0.4 \\
\hline $\begin{array}{l}\text { UTILIZE HIGHER EFFICIENCY LAMPS AND/OR } \\
\text { BALLASTS }\end{array}$ & 2.7142 & 117 & 2,473 & $1.7 \%$ & $\$ 16,183$ & $1.5 \%$ & 2.7 \\
\hline $\begin{array}{l}\text { ELIMINATE LEAKS IN INERT GAS AND } \\
\text { COMPRESSED AIR LINES/ VALVES }\end{array}$ & 2.4236 & 103 & 1,889 & $1.1 \%$ & $\$ 10,690$ & $0.9 \%$ & 0.4 \\
\hline
\end{tabular}

\footnotetext{
${ }^{4}$ http://iac.rutgers.edu/database/topten/, Extracted for any center and any time on Dec 19, 2010
} 


\subsection{Chemicals Manufacturing}

One of the leading chemical manufacturers in the world undertook a plant-wide energy assessment performed by an IAC. The objectives were to identify energy saving projects in the company's utilities area, including boilers and associated steam systems, compressor systems, and electrical motor-driven pump systems. The project evaluation process was unique in that the company has obtained very favorable rates for electricity. Even so, the company found strong economic justification for several projects that would reduce either electricity consumption or fossil fuel consumption. The plant produces more than 1.2 billion pounds or 544,320 tons of chemical products each year. These materials are used in cars, appliances, furniture, home construction, steel manufacturing, food preparation, and many consumer products. The group operates around 350 companies worldwide and employs 117,000 workers. The energy efficiency measures that were determined were burner replacement, condensate return, use of VSDs on pumps, compressed air system optimization, insulating steam system components, repairing steam leaks, adjusting the fuel/air ratio in one of the boilers, and repairing compressed gas leaks (air, NG, and nitrogen). The total cost savings were identified as $\$ 1,427,800$ with and estimated implementation cost of $\$ 937,200$ which results in a simple payback of less than 8 months.

Table 4.4 presents the top 10 energy saving recommendations (by \% savings) in chemicals manufacturing. 
Table 4.4: Top 10 Energy Saving Recommendations (by \% savings) in Chemicals Manufacturing 5

\begin{tabular}{|c|c|c|c|c|c|c|c|}
\hline $\begin{array}{l}\text { Top Ten Frequently Recommended Opportunities (IAC } \\
\text { - } 2006 \text { to 2010) }\end{array}$ & ARC Code & Frequency & $\begin{array}{l}\text { Average Source } \\
\text { Energy Savings } \\
(\text { MMBtu/Yr) }\end{array}$ & $\begin{array}{l}\text { Average \% } \\
\text { Source } \\
\text { Energy } \\
\text { Savings }\end{array}$ & $\begin{array}{c}\text { Average } \\
\text { Energy Cost } \\
\text { Savings }(\$ / Y r)\end{array}$ & $\begin{array}{l}\text { Average \% } \\
\text { Cost } \\
\text { Savings }\end{array}$ & $\begin{array}{c}\text { Average } \\
\text { Payback } \\
\text { Period (Yr) }\end{array}$ \\
\hline REPAIR AND ELIMINATE STEAM LEAKS & 2.2135 & 17 & 15,436 & $1.0 \%$ & $\$ 124,830$ & $1.3 \%$ & 0.2 \\
\hline REPAIR OR REPLACE STEAM TRAPS & 2.2113 & 19 & 14,232 & $4.5 \%$ & $\$ 107,153$ & $4.4 \%$ & 0.3 \\
\hline $\begin{array}{l}\text { LOWER TEMPERATURE DURING THE WINTER } \\
\text { SEASON AND VICE-VERSA }\end{array}$ & 2.7221 & 10 & 6,433 & $4.0 \%$ & $\$ 60,519$ & $4.2 \%$ & 0.6 \\
\hline $\begin{array}{l}\text { INCREASE AMOUNT OF CONDENSATE } \\
\text { RETURNED }\end{array}$ & 2.2121 & 16 & 6,144 & $1.6 \%$ & $\$ 67,948$ & $2.4 \%$ & 1.2 \\
\hline $\begin{array}{l}\text { ELIMINATE OR REDUCE COMPRESSED AIR USED } \\
\text { FOR COOLING, AGITATING LIQUIDS, MOVING } \\
\text { PRODUCT, OR DRYING }\end{array}$ & 2.4232 & 15 & 4,908 & $2.8 \%$ & $\$ 37,333$ & $2.5 \%$ & 0.8 \\
\hline TURN OFF EQUIPMENT WHEN NOT IN USE & 2.6218 & 12 & 4,674 & $5.0 \%$ & $\$ 38,833$ & $4.3 \%$ & 0.1 \\
\hline $\begin{array}{l}\text { USE MULTIPLE SPEED MOTORS OR AFD FOR } \\
\text { VARIABLE PUMP, BLOWER AND COMPRESSOR } \\
\text { LOADS }\end{array}$ & 2.4141 & 35 & 3,901 & $1.5 \%$ & $\$ 25,421$ & $1.2 \%$ & 1.6 \\
\hline $\begin{array}{l}\text { USE WASTE HEAT FROM HOT FLUE GASES TO } \\
\text { PREHEAT COMBUSTION AIR }\end{array}$ & 2.2411 & 20 & 3,301 & $1.2 \%$ & $\$ 34,109$ & $1.5 \%$ & 1.3 \\
\hline INSULATE STEAM / HOT WATER LINES & 2.2131 & 22 & 2,828 & $0.7 \%$ & $\$ 24,040$ & $0.8 \%$ & 0.6 \\
\hline $\begin{array}{l}\text { ANALYZE FLUE GAS FOR PROPER AIR/FUEL } \\
\text { RATIO }\end{array}$ & 2.1233 & 30 & 2,350 & $1.3 \%$ & $\$ 17,961$ & $1.1 \%$ & 0.5 \\
\hline
\end{tabular}

\footnotetext{
${ }^{5}$ http://iac.rutgers.edu/database/topten/, Extracted for any center and any time on Dec 19, 2010
} 


\section{Crosscutting Technologies for Improved Energy Efficiency}

\subsection{Process Heating Systems}

Process heating systems are one of the largest energy intensive systems in most industrial facilities and account for approximately $36 \%$ of industrial energy consumption. These systems may include equipment such as furnaces, ovens, heaters, kilns, lehrs, etc. They are used in variety of processes in an industrial energy system to transfer heat from energy source(s) to the products. The energy source in these systems may be electricity, fuel (natural gas, fuel oil, etc.), steam, other gases, or a combination of two or more of these sources. Based on the energy assessments performed at several industrial facilities, the typical energy efficiency of the process heating equipment may be between $15 \%$ and $85 \%$. The general losses in the process heating system can be categorized as flue gas loss (exhaust stack), wall loss (through insulation), opening (used for access in the system) loss, fixture/conveyor (for movement of product in/out of equipment) loss, water cooling (for maintaining temperatures) loss, and atmospheric loss (through changes in the inside air/gas or other atmosphere).

This article outlines the summary of case studies resulting from the energy assessment of process heating systems at seven large industrial facilities. The average energy savings produced by each of the five ARs in these facilities were estimated as $13 \%$ (with the range as $6 \%$ to $28 \%$ ). Since the percentages on figure 4.1 are averages for all the facilities, they do not add up to $100 \%$ on the pie chart. The top five energy saving potentials were realized in the following areas (Figure 4.1):

1. Recover waste heat from the exhaust stacks to preheat combustion air for the system

2. Recover waste heat from the exhaust stacks to preheat incoming material, heat the plant in winter or use it in a waste heat boiler

3. Adjust air to fuel ratio of the system

4. Improve insulation of the process heating equipment and distribution pipes

5. Replace old burners with energy efficient burners 


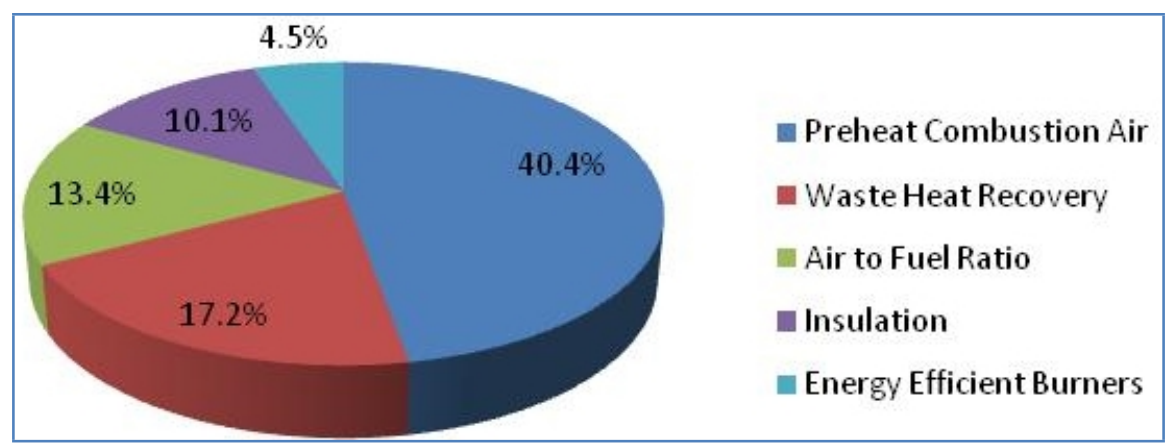

Figure 4.1: Profile of average percentage savings produced by each ARs in the seven facilitis

For each recommendation made to the plants, the estimated implementation cost was used to calculate simple payback period (ratio between implemetation cost and energy cost savings). This cost may include equipment, labor for installing or maintaining the equipment and/or labor for planning activities. In most plants, the threshold for simple payback period was two years. For the top five energy savings recommendations, the simple payback was found to be within this threshold (Figure 4.2). It may be noted that several states offer financial incentives and/or low interest loans for energy efficiency improvements but they were not considered in this analysis. Including such incentives may reduce the simple payback period further.

Payback (Months)

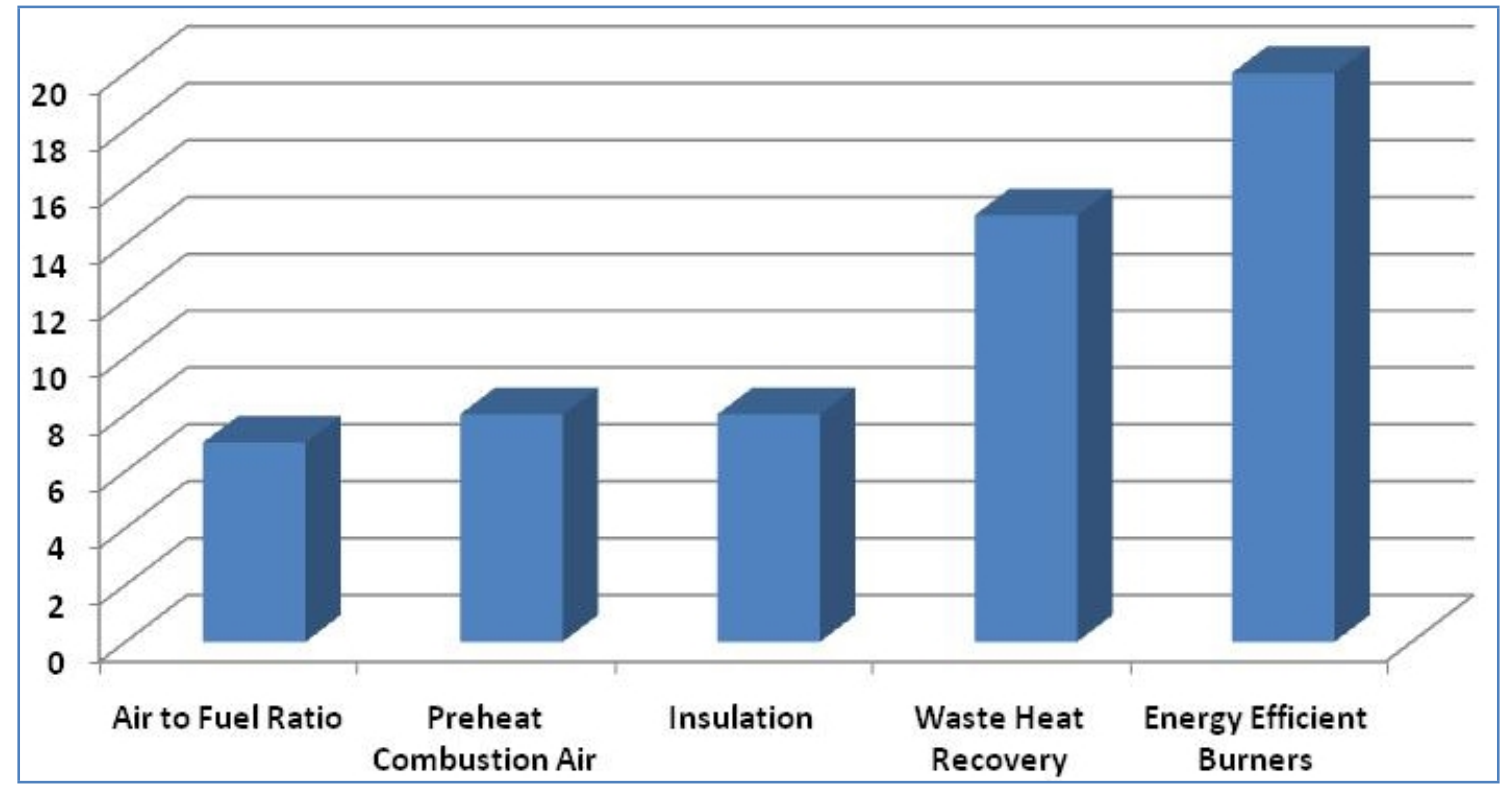

Figure 4.2: Profile of Average Simple Payback on Investment (in Months) 
The plant considered in this example had one of the furnaces with gross fuel input rate as approximately 14.15 MMBtu/hr or 14,929 Megajoules/hr. The exhaust stack gases for this furnace was analyzed using a portable combustion analyzer and thermography study was conducted with a thermal camera. Other operating charateristics were also analyzed with appropriate equipment. It was also found that the charge material for this furnace was incoming at room temperature and the furnace door had water cooling system. The results of the stack analysis were as follows: Flue gas temperature: over $1,400^{\circ} \mathrm{F}$ or $760^{\circ} \mathrm{C}$; Oxygen in flue gas: over 5.75 ; Combustion air temperature: $\sim 450^{\circ} \mathrm{F}$ or $232^{\circ} \mathrm{C}$.

Based on the information available during this assessment, the furnace was modeled in the Process Heating Assessment and Survey Tool (PHAST) provided by the Department of Energy (DOE) (Figure 4.3). It may be seen that in the present scenario, approximately 6.07 MMBtu/hr or 6,404 Megajoules is used as useful output and remaining 8.07 MMBtu/hr or 8,514 Megajoules is lost through the system.

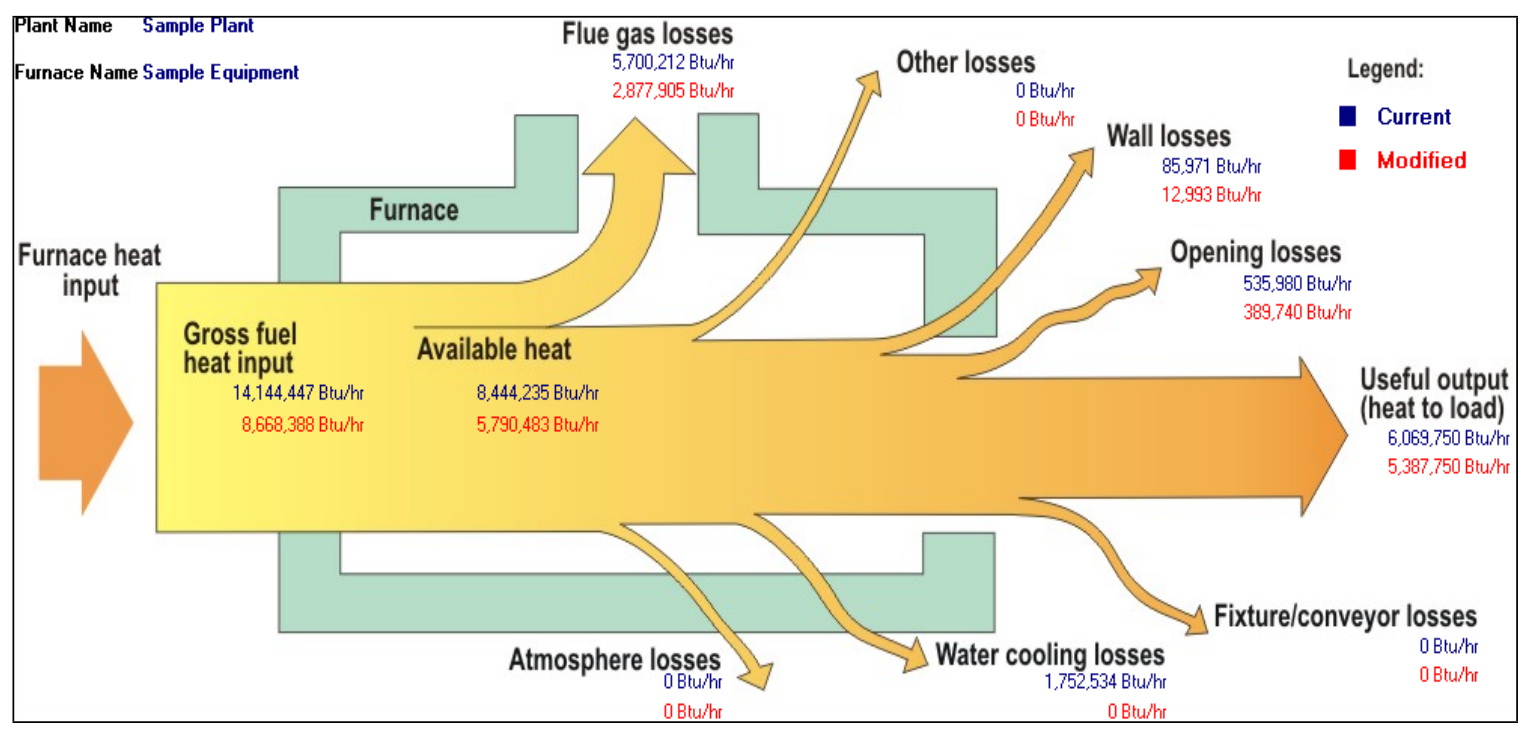

Figure 4.3: Profile of Energy Consumption and Losses in the Example Furnace

After analyzing the PHAST model, following recommendations were made to the plant:

1. Preheat combustion air and charge material using waste heat available in the stack 
2. Use automatic air to fuel ratio adjustment system to maintain oxygen in the stack at $\sim 3 \%$

3. Replace the water cooling based furnace door with an insulated door

4. Improve insulation on the furnace walls

5. Minimize the open time of variable openings used to charge material etc.

The proposed changes were also modeled in PHAST and the results are included in Figure 4.3. It can be seen that the gross fuel input requirement is reduced to approximately $8.67 \mathrm{MMBtu} / \mathrm{hr}$ or 9,147 Megajoules (approximately 39\% energy savings). The profile of energy consumption in present and proposed scenarios is shown in Figure 4.4 .

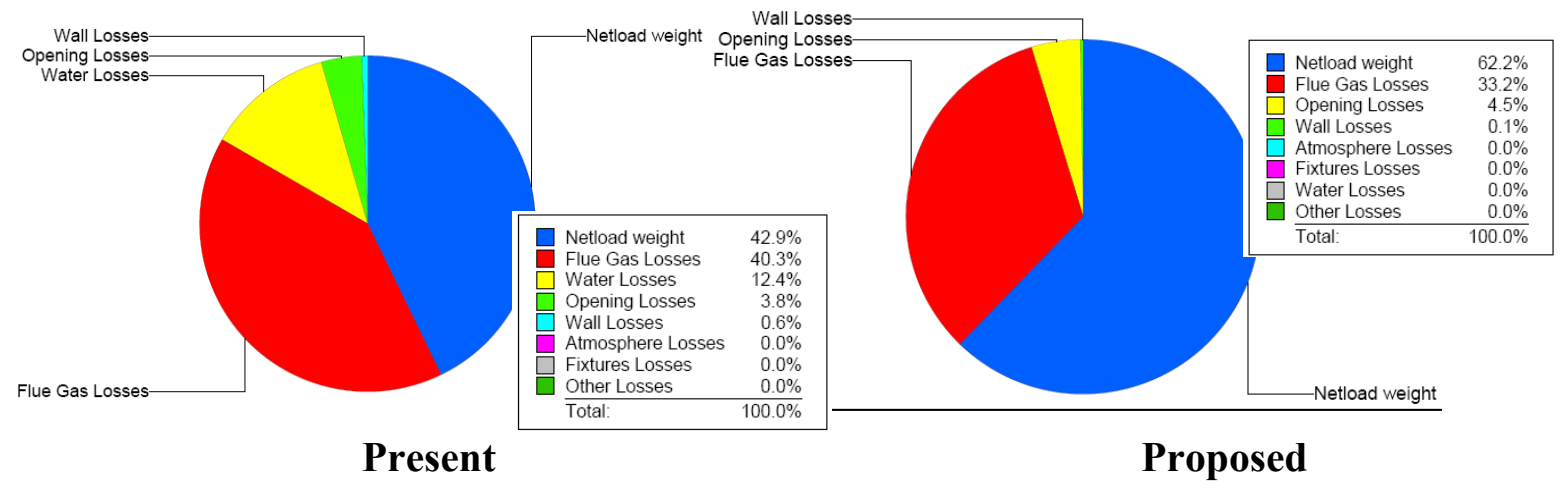

Figure 4.4: Profile of Present and Proposed Energy Consumption in the Example

\section{Furnace}

Process heating systems are one of the most energy intensive systems in industrial facilities. Based on the operating characteristics, energy savings may be realized by small modifications in the system. DOE's software tool (PHAST) can be used to model process heating systems and perform sensitivity analysis to evaluate energy savings recommendations. The assessment methodology can be applied to any industry with process heating equipment and energy savings can be realized by implementing similar recommendations.

\section{- Combined Heat and Power (CHP)}

Combined heat and power systems generate heat and electricity as against traditional power plants only producing electricity. A CHP system typically involves a 
compressor, combustion chamber, gas turbine, and mechanical equipment or a generator coupled to the turbine shaft. The exhaust gases leave the turbine at an elevated temperature. Considerable heat is lost from the turbine exhaust. This heat energy is recovered and serves as a heat source for process heating, space heating, and boiler feed water heating.

A back pressure turbine can be installed at the boiler house to use the potential pressure difference between the turbine's inlet and exit steam as a prime mover or power source to any equipment using electricity. It is observed that the high pressure steam produced by the boiler is often throttled at reducing stations to a lower pressure before it is used in the production process. There exists heat energy potential in this steam, which can be used by replacing the reducing station with a back pressure turbine. Therefore, the back pressure turbine will use the energy between the high pressure steam at boiler operating conditions and the low pressure steam being supplied to the plant. The back pressure turbine can therefore serve as a prime mover to any rotating equipment such as an electric motor. Also, a generator can be coupled to the turbine shaft to generate electricity, which can serve as a source of power for any equipment (electric motors) using electricity. The Energy savings is a function of the mass flow rate of the steam, difference in enthalpies of the high pressure and low pressure steam, overall efficiency of the back pressure turbine, and the efficiency of the mechanical coupling between the back pressure turbine and the rotating equipment. 


\section{Tools and Techniques}

The Industrial Assessment Centers use a variety of tools and techniques that enable them to be successful in performing the energy assessments as well as maintain high level of energy saving metrics. The DOE Best Practices software tools such as PHAST, AirMaster+, FSAT,PSAT, SSAT and SSST are being utilized by the IACs in evaluating the potential of energy assessment recommendations. In addition, many of the IACs use custom made spreadsheet tools and other software tools that help in this regard. During the energy assessment process, the IAC team will recognize potential areas for energy savings and will gather data regarding the specific opportunity associated with an energy system. The data collected will be input into the software tools in order to evaluate the potential further. The developed recommendations are then written in the report in an elaborate manner, with screen shots of the software tools utilized, showing the data that was collected and input.

The techniques that the IACs use in generating energy savings based on assessments vary, but share a general theme with respect to effectively recognizing the potential for large energy savings in the various energy systems. In other words, there may be numerous opportunities to save energy within a manufacturing facility, however, many of these opportunities may not generate much energy savings and may also have poor payback on investment. Since the energy assessment is usually done within one day, the IACs do not spend much time on such opportunities because of the possibility of not having enough time for data collection and analysis of some of the larger energy savings measures with an attractive rate of return.

The following sections illustrate some specific tools and techniques that have been beneficial to the IACs in determining energy efficiency recommendations.

\subsection{Pressure Profile Monitoring}

The IAC uses data loggers to monitor the pressure profile over a certain period of time. The pressure profile is quite useful in making decisions concerning the level of pressure to be maintained in the plant or handling demand fluctuation. The IAC uses 
pressure transducers along with data loggers to record the pressure profile. The following section describes the process of pressure monitoring.

\subsubsection{Data Loggers}

There are different types of data loggers available in the market. The IAC uses 2external channel data loggers (Figure 5.1) that records the pressure profile in terms of current. The key specifications for the data loggers used are as follows.

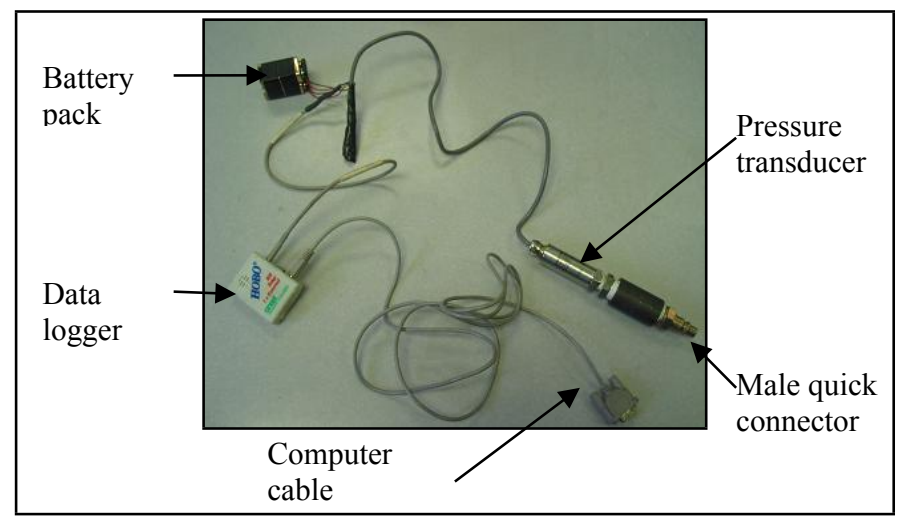

Figure 5.1: Typical 4-20 mA data logger and connection

\section{$\underline{\text { Specifications }}$}

- Temperature Measurement Range: $-20^{\circ}$ to $70^{\circ} \mathrm{C}\left(-4^{\circ}\right.$ to $\left.158^{\circ} \mathrm{F}\right)$

- Temperature Accuracy: $\pm 0.7^{\circ}$ at $21^{\circ} \mathrm{C}\left( \pm 1.27^{\circ}\right.$ at $\left.70^{\circ} \mathrm{F}\right)$

- RH Measurement Range: 25\% to 95\% RH (user-replaceable RH sensor)

- $\mathrm{RH}$ Accuracy: $\pm 5 \% \mathrm{RH}$

- External Input Channel Measurement Range: 4-20 mA

- External Input Channel Accuracy: $\pm 3 \%$ of reading

\section{Application}

The value of current at any given point can be converted to the corresponding pressure reading using the pressure range output of the transducer used with the data logger. For a $0-300 \mathrm{psig}(1 \mathrm{psi}=6.8948 \mathrm{kPa})$ pressure transducer, the following equation can be used to convert the current ( $\mathrm{mA}$ ) reading to the pressure reading.

Pressure $=(18.75 *$ current in $\mathrm{mA})-75$ 
In this case, a value of $4 \mathrm{~mA}$ corresponds to zero psig ( $1 \mathrm{psi}=6.8948 \mathrm{kPa})$ and $20 \mathrm{~mA}$ corresponds to $300 \mathrm{psig}(1 \mathrm{psi}=6.8948 \mathrm{kPa})$. As an example, the pressure reading corresponding to a value of $8 \mathrm{~mA}$ can be calculated as $75 \mathrm{psig}(1 \mathrm{psi}=6.8948 \mathrm{kPa})$. It may be noted that the pressure reading is linearly dependent on the current $(\mathrm{mA})$ reading. Similar equations can be developed using the transducer and data logger characteristics.

\section{Selection of time interval between two data points}

The data loggers can record the pressure readings at different time intervals. The time interval setting option depends on the type of data logger used. In general, small time intervals between the data points are desired when the compressed air demand fluctuation is frequent. But it limits the total time period over which the pressure can be recorded because of limited memory of the data loggers. For fairly constant demand scenarios, a higher value of time interval between two data points can be selected which results in a longer time period for data collection. The decision regarding the time interval settings can be made based on discussions with the plant personnel regarding their compressed air usage.

\section{Pressure Transducers}

The pressure transducers used by the IAC can record the data over 0-300 psig (1 $\mathrm{psi}=6.8948 \mathrm{kPa})$ range (Figure 5.2).

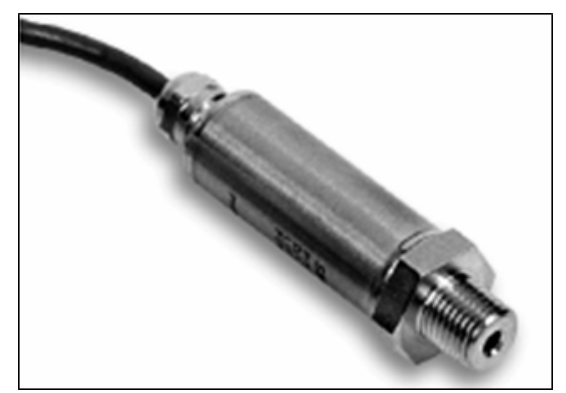

Figure 5.2: Typical pressure transducer

There are other transducers available that can have different pressure range specifications. The features and key specifications for the transducers used are as follows. 


\section{Features}

- Reliable Semiconductor Technology

- Calibrated and Temperature Compensated

- Rugged Stainless Steel Package

- NEMA 4 Design

- Small Size

- Absolute, Gauge, Sealed Gauge, Vacuum Gauge Pressures

$\underline{\text { Specifications }}$

- Operating pressure range: $0-300 \mathrm{psig}(1 \mathrm{psi}=6.8948 \mathrm{kPa})$

- Proof pressure: $900 \mathrm{psig}(1 \mathrm{psi}=6.8948 \mathrm{kPa})$

- Burst pressure: $1500 \mathrm{psig}(1 \mathrm{psi}=6.8948 \mathrm{kPa})$

Other accessories needed for the pressure transducer and data logger are as follows.

- Two 9-volt batteries

- 4-20 mA cable

- Male quick connector to fit to the compressed air line

- Computer cable

The complete attachment for compressed air pressure monitoring is shown in Figure 5.1.

\section{Pressure monitoring steps with transducers and data loggers}

The data logger is initialized by connecting it to the computer using the computer cable shown in Figure 5.1. Based on the compressed air demand, a suitable time interval is selected for data monitoring. The data loggers used at the IAC have an option to be initialized at a specified time rather than starting the data collection immediately. This may be helpful in cases where the actual place to be monitored may be far away from the place where the loggers are initialized. After initialization, the data logger is connected to the pressure transducer and the battery pack. At this time, the computer cable is detached. This assembly is then connected to the compressed air line using the quick connector. After the total time of data collection period is complete, the logger is disconnected from 
the line and taken back to the computer and connected using the computer cable. Specified software is used to extract the data from the data logger which outputs the pressure profile in DC current (mA). Using the equations discussed in the data logger section, this profile can be converted to the actual pressure profile.

An example of a pressure profile is shown in Figure 5.3. It may be noted that there is a pressure fluctuation from $63 \mathrm{psig}$ to $69 \mathrm{psig}(1 \mathrm{psi}=6.8948 \mathrm{kPa})$. An appropriate storage tank before a pulsing baghouse (point of pressure monitoring) for example, can reduce this pressure fluctuation significantly. This results in an opportunity to reduce the plant air pressure setting by 5-6 psig $(1 \mathrm{psi}=6.8948 \mathrm{kPa})$. Similar decisions can be made in terms of pressure reduction based on the pressure profile. In cases where the product quality is a function of pressure, the quality can be improved by reducing the amount of pressure fluctuation.

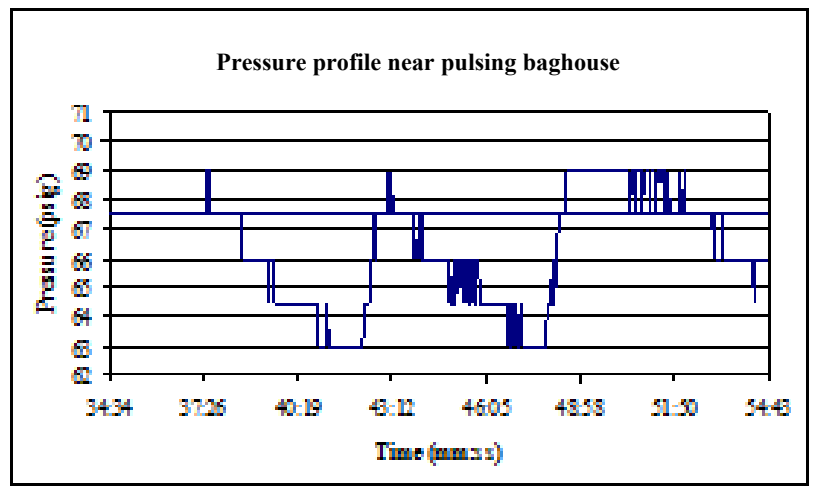

Figure 5.3: Example of pressure profile

\section{Digital Pressure Gauge}

A good understanding of the pressure profile in a compressed air system plays a vital role in minimizing the energy consumption of the compressor. A digital pressure gauge is one such equipment used to monitor the pressure in a compressed air line. Pressure loss may be due to factors such as friction in the pipe and an end user which has an intermittent need of high pressure. The gauge displays the pressure in the line near the place where it is fixed. Various pressure gauge models are available in the market. Figure 5.4 shows a schematic diagram of a digital pressure gauge. 


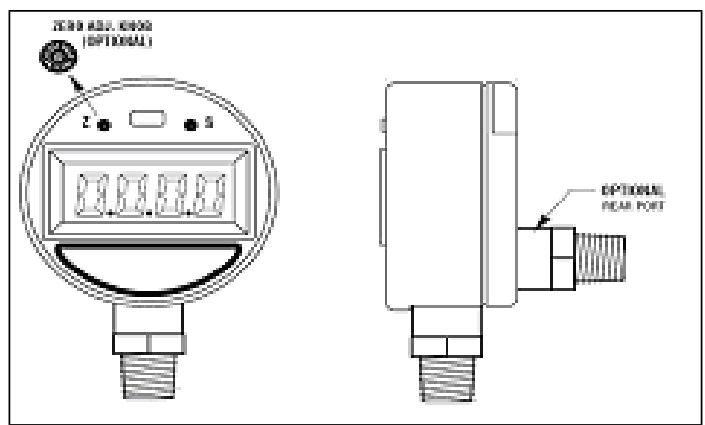

Figure 5.4: Digital Pressure Gauge

\section{$\underline{\text { Specifications }}$}

The pressure gauge is a battery operated unit. A four digit LCD display on the gauge incorporates stainless steel sensors which are vibration and shock resistant. The digital pressure is immune to the pulsating behavior of the pressure. The specifications of the gauge are as follows:

- Self-powered by standard 9V battery.

- $\quad$ Large, full 4 digit display with 0.5 inch characters.

- Microprocessor-based circuit has "TARE” capability standard.

- $\quad$ Ranges vacuum to 10,000 psi (1 psi $=6.8948 \mathrm{kPa})$.

- On/off switch with optional auto-off circuit.

- Peak-hold and analog outputs.

- $\quad \pm 0.25 \%$ of full-scale accuracy.

- Injection Molded Case Material.

Application

Usually, there is a pressure loss in the air lines of a compressed air system. Intermittent high demand by an end user of compressed air increases the energy consumption of the compressor. The pressure gauge can be fixed on an air line and the pressure through that line may be monitored. For example if there is a bag house which pulsates every few seconds and hence has a high intermittent demand for air while the rest of the equipment need much less pressure at a constant rate, then a storage tank designed to suit the need of the dust collector could be installed. Further, the pressure setting at the compressor can be reduced. This helps to save the energy consumed by the compressor, since it would be operating at a lower pressure. Based on the past 
experiences during the energy assessments carried out by the IAC, it could be estimated that $5-10 \%$ of the total energy consumed by the compressor could be saved by the use of a pressure gauge to monitor pressure and streamlining it.

\section{Pros and Cons}

\section{Advantages}

1. Easy to install and operate.

2. Digital output is very accurate.

3. It is cost effective.

4. Its compact size makes it a good replacement for the less accurate mechanical gauges. Disadvantages

1. Not easy to monitor pressure over a long period of time since it cannot log the data.

2. May need some special tools and attachments to be fixed on the pressure line.

\subsection{POWER Consumption Monitoring}

Power monitoring in compressed air system is useful for analyzing the load profile of the compressor. The following section describes the process of power monitoring using data loggers.

\subsubsection{Data Loggers for AC Current Measurement}

Data loggers are used to monitor data continuously for a sufficient length of time.

Here, the data corresponds to the alternating current supplied to the equipment such as an air compressor motor. AC current data logging requires a storage device for continuous storage of the measured quantity i.e. the $\mathrm{AC}$ current, a transducer which actually measures the $\mathrm{AC}$ current, and an electronic cable connecting the data logger and the transducer. The logger is an electronic device with limited memory and the transducer is a transformer to measure the current flowing through the conductors. In case of a three phase three wire electrical connection, $\mathrm{AC}$ current can be measured on either one or all three conductors. Power consumed by an air compressor motor is a function of the supply voltage, the current draw, and the power factor. The supply voltage and the power factor do not vary significantly for a set of operating conditions. But, the AC current will vary based on the load at which the air compressor is operating. Monitoring the AC current 
drawn by the air compressor motor over a period of time, for the corresponding compressed air demand in that period, will demonstrate the load profile of the air compressor system. Efficiency of an electric motor is very poor at part load conditions (loads less than $40 \%$ of the full load). Thus, a particular set of operating conditions for an air compressor such as the air pressure setting will determine the load on the air compressor motor and also the efficiency of the system.

\section{$\underline{\text { Specifications }}$}

Data logger units available in the market can be used for a wide range of measurements. The length or the period of recording the data will depend on the logger memory size and the resolution of the measurements to be made. For example, a memory size of 63 kilobytes with a 12 bit measurement resolution will record up to 42,000 measurements. Memory size of up to a few gigabytes with both 8 bit and 12 bit resolution are available. The loggers can be used at ambient conditions of $158^{\circ} \mathrm{F}$ or $70^{\circ} \mathrm{C}$ and $95 \%$ relative humidity.

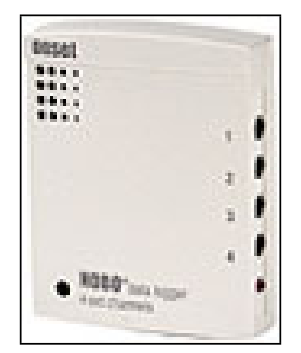

Figure 5.5: AC current data logger with 4 channels

The accuracy of the measurement combined for the logger and the transducer is a maximum of $5 \%$ of the full scale reading. A single logger can be used to measure various physical properties for which data loggers with multiple channels are also available (Refer Figure 5.5). The individual channels can be either used for the measurement of a specific parameter such as $\mathrm{AC}$ current, AC voltage, DC current, DC voltage, and temperature, or for the measurement of the same property for multiple applications. Measurement of a particular physical property will require a particular type of transducer. Typical logger sizes vary between $50 \mathrm{~mm}$ x $74 \mathrm{~mm}$ x $20 \mathrm{~mm}$ to $64 \mathrm{~mm}$ x $114 \mathrm{~mm}$ x 40 $\mathrm{mm}$. AC current transducers known as the current transformers are available with a 
maximum current measuring capability of $20 \mathrm{~A}, 100 \mathrm{~A}, 200 \mathrm{~A}, 600 \mathrm{~A}, 100 \mathrm{~A}, 2000 \mathrm{~A}$, up to $10,000 \mathrm{~A}$. Typical voltage ratings of $600 \mathrm{VAC}$, power factor of 0.5 to 1.0 lead or lag, and a frequency of $50 \mathrm{hz}$ or $60 \mathrm{hz}$ are available on transducers capable of measuring current up to $5000 \mathrm{~A}$ and higher. Also, the current transformers are split core type with different shapes, typically a hollow rectangular, hollow circular, or even a flexible probe type. The hollow cross sections have a molded plastic housing as shown in Figure 5.6.

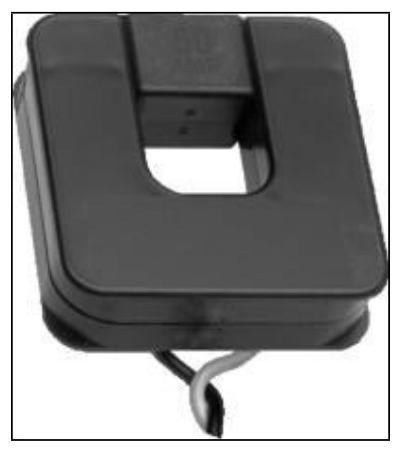

Figure 5.6: Split core AC current transformer

The maximum window size for a hollow rectangular cross section split core transducer is around $75 \mathrm{~mm} \times 65 \mathrm{~mm}$. For a flexible probe type, the length can be a maximum of 900 $\mathrm{mm}$ and the opening diameter of $300 \mathrm{~mm}$ and is shown in Figure 5.7.

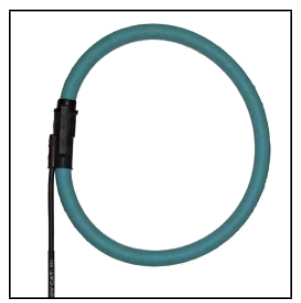

Figure 5.7: Flexible current probe transducer

\section{Application}

This section describes the use of data logger units. Before starting the actual data measurement, most of the data loggers are required to be launched or initiated to start the logging operation. This task can be achieved on some loggers by simply toggling the on/off switch. For other types, it can be done by using software developed for that particular product. While performing the launch operation using the software on a computer, the user needs to select the channel number to be used for data logging, type of transducer to be used for the selected channel, logging interval for the data to be 
monitored, duration of data logging, and the start time of the logging operation. After selecting the appropriate options using the software, the device is then ready to be used for data logging. A snapshot of a software used for launching the current logger for measuring AC current up to $600 \mathrm{~A}$ using channel 1 on an air compressor is shown in Figure 5.8.

Figure 5.9 shows three split core AC current transformers with the data logger (not shown) in use for monitoring the current on the three conductors of an air compressor. After the data collection process is over, the data logger can be disconnected form the transducer and connected to the computer using a USB cable. The results of the data logging can be read and plotted on a graph using the software. Also, the data can be exported to Microsoft Excel ${ }^{\mathrm{TM}}$ spreadsheet. The software is capable of performing descriptive statistics on the monitored data.

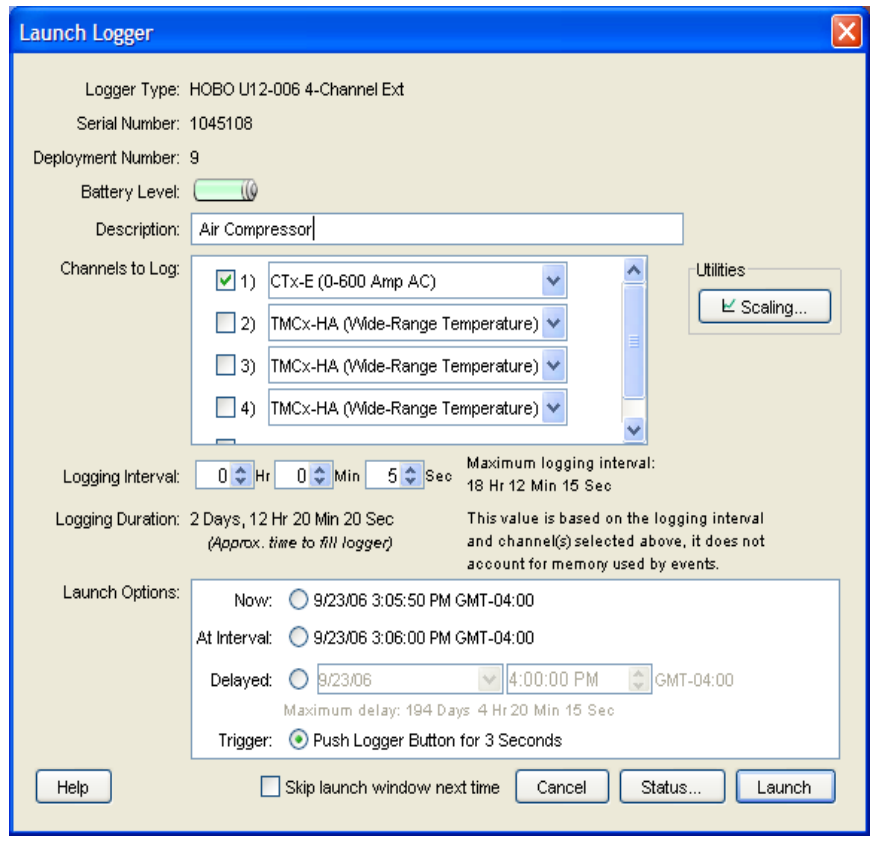

Figure 5.8: Launching the data logger 


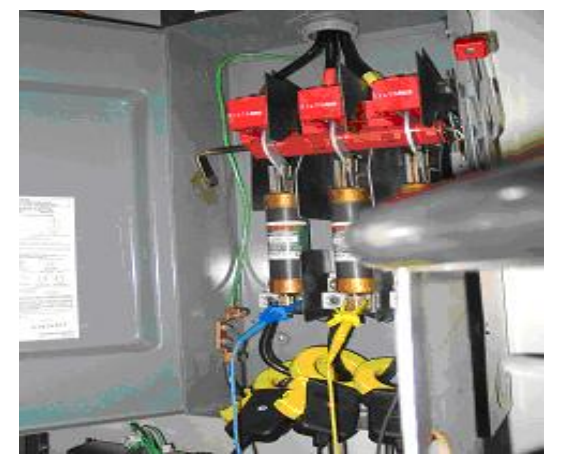

Figure 5.9: Data logging operation

\section{$\underline{\text { Pros and Cons }}$}

The loggers can record important and accurate data for a prolonged period of time with very little effort from the user. Data loggers are very effective in generating a load profile. Innovative logger designs are available at very competitive prices. Data logging on high voltage equipment can be unsafe and dangerous unless proper safety precautions are taken.

\subsubsection{Power Logger}

To keep productivity and efficiency high, and energy consumption low, power measurement itself along with other measurements is vital. Power logger is an advanced data logger that can help measure important energy consumption parameters of electrical motors and other energy consuming equipment using electricity.

\section{$\underline{\text { Features }}$}

It serves as an effective tool for three-phase power measurement. Along with the three phase voltages and line currents, it also measures the power factor at the local equipment, the real $(\mathrm{kW})$, apparent $(\mathrm{kVA})$ and reactive $(\mathrm{kVAR})$ power. The measurement of real power can provide an insight into the actual power drawn by the particular equipment. If the equipment contains a motor, it may provide information about the current loading under which the motor is operating thus indicating possible energy efficiency opportunities, if any. The measured line currents and voltages can be used for the load factor evaluation by using the line current measurement method and voltage corrected slip method for squirrel cage induction motors. 


\section{$\underline{\text { Specifications }}$}

The technical specifications of the equipment are as given in Table 5.1. The data logger has a capacity to record voltages in the range 0 to $600 \mathrm{~V}$ whereas for current the capacity is up to $1,000 \mathrm{~A}$. Special current transducers (CT) need to be used in order to expand the capacity.

Table 5.1: Technical Specifications of Power Logger

\begin{tabular}{|l|l|}
\hline AC Voltage & $0-600 \mathrm{~V}$ \\
\hline AC Current & $1-1,000 \mathrm{~A}$ (expandable \\
\hline Power & Actual (W), Reactive \\
\hline Power Factor & $0-1$ \\
\hline Energy & $\mathrm{kWh}$ \\
\hline Peak Demand & $\mathrm{kW}$ \\
\hline Fund. Frequencies & $50 / 60 \mathrm{~Hz}$ \\
\hline Available Recording & 1 hour to several months \\
\hline
\end{tabular}

The fundamental frequency for the equipment can be varied depending on the source. The equipment can record the values for each second or each 5 seconds or 15 seconds etc. depending on how the available recording time of the equipment varies.

\section{Application}

During measurement, specific connections need to be followed. Usually, in the manufacturing industry, the 3 phase induction motors are connected by three phase three wire arrangements. The arrangement is shown in Figure 5.10.

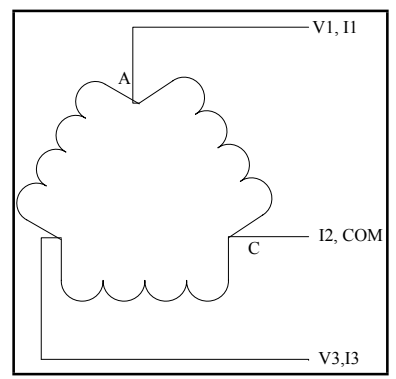

Figure 5.10: 3 Phase 3 Wire Delta Connection for Logger 


\subsubsection{Connections Diagram}

The connection scheme that has been used is shown in Figure 5.11. The connecting wires that are used are color coded. For the voltage leads 'COM' is connected by yellow voltage pin to phase II. V1 lead connects with phase III by black voltage pin. V3 lead connects to phase I by blue voltage pin. The black current probe from I1 connects to phase III. The red current probe from I2 connects to phase II and the blue current probe connects to phase I, as shown in the Figure 5.11. The data logger records data for the specified time interval after the connections are made.

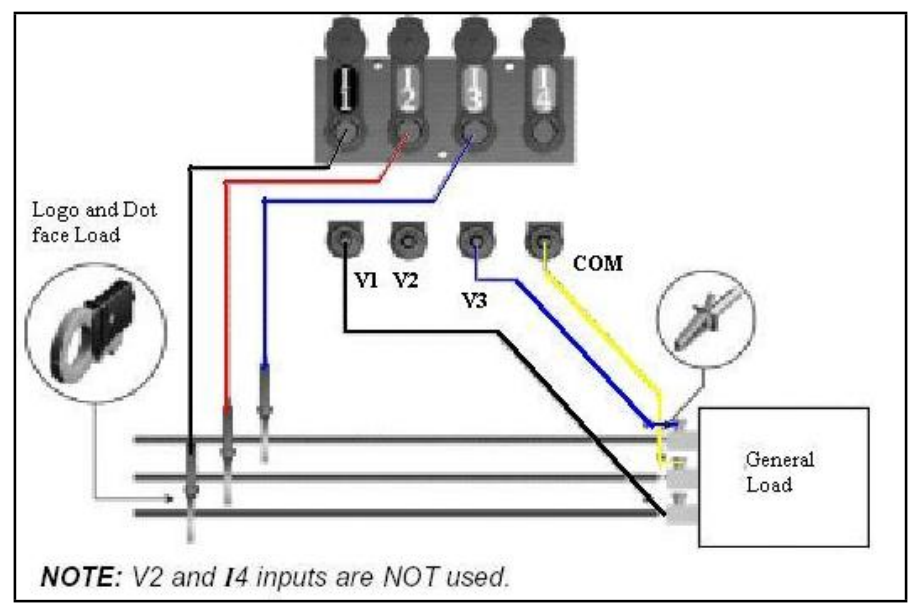

Figure 5.11: Power logger 3 Phase 3 wire (Phase to Phase Measurement) Connections Diagram

\subsubsection{Downloading Data}

Recorded data is exported to a laptop computer through COM port and RS-232 connection. The power logger software is necessary for transferring data to the laptop computer. A typical setup is shown in Figure 5.12. This data can be used for the system analysis. 


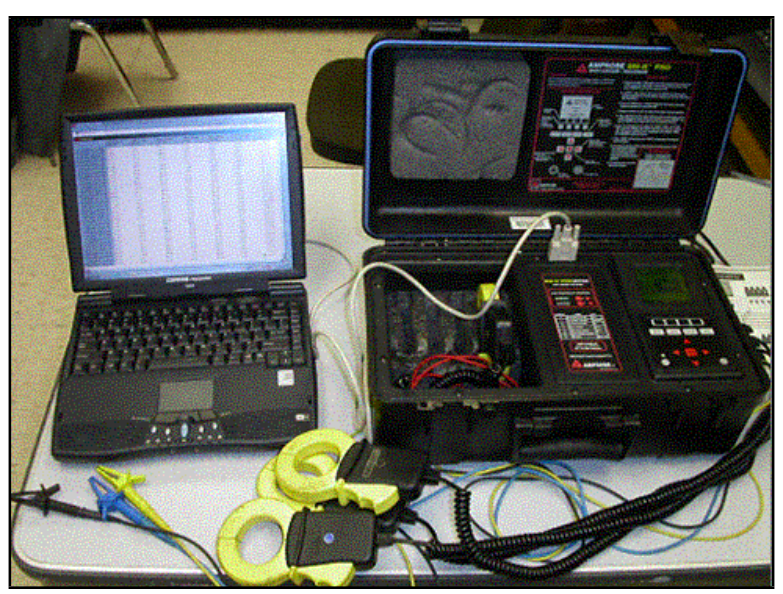

Figure 5.12: Power logger setup

The power logger records root mean square (RMS) values of voltages of each phase and current. AC current and voltages supplied are in the form of a sinusoidal wave, so to calculate the effective value of particular current or voltage, it is expressed in RMS values. The logger records RMS values of 3 phase voltages $V_{A B}, V_{B C}$ and $V_{C A}$ and line current $\mathrm{I}_{\mathrm{A}}, \mathrm{I}_{\mathrm{B}}$ and $\mathrm{I}_{\mathrm{C}}$.

A methodical analysis of the data can provide useful insight into energy efficiency measures such as retrofitting the equipment with varying capacity or scheduling different equipment in the facility to stagger electrical demand (depending on real power draw). Figure 5.13 shows industrial setup for compressor power measurement.

\section{$\underline{\text { Pros and Cons }}$}

Reliable results are dependent upon the detailed and accurate data measurement. Power logger provides an accurate means to log electrical power consumption data for variety of electrical equipment. The power logger software is user friendly and readily available. Three basic things that may limit use of the equipment are,

- Time

- Cost

- Safety 
The setup can be time consuming depending on a particular type of equipment and its connections. The safety of the involved personnel is of prime importance since the power logging task requires connections around high voltages and currents.

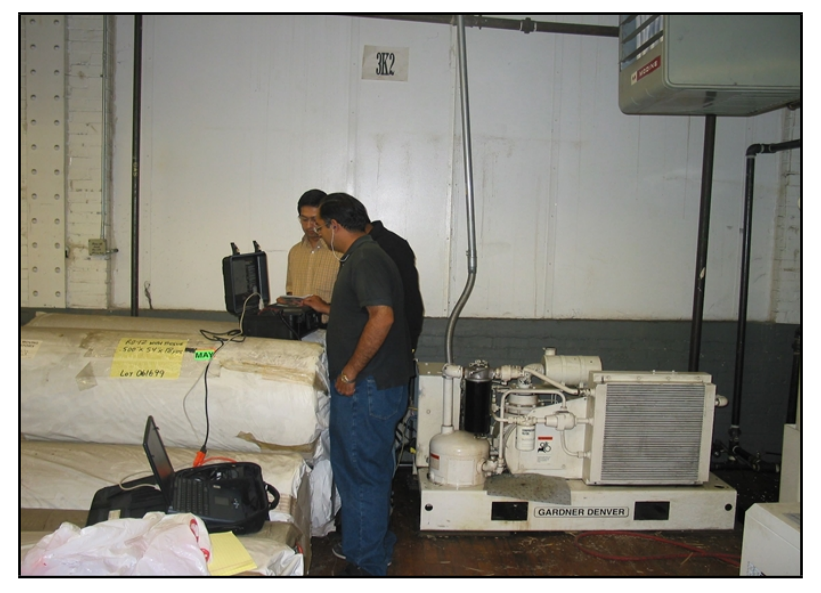

Figure 5.13: Compressor Power Measurement

\subsubsection{Motor On/Off Data Loggers}

This family of data loggers record On/Off or open/closed status changes, storing time, date, and state information for each change. The Motor On/Off sensor is shown in Figure 5.14.

\section{$\underline{\text { Features }}$}

These sensors monitor the On/Off status of an electric motor. The recorded data indicates equipment states at different times and detailed run-times. The detailed run times are useful for evaluating exact utilization of the compressor and also the load profile of the motor.

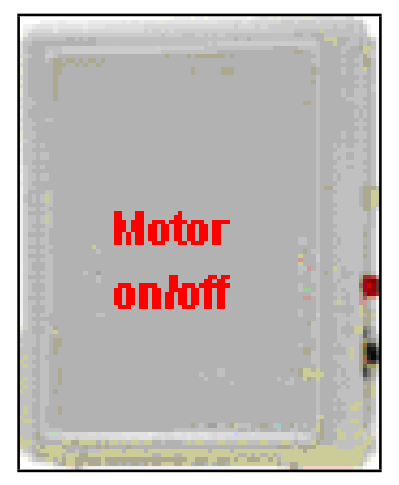

Figure 5.14: Motor On/Off sensor 


\section{Specifications}

The technical specifications of motor On/Off sensor are given in Table 5.2.

Table 5.2: Motor On/Off sensor Specifications

\begin{tabular}{|l|l|}
\hline Min. state & 0.5 seconds \\
\hline Time accuracy & approx. \pm 1 minute per week \\
\hline Capacity & 2,000 state changes $(8 \mathrm{kB})$ \\
\hline Op. temperature & $-20^{\circ} \mathrm{C}$ to $+70^{\circ} \mathrm{C}$ \\
\hline Rel. humidity & 0 to $95 \%$ \\
\hline Size/weight & $2.4 " \mathrm{x} 1.9^{\prime \prime} 0.8^{\prime \prime} / 1$ oz. $(28.35$ \\
\hline Battery & CR-2032 (lithium) \\
\hline Storage temp. & $-40^{\circ} \mathrm{C}$ to $+75^{\circ} \mathrm{C}$ \\
\hline
\end{tabular}

The relative humidity range is for non-condensing and non-fogging conditions. In general, the battery provides one year of continuous service and is user-replaceable. The $\mathrm{AC}$ magnetic-field threshold is approximately 2 Gauss at $60 \mathrm{~Hz}$ fundamental frequency.

\section{Applications}

While deploying the logger on a particular compressor motor, the following mounting conditions should be followed.

- AC-field sensor is in the front of the logger, therefore it should be mounted facing the field source (i.e., with the tape or magnet on the logger front).

- Intensity of magnetic field diminishes rapidly with the distance from the source; therefore the logger should be ideally mounted directly on the field source, if possible or at least very close otherwise. This will ensure less interference from other sources. Sensor software is required for data viewing and analysis. The data analysis can be used to reveal opportunities for the reduction in the compressor capacity or in the determination of a particular time period during which the compressor keeps running (instead of cycling) due to extra demand for air.

\section{$\underline{\text { Pros and Cons }}$}

The recorded data can be used to determine the actual time when the compressor under study was loaded and its total operation times during the day. This data may not be 
useful if the compressor does not have an automatic on/off control installed on it which responds to the air demand from the plant operation.

\subsection{Vibration Meters}

Electric motors serve as the most common type of prime movers to the air compressors. Electric motors, in general, are poorly maintained and attract attention of the maintenance personnel only when the motors burn out or the bearings fail; both resulting in production downtime. There is a significant drop in motor efficiency, before a complete failure occurs. Vibration analysis is a method that can be used by the maintenance personnel to determine mechanical faults in rotating equipment. The equipment (for example, compressor motors) can be monitored while it is operating and can detect signs of failures, thereby reducing the risk of catastrophic failures. Energy losses can occur due to bearing failure, inadequate lubrication (greasing), improper belt tension, misalignment and unbalances in the equipment. These losses surface out as vibration, heat and noise. One of the equipment used to perform the vibration analysis is the "Miniature Vibration Meter". It measures the vibration velocity in equipment in inches per second. It can be used to check vibrations in motors, pumps, compressors, and fans. Adequate implementation of a maintenance program in plants has justified a 10$14 \%$ reduction in energy consumption. Figure 5.15 shows the picture of a vibration meter.

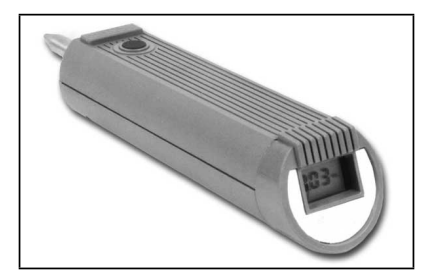

Figure 5.15: Vibration meter

Some of the reasons for failure due to excessive vibrations in the case of an electric motor used as a prime mover for an air compressor or any other rotating equipment are briefly described: 
- High vibration amplitudes (Vibration in inches per second) can be due to locked drive coupling. These high amplitudes can damage the motor bearings. The drive coupling should be checked and the motor should be serviced periodically.

- High vibrations can be due to problems in motor sheave and drive belts. The motor sheave wears out with time, and can become eccentric. In this scenario, the sheave should be replaced. The belts should be checked for proper tension and alignment. If not, then the belt tension should be adjusted.

- Improper lubrication in the bearings can cause excessive vibrations in the motor. Greasing the motor bearings will reduce the friction in the bearings and vibration amplitudes.

- The motor bearing housing (fasteners) gets loose with time. It needs to be tightened to reduce vibrations in the equipment.

- Journal or bearing housing wear results in bearing wear. The housing should be inspected to reduce the wear in the bearings.

\section{$\underline{\text { Specifications }}$}

A wide variety of vibration meters both simple hand held and of a complex kind are available in the market. These meters can measure vibration velocity between 0.01 inches per second $(1 \mathrm{inch}=2.54 \mathrm{~cm})$ to 2 inches per second. Accuracy up to a maximum of $5 \%$ of the full scale can be achieved using the hand held vibration meter. A typical hand held vibration meter will be approximately 8 inches $(1$ inch $=2.54 \mathrm{~cm})$ long and 2 inches in diameter. The frequency response on these meters can vary between $1 \mathrm{hz}$ to $1,000 \mathrm{hz}$.

\section{Application}

The vibration meter has a stylus on one end and a digital display on the other end. To perform a vibration analysis, the on/off toggle switch be pushed and the meter stylus should be gently pressed on the motor casing. Electric motors can be classified based on their operating frequency or speed. Hence, a wide variety of tables are used to determine the operating condition of the equipment knowing the vibration velocity read from the meter. Based on the motor speed or frequency, different motors can be categorized into one of the categories or classes listed in Table 5.3. 
Table 5.3: Determination of equipment condition using a vibration meter

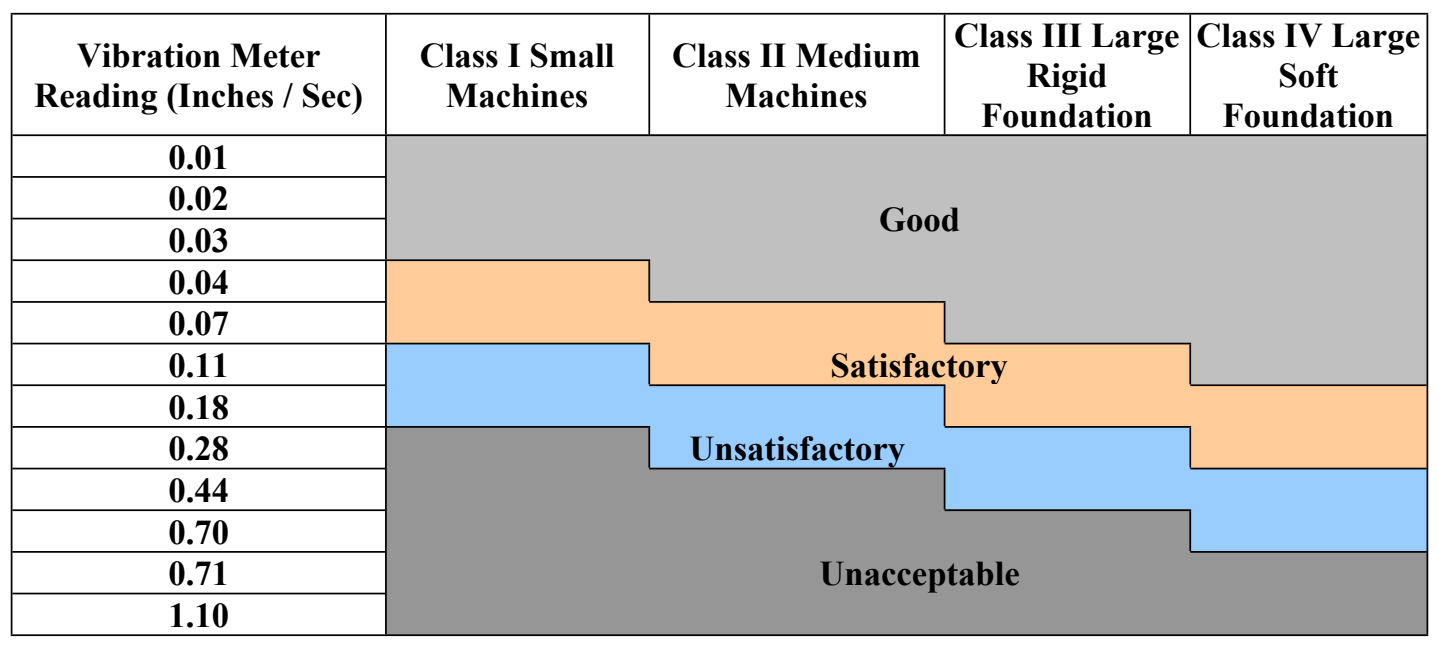

For example, the motors in class 1 operate in the $60-200 \mathrm{~Hz}$ (600 to 12,000 rpm) range. Hence, different classes are considered for determining the motor performance. Referring to Table 5.3, for example, any equipment falling in the class 1 and having a vibration meter reading of 0.07 or less will be considered to be operating under satisfactory conditions.

\section{$\underline{\text { Pros and Cons }}$}

- Hand held units are convenient and easy to use.

- These meters can serve as a diagnostic tool in the determination of excessive vibration levels in the equipment and provide warnings for unforeseen failures.

- Data collection is quick and instantaneous.

- The pointed stylus when strongly held against a motor casing of the equipment has a possibility of slipping and getting caught in the rotating shaft.

\subsection{Ultrasonic Leak Detector}

Air leak detection is facilitated by the use of ultrasonic leak detector. It has been linked with the energy conservation and predictive maintenance programs for a long time ever since it has been introduced in the industrial market. It has a continuum of uses, one of which is detecting the pressurized air leaks. Ultrasound technology is used by the leak detector which makes it extremely versatile and relevant for use in the industrial milieu to detect leaks. 


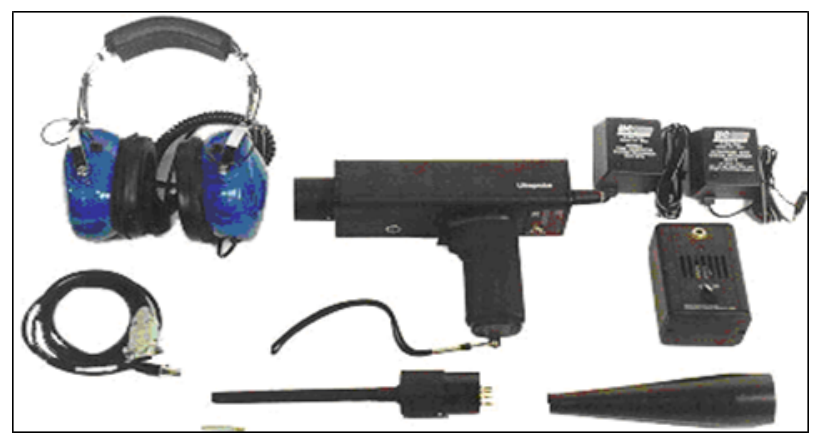

Figure 5.16: Complete ultrasonic leak detector kit

\section{$\underline{\text { Specifications }}$}

$\underline{\text { Probes }}$

Scanning Module is a plug-in type, consisting of a phased array of multiple transducers for airborne ultrasound. Rubber Focusing Probe (flexible) slides over the scanning module to focus narrowed directivity and to safeguard reception of stray ultrasound. It also fits over Stethoscope Module to shield against high ambient ultrasound while unit is at a maximum sensitivity level. Stethoscope Module is a plug-in type, insulated probe with RF shielding; 4 1/2" (11.4 cm) long steel probe tip, conically shaped for uniform surface contact. Probe tip is interchangeable.

Table 5.4: Specification of the ultrasonic leak detector

\begin{tabular}{|l|l|}
\hline Construction & Hand held pistol type with coated aluminum and ABS plastic \\
\hline Frequency range & $20 \mathrm{kHz}$ to $100 \mathrm{kHz}$ \\
\hline Response time & $<10$ milliseconds \\
temperature & $32^{\circ} \mathrm{F}$ to $122^{\circ} \mathrm{F}\left(0^{\circ} \mathrm{C}\right.$ to $\left.50^{\circ} \mathrm{C}\right)$ \\
\hline Sensitivity & $\begin{array}{l}\text { Detects } .005^{\prime \prime}(.127 \mathrm{~mm}) \text { diameter leak } @ 5 \text { psi }(.34 \text { bar }) \text { at a distance } \\
\text { of } 50 \text { feet }(15.24 \mathrm{~m})\end{array}$ \\
\hline Dimension & $\begin{array}{l}\text { Complete kit in zero Halliburton aluminum carrying case } 15^{\prime \prime} \mathrm{x} 22^{\prime \prime} \mathrm{x} \\
7^{\prime \prime}(38.1 \mathrm{x} 55.9 \mathrm{x} 17.8 \mathrm{~cm})\end{array}$ \\
\hline Weight & $\begin{array}{l}\text { Pistol :- } 2 \mathrm{lbs}(0.9 \mathrm{~kg}) \\
\text { Complete kit with case:- } 14 \text { lbs }(6.4 \mathrm{kgs})\end{array}$ \\
\hline
\end{tabular}

$\underline{\text { Headset }}$ 
Noise isolating type: double headset wired monophonic.

\section{$\underline{\text { Indicators }}$}

Indicators are model specific. For analog ultrasonic detector there is a Ballistic output meter which consists of a linear calibration scale for logging relative measurements. There is a Low level Battery LED indicating when the battery is low. For digital detectors there are $\mathrm{dB}$ indicators, and 16 Segment Bar Graph indicators.

\section{Applications}

Compressed air is used for various purposes in a manufacturing plant such as, in production processes, cleaning purposes, and operating pneumatic equipment. The use of the ultrasonic detector varies based on the application area. Since the papers focus is mainly on the compressed air system, the application of the ultrasonic leak detector in detecting the air leaks will be discussed further. Scanning module (refer to Figure 5.17) is used to conduct an inspection in order to locate the air leaks. The rubber focusing probe is used to determine the air losses. The probe is to be held at a distance of 12 to 15 inches $(1 \mathrm{inch}=2.54 \mathrm{~cm})$ away from the point of leak.

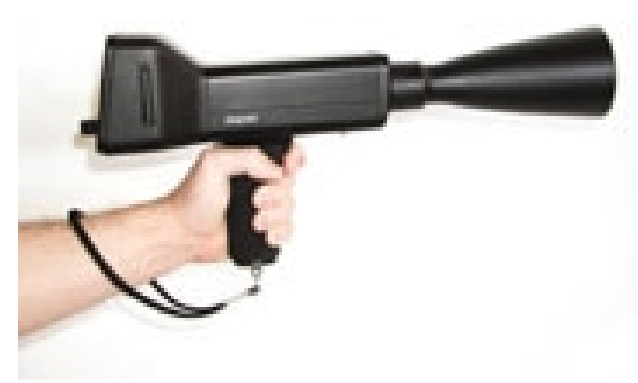

Figure 5.17: Ultrasonic detector

Figure 5.17 shows an example for the use of an ultrasonic detector. Based on whether the detector is an analog or digital type the sensitivity dial is to be adjusted until the meter reads $50 \%$ of the full scale at which the reading displayed on the screen is noted. The charts presented in Table 5.5 or Table 5.6 are used to get an estimate of the CFM of the air loss at the point of leak based on the meter reading depending on whether the probe is an analog or digital respectively. The presence of leaks in the compressed air system is one of the reasons for having higher pressure setting than required by the actual users of the compressed air. The compressor has to feed the leaks along with the end uses. Air fed 
to leaks is wasted and hence the excess work done by the compressor to feed them is a waste of energy. The volume of the air loss found with the help of the leak detector and the related tables helps to identify how much air is being fed to the leaks by the compressor. By fixing these leaks, the pressure setting for the compressor can be reduced and hence energy is conserved.

Table 5.5: Flow rate in CFM $\left(1 \mathrm{CFM}=471.9474 \mathrm{~cm}^{3} / \mathrm{sec}\right)$ for analog leak detector $(1 \mathrm{psi}=6.8948 \mathrm{kPa})$

\begin{tabular}{|c|c|c|c|c|}
\hline $\begin{array}{c}\text { Sensitivity } \\
\text { Dial }\end{array}$ & 100 PSIG & 75 PSIG & 50 PSIG & 25 PSIG \\
\hline 8.5 & .50 & .30 & .15 & .10 \\
\hline 8.0 & 1.0 & 0.5 & .30 & .20 \\
\hline 7.5 & 1.1 & 0.8 & 0.7 & 0.7 \\
\hline 7.0 & 1.6 & 1.0 & 1.0 & 0.9 \\
\hline 6.5 & 2.0 & 1.3 & 1.3 & 1.4 \\
\hline 6.0 & 2.3 & 1.7 & 1.7 & 1.8 \\
\hline 5.5 & 3.3 & 2.2 & 2.2 & 2.2 \\
\hline 5.0 & 3.9 & 2.8 & 2.6 & 2.7 \\
\hline 4.5 & 5.5 & 3.6 & 3.2 & 3.7 \\
\hline 4.0 & 6.2 & 3.9 & 3.7 & 4.0 \\
\hline 3.5 & 6.9 & 4.9 & 4.6 & 4.6 \\
\hline 3.0 & 7.5 & 5.7 & 5.2 & 5.1 \\
\hline 2.5 & 8.0 & 6.2 & 5.8 & 6.0 \\
\hline
\end{tabular}

Table 5.6: Flow rate in CFM $\left(1 \mathrm{CFM}=471.9474 \mathrm{~cm}^{3} / \mathrm{sec}\right)$ for digital leak detector (1 psi $=6.8948 \mathrm{kPa})$

\begin{tabular}{|c|c|c|c|c|}
\hline $\begin{array}{c}\text { Digital } \\
\text { Reading }\end{array}$ & 100 PSIG & 75 PSIG & 50 PSIG & 25 PSIG \\
\hline $10 \mathrm{~dB}$ & 0.5 & 0.3 & 0.15 & 0.1 \\
\hline $20 \mathrm{~dB}$ & 0.8 & 0.9 & 0.5 & 0.3 \\
\hline $30 \mathrm{~dB}$ & 1.4 & 1.1 & 0.8 & 0.5 \\
\hline $40 \mathrm{~dB}$ & 1.7 & 1.4 & 1.1 & 0.8 \\
\hline $50 \mathrm{~dB}$ & 2.0 & 2.8 & 2.2 & 2.0 \\
\hline $60 \mathrm{~dB}$ & 3.6 & 3.0 & 2.8 & 2.6 \\
\hline $70 \mathrm{~dB}$ & 5.2 & 4.9 & 3.9 & 3.4 \\
\hline $80 \mathrm{~dB}$ & 7.7 & 6.8 & 5.6 & 5.1 \\
\hline $90 \mathrm{~dB}$ & 8.4 & 7.7 & 7.1 & 6.8 \\
\hline $100 \mathrm{~dB}$ & 10.6 & 10.0 & 9.6 & 7.3 \\
\hline
\end{tabular}


Based on the experience through several assessments conducted by the IAC, it is estimated that for medium scale manufacturing plants, fixing the leaks in the system, would save approximately $10-15 \%$ of the total energy required to operate an air compressor.

\section{$\underline{\text { Pros and Cons }}$}

\section{Advantages}

Ultrasound technology used by the leak detector makes it extremely easy to use. The leak detector can be used in extremely noisy surrounding which makes it a very appropriate choice for industries. It is directional and localized. The use of this equipment can help in preventive maintenance hence reducing the production downtime. It is useful in the way it helps to save energy as explained before.

\section{Disadvantages}

The estimate of the CFM using an analog leak detector may have errors due to human intervention in setting the sensitivity dial. The limitation of locating the leaks within 12 to 15 inches from the probe may be a problem in a way that some leaks might be located where the person would not be within the specified distance. Hence not all leaks are located. Capital investment to purchase the most advanced leak detector could be high for small and a few of the medium scale industries.

\subsection{AIRMaster+}

AIRMaster+ is one of the BestPractices software tools developed by the United States Department of Energy. It is used to model the compressed air system and analyze the energy efficiency measures (such as reduce air leaks, reduce compressed air pressure, use appropriate compressor controls, reduce run time of the compressor, and sequence/stage air compressors in the facility). The data collected with the equipment discussed in this paper, greatly help in quantifying energy savings using AIRMaster+.

\section{Example Case Study}

During one of the industry visits, it was observed that a compressor was set at 110 psig, even though the process required a maximum pressure of 80 psig. After discussion with the plan personnel, the compressor pressure (Figure 5.18) and power usage profiles 
(Figure 5.19) in the plant were monitored. It can be seen that the pressure fluctuation start between 88 psig and 96 psig (Figure 5.18). Also, the minimum available pressure drops to 85 psig after some time which was close to the maximum pressure requirement of 80 psig. On the other hand, the profile of current drawn by the compressor (Figure 5.19) revealed that the compressor was working almost all the time with electrical current values close to 55 Amps and 90 Amps. It may be noted that the compressor was generating compressed air when it was at 90 Amps level and was idling when it was at the 55 Amps level i.e. it was not generating any compressed air.

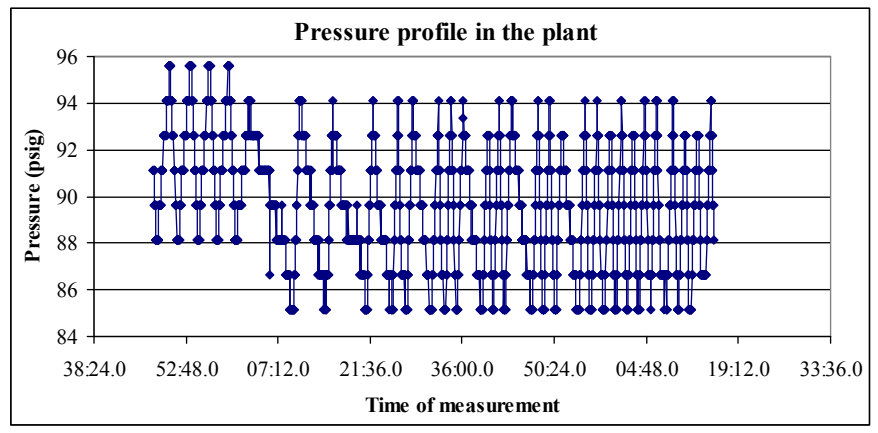

Figure 5.18: Example pressure profile

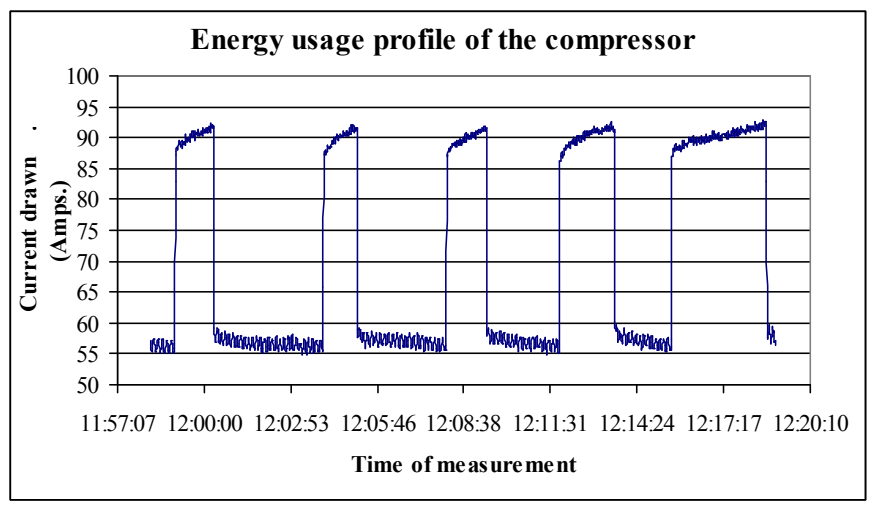

Figure 5.19: Example profile of electrical current usage

It was discovered that there were no dedicated storage tanks and only the distribution lines were acting as effective compressed air storage. Therefore, to meet the intermittent needs of the compressed air in the processes, the inadequate storage capacity caused high pressure fluctuations and made the compressor run all the time. It was recommended to install a 500 gallons dedicated storage tank to minimize the pressure fluctuations and 
change the compressor controls to On/Off or set the no load level to a value close to zero Amps. This will minimize the power loss since the compressor did not produce any air during idling condition but it was consuming almost $50 \%$ of the full load power.

\subsection{Insulation}

Insulation is one of the highly recommended opportunities for energy savings. As per the IAC database, insulation is in the top 10 list in terms of number of times recommended to industrial facilities. It is interesting to examine the insulation recommendations for manufacturing companies across various SIC (Standard Industrial Code) with respect to corresponding energy and cost savings.

Instruments such as handheld infrared temperature measurement gun and digital thermal imaging were used in the generation of these recommendations. In addition, the US Department of Energy's recommended BestPractices software tool 3E Plus and fundamental engineering principles were used to estimate the energy and cost savings. Figure 5.20 shows the digital and thermal image of a boiler surface. The thermal image reveals that the center part of this boiler surface is extremely hot with temperature over $500^{\circ} \mathrm{F}$ or $260^{\circ} \mathrm{C}$ and most of the surface temperature is in the range of $250^{\circ} \mathrm{F}$ or $121^{\circ} \mathrm{C}$ to $300^{\circ} \mathrm{F}$ or $149^{\circ} \mathrm{C}$.
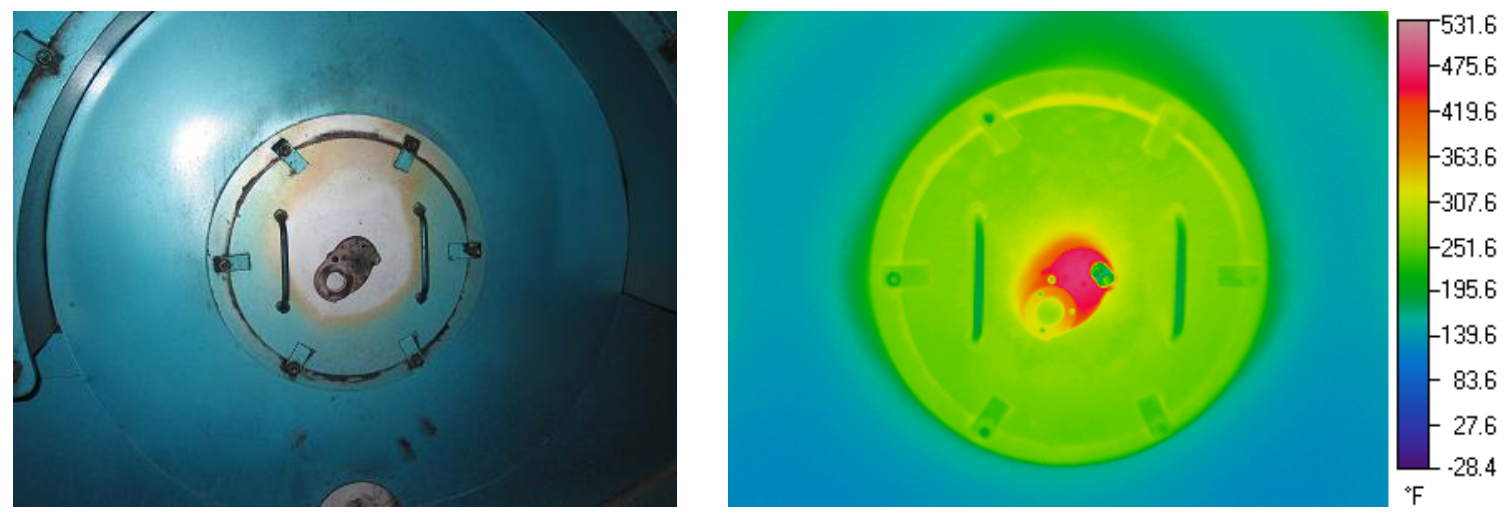

Figure 5.20: Digital (left) and Thermal (right) Image of the Boiler Surface

Most manufacturing facilities recognize the attractiveness of the recommendation to have proper insulation on hot and cold surfaces and pipes while others neglect this important aspect mainly due to their efforts constantly aimed towards fulfilling production targets, thus leaving minimal time to investigate energy losses due to lack of 
insulation. The general description and the SIC for some of the manufacturing facilities visited by the IAC are shown on Table 5.7.

Table 5.7: Sample Manufacturing Industries with SIC Code

\begin{tabular}{|r|l|}
\hline SIC & \multicolumn{1}{|c|}{ Description } \\
\hline 2024 & Ice Cream and Frozen Dessert Manufacturing \\
\hline 2033 & Fruit and Vegetable Canning \\
\hline 2299 & Textile Goods \\
\hline 2421 & Sawmills and Planing Mills, General \\
\hline 2436 & Softwood Veneer and Plywood \\
\hline 2491 & Wood Preserving \\
\hline 2653 & Corrugated and Solid Fiber Boxes \\
\hline 2674 & Uncoated Paper and Multiwall Bags \\
\hline 2869 & Industrial Organic Chemicals \\
\hline 3089 & Plastics Products \\
\hline 3251 & Brick and Structural Clay Tile \\
\hline 3365 & Aluminum Foundries \\
\hline 3471 & Electroplating, Plating, Polishing, Anodizing, and Coloring \\
\hline 3492 & Fluid Power Valves and Hose Fittings \\
\hline SIC & \\
\hline 3499 & Fabricated Metal Products \\
\hline 3553 & Woodworking Machinery \\
\hline 3599 & Industrial and Commercial Machinery and Equipment \\
\hline 3955 & Carbon Paper and Inked Ribbons \\
\hline
\end{tabular}

The average amount of annual recommended energy savings amongst the manufacturing sector showcased on Table $\mathrm{X}$ is shown on Figure 5.21. 


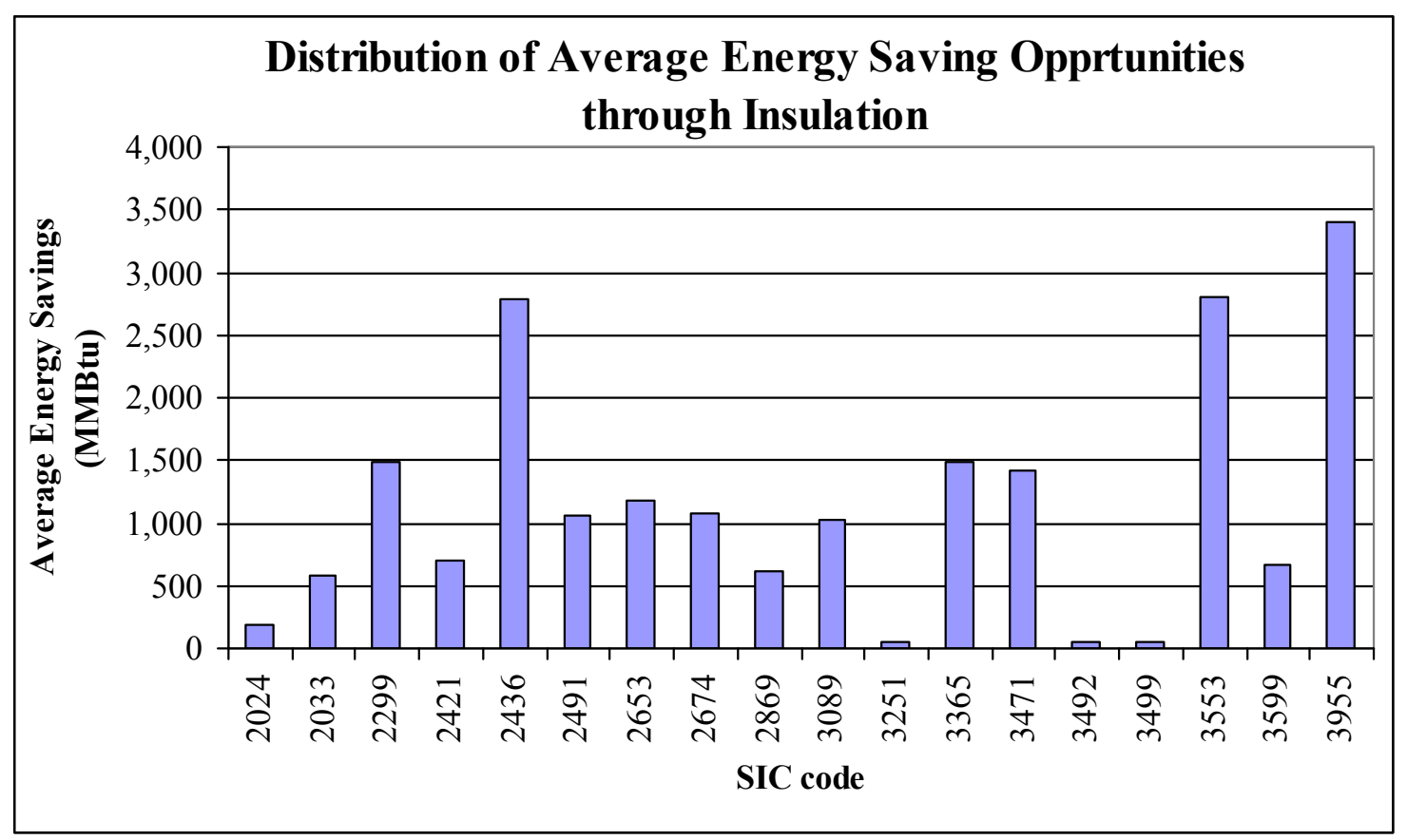

Figure 5.21: Average Insulation Energy Savings in Manufacturing Industries

Close to $64 \%$ of the total recommended energy savings from insulation projects were realized in terms of natural gas equipment surfaces and/or distribution lines followed by saw dust systems with $24 \%$ savings. Insulation of electrical systems contributed to $7 \%-8 \%$ of the total recommended savings. Coal and other fuels together had less than $5 \%$ of the total savings. Based on this analysis, it is evident that natural gas systems (e.g. boiler surfaces and steam distribution lines) have high potential for effective insulation and should receive adequate attention for insulation projects.

It may be noted that manufacturing facilities with SIC 3955, 3553, and 2436 had highest energy saving opportunity (Figure 5.21) from insulation projects. The first one in this list is "Carbon Paper and Inked Ribbons" manufacturing and other two are related to wood manufacturing industries. The analysis of the energy saving recommendations reveals that the recommendations related to SIC 3955 were in regard to insulating the coating machines. The machine surfaces were not insulated and were losing significant heat energy. It was noted that the amount of energy loss through the surfaces were close of $20 \%$ of the total energy used by the plant. After insulting the surface with proper insulation material, the plant was able to reduce their energy cost by approximately $\$ 25,000$ per year. As an example, one of the vertical surfaces that needed insulation had a 
temperature of $260^{\circ} \mathrm{F}$. The surrounding temperature was measured as $70^{\circ} \mathrm{F}$ or $21^{\circ} \mathrm{C}$ and the maximum allowed temperature was assumed as $140^{\circ} \mathrm{F}$ or $60^{\circ} \mathrm{C}$. Since this was an indoor area, the wind speed was assumed as zero. Based on this information, 3E Plus software (Figure 5.22) was used to estimate the amount of energy loss before and after the insulation.

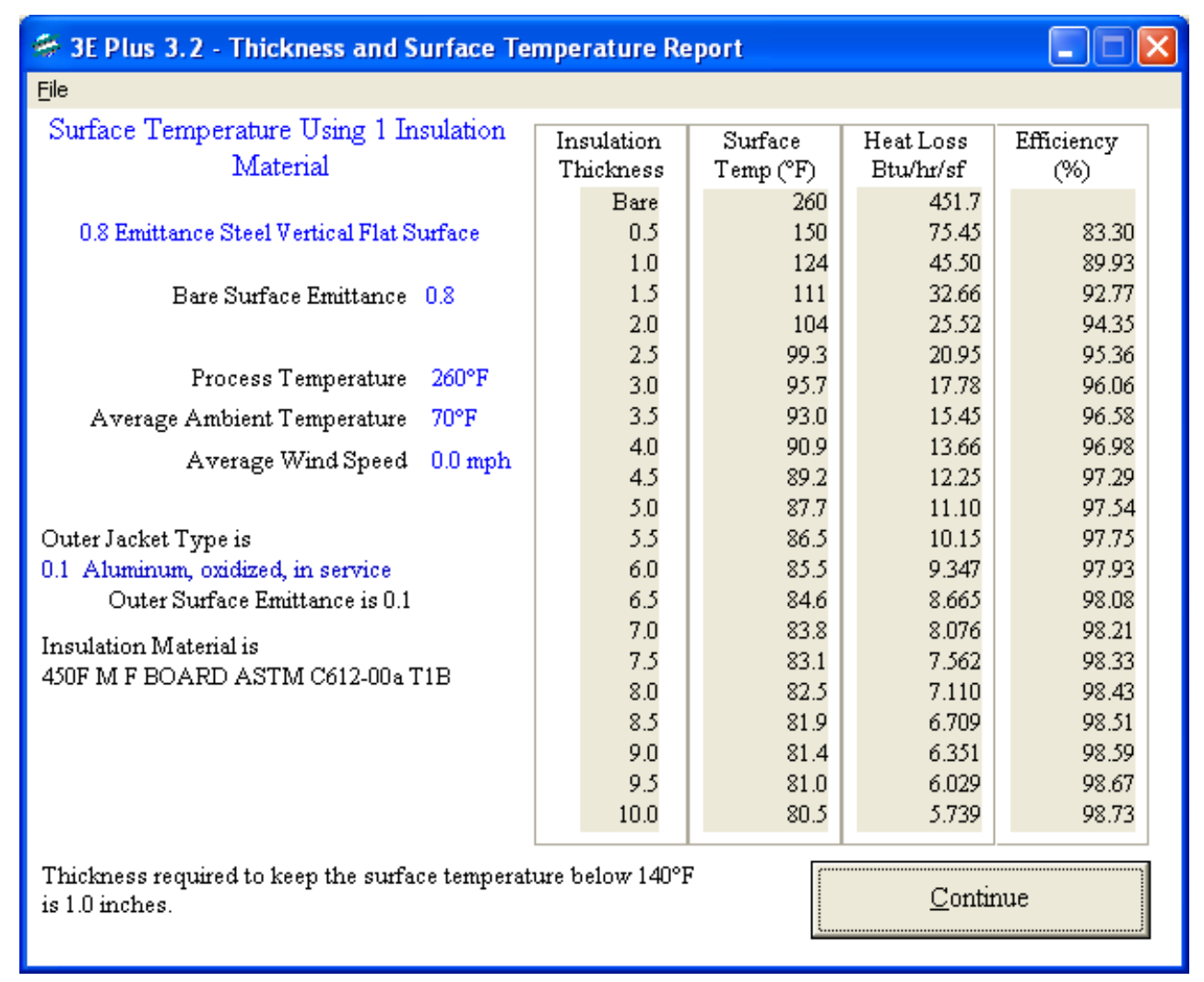

Figure 5.22: Example Savings from the Coating Line Surface Insulation

As shown in Figure 5.22, after adding 1 inch "450F M F BOARD ASTM C61200a T1B" insulation material, the heat loss reduced from $451.7 \mathrm{Btu} / \mathrm{hr} / \mathrm{sf}$ or 476,544 Joules $/ \mathrm{hr} / \mathrm{sf}$ to $45.50 \mathrm{Btu} / \mathrm{hr} / \mathrm{sf}$ or $48,003 \mathrm{Joules} / \mathrm{hr} / \mathrm{sf}$. Therefore, the total savings from insulating the surface is $273 \mathrm{MMBtu} / \mathrm{yr}$ or 288,031 Megajoules. Similar analysis was performed to quantify the recommended energy savings from insulating all the surfaces identified.

One of the companies under SIC 3553 had recommendations related to insulation of steam distribution lines and dock doors. The total savings form the two insulation 
recommendations resulted in savings of approximately $8 \%$ of the total natural gas cost per year. Similar savings from insulation improvement were recommended for other companies. In most of the cases, the insulation recommendations were related to steam distribution lines, boiler surfaces, dock doors, and ovens. Energy savings opportunities not only reduce the operating cost of the company but also reduce the amount of $\mathrm{CO} 2$ emissions (approximately $113 \mathrm{lbs}$ per MMBtu of natural gas usage reduction). This makes the company competitive and environmentally effective at the same time.

The cost of implementing the recommendations was also considered and was estimated to result in an average simple payback period on investment of less than six months. There were only few facilities for which the simple payback period on investment was over one year. Because of the low implementation cost, simple implementation procedures, and significant cost savings, the insulation recommendations have proven to be attractive for facilities to implement, thus resulting in a an implementation rate close to $70 \%$. 


\section{Appendix}




\subsection{Appendix I: Equipment List}

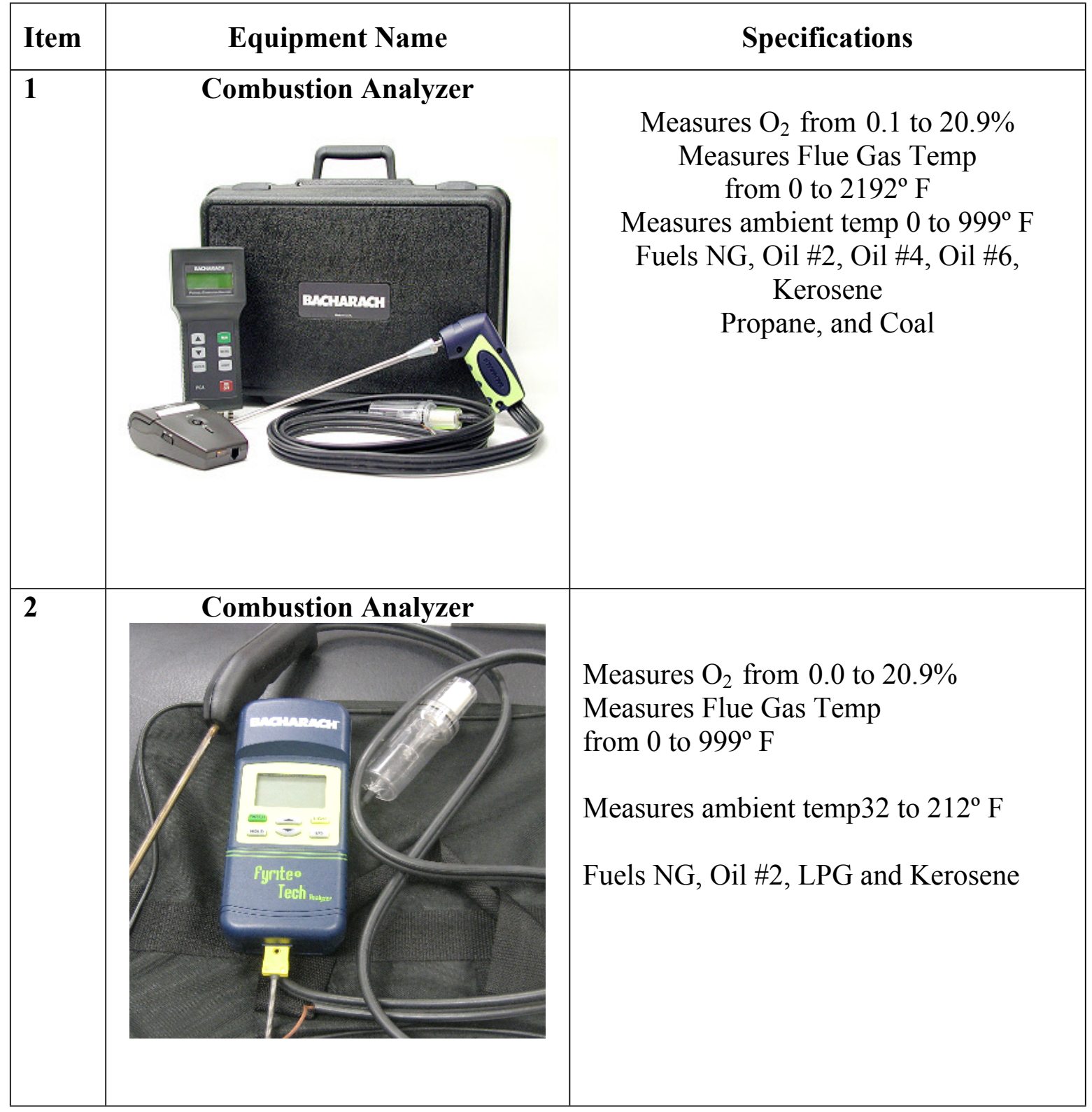




\begin{tabular}{|c|c|c|}
\hline 3 & $\begin{array}{l}\text { Combustion Analyzer } \\
=\end{array}$ & $\begin{array}{l}\text { Measure Efficiency of Combustion, } \\
\text { Carbon Dioxide, Library of } 15 \text { fuels, } \\
\text { Runs on Batteries or AC Current } \\
\text { Uses desiccant }\end{array}$ \\
\hline 4 & 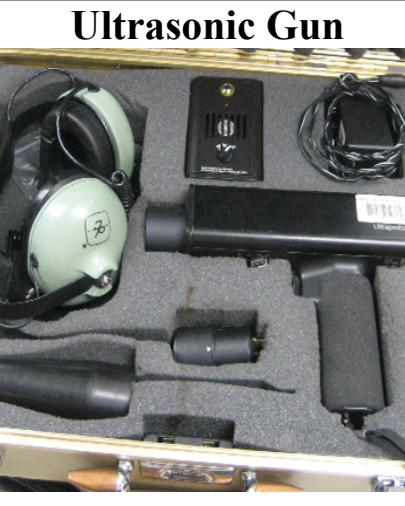 & $\begin{array}{l}\text { Analog Ultrasonic Leak Detection } \\
\text { System } \\
\text { Detect ultrasonic frequencies between } 20 \\
\mathrm{kHz} \text { and 100kHz, continuously variable. } \\
\text { Frequencies are converted to } 100 \mathrm{~Hz} \text { to } 3 \\
\text { kHz audio. } \\
\text { Frequency tuning adjustment dial: Scale } \\
\text { 20-100 kHz with "fixed band" positions } \\
\text { for ultra-narrow frequency response. }\end{array}$ \\
\hline 5 & Ultra Probe 100 & $\begin{array}{l}\text { Frequency Response: } 20-100 \mathrm{kHz} \\
\text { (centered at } 38-42 \mathrm{kHz} \text { ) }\end{array}$ \\
\hline
\end{tabular}




\begin{tabular}{|c|c|c|}
\hline 6 & Drill/Screw Driver & $\begin{array}{l}\text { Ambient Operating Temperature Range: } \\
32^{\circ}-120^{\circ} \mathrm{F}\left(0^{\circ}-50^{\circ} \mathrm{C}\right) \\
\text { Relative Humidity: } 10-95 \% \text { non } \\
\text { condensing at up to } 86^{\circ} \mathrm{F}\left(30^{\circ} \mathrm{C}\right) \\
\text { Sensitivity Selection: } 8 \text { position precision } \\
\text { attenuation } \\
\text { Ambient Operating Temperature Range: } \\
32^{\circ}-120^{\circ} \mathrm{F}\left(0^{\circ}-50^{\circ} \mathrm{C}\right) \\
\text { Relative Humidity: } 10-95 \% \text { non } \\
\text { condensing at up to } 86^{\circ} \mathrm{F}\left(30^{\circ} \mathrm{C}\right) \\
\text { Sensitivity Selection: } 8 \text { position precision } \\
\text { attenuation }\end{array}$ \\
\hline 7 & Thermo-Anemometor, Compuflow & $\begin{array}{l}\text { Measures Temp and air flow } \\
\text { This item is pretty old so the range data } \\
\text { could not be found, but for the newer } \\
\text { models: } \\
\text { Velocity: } 20-9999 \mathrm{fpm} \\
\text { Temp: } 0-140^{\circ} \mathrm{F} \\
\text { Humidity: } 0-95 \% \text { RH } \\
\text { (Not In Use) }\end{array}$ \\
\hline 8 & Amprobe DM-II Pro & $\begin{array}{l}\text { AC Voltage: } 0 \text { - 600V } \\
\text { AC Current: } 1 \text { - 1000A (expandable to } \\
\text { 3000A with optional CT's) } \\
\text { Power: Actual (W), Reactive (VAR) and } \\
\text { Apparent (VA) } \\
\text { Power Factor: } 0 \text { - } 1 \\
\text { Energy: kWh } \\
\text { Peak Demand: kW } \\
\text { Fund. Frequencies: } 50 / 60 \mathrm{~Hz} \\
\text { Available Recording Time: } 1 \text { hour to } \\
\text { several months depending on setup }\end{array}$ \\
\hline 9 & AmpFlex Current Logger & $\begin{array}{l}\text { - } \text { True RMS recording } \\
\text { - Range 0-250 Arms,0-2500 Arms } \\
\text { - Records up to six months } \\
\text { - Load profiling-Machine load } \\
\text { monitoring, Substation } \\
\text { monitoring }\end{array}$ \\
\hline 10 & AC Clamp-on Ammeter & \\
\hline
\end{tabular}




\begin{tabular}{|l|l|}
\hline 11 & $\begin{array}{l}\text { Measures amps, volts and ohms from } 0.1 \\
\text { to } 1000 .\end{array}$ \\
\hline 13 & \\
\hline
\end{tabular}




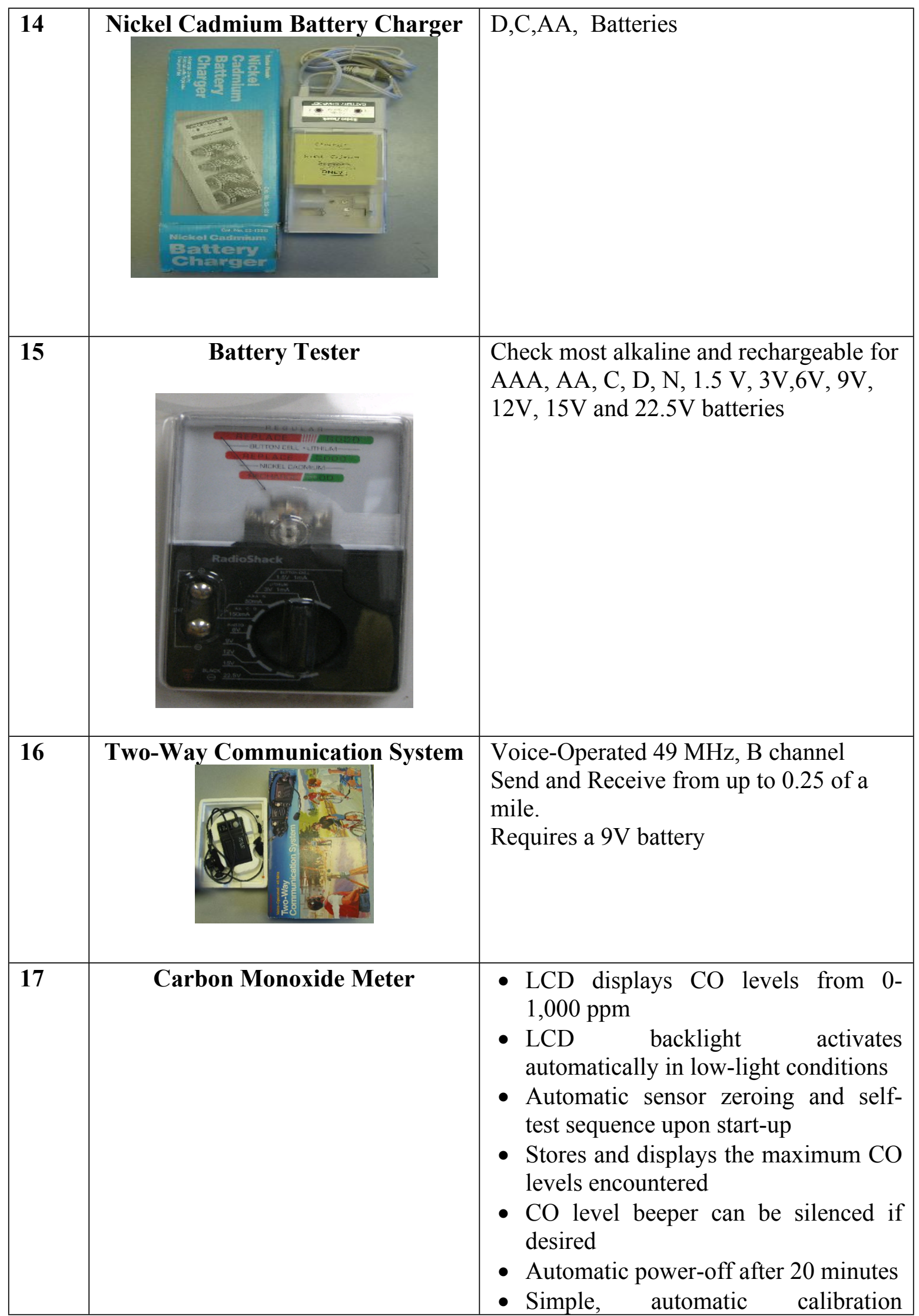




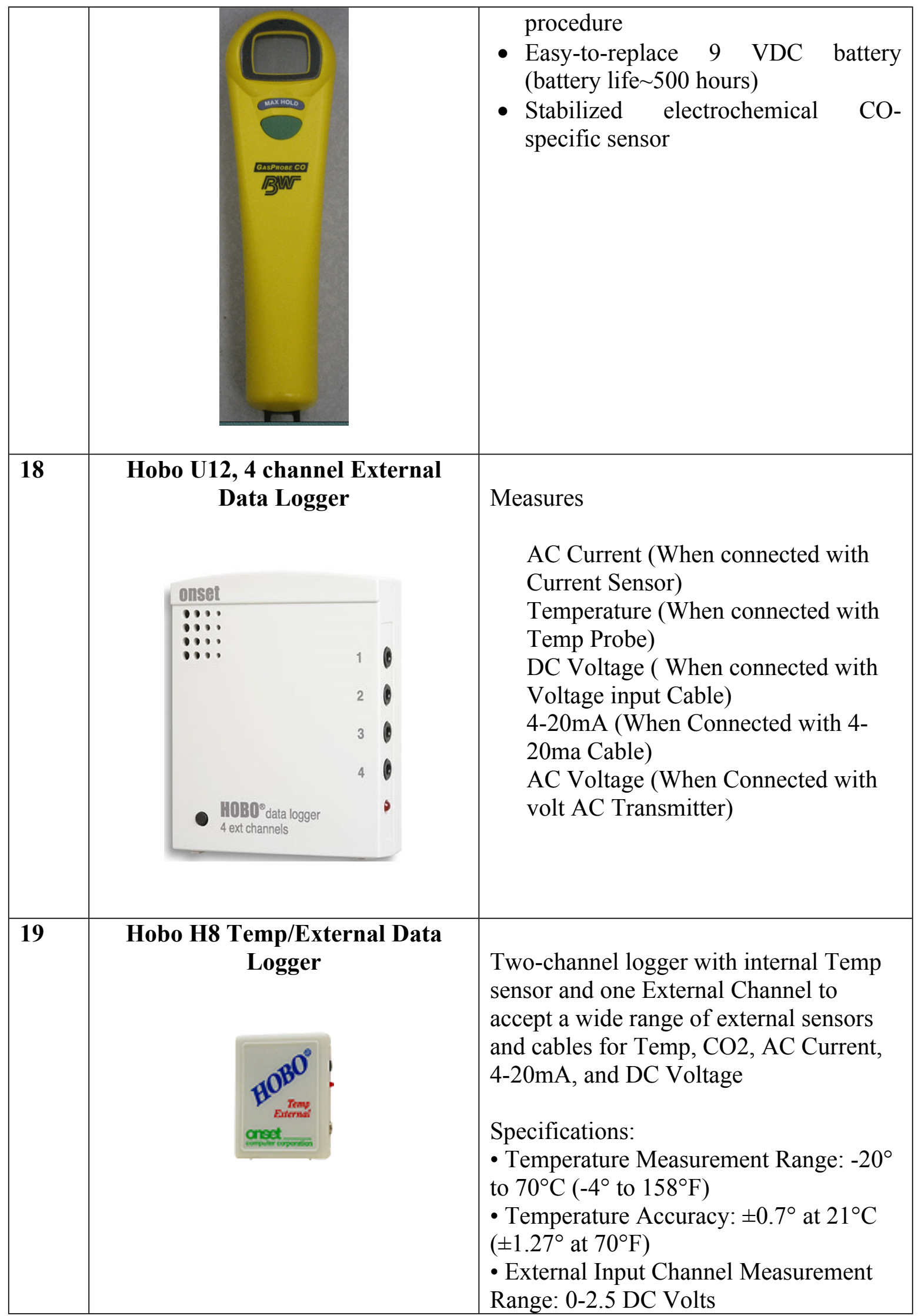




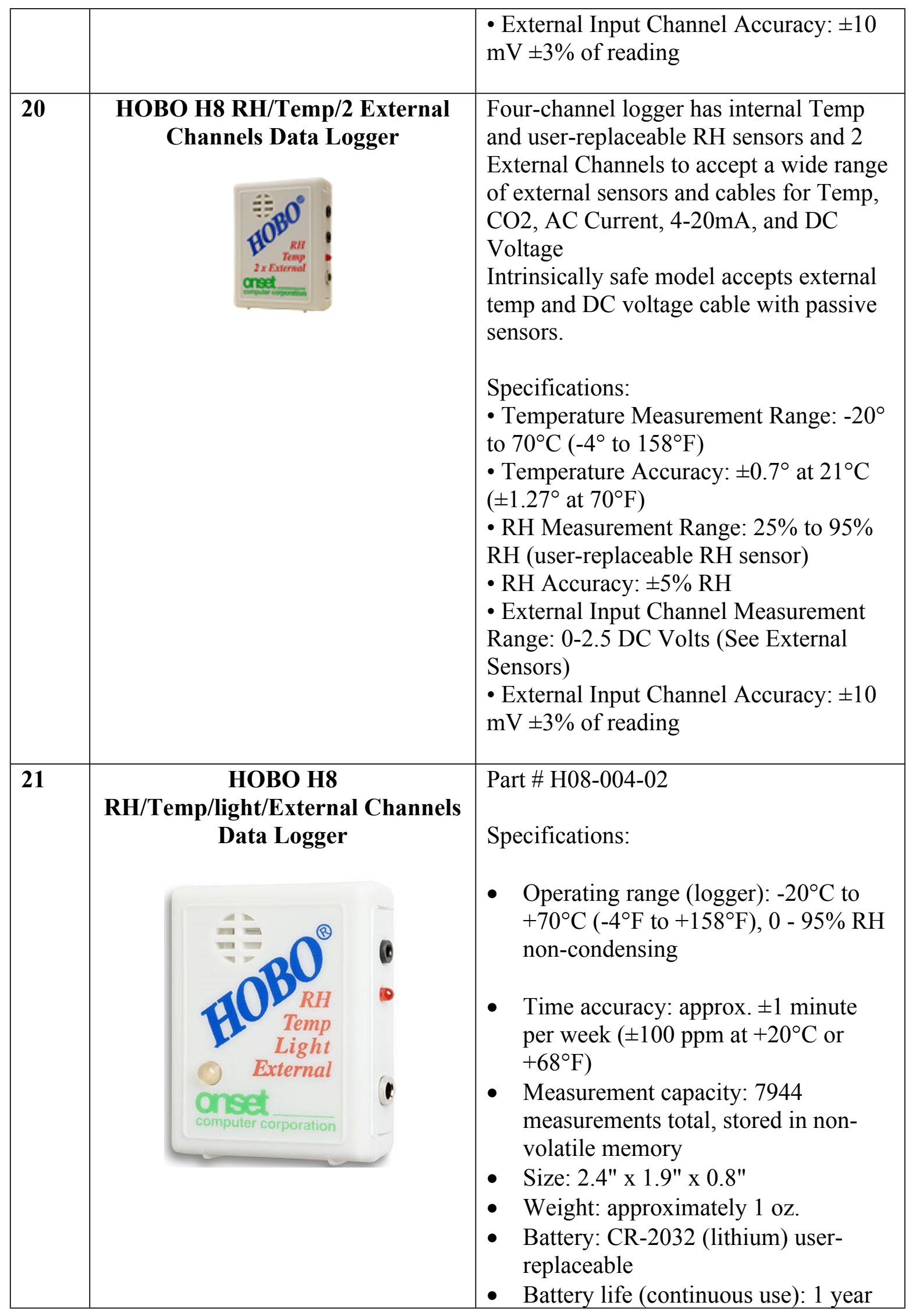




\begin{tabular}{|c|c|c|}
\hline & & $\begin{array}{l}\text { - Storage temperature: }-40^{\circ} \mathrm{C} \text { to }+75^{\circ} \mathrm{C} \\
\left(-40^{\circ} \mathrm{F} \text { to }+167^{\circ} \mathrm{F}\right)\end{array}$ \\
\hline 22 & $\begin{array}{l}\text { HOBO H6 Motor On/Off with } \\
\text { Vibration Sensor Data Logger }\end{array}$ & $\begin{array}{l}\text { A vibration is only weakly dampened by distance so } \\
\text { the logger need not be mounted directly on the } \\
\text { source. However, this leads to the potential of } \\
\text { interference from other sources. The logger's } \\
\text { threshold adjustment can be used to help } \\
\text { discriminate against other sources. } \\
\text { Specifications: } \\
\text { - Vibration Threshold: adjustable } 0.05 \mathrm{G} \text { to } \\
0.5 \mathrm{G} \text { at } 60 \mathrm{~Hz} \text { (.0001 to } .001 \text { " } \\
\text { displacement) } \\
\text { Angular response: the logger is sensitive to } \\
\text { the part of the vibration that is } \\
\text { perpendicular to the logger's face }\end{array}$ \\
\hline 23 & Hobo H12 Type K Thermocouple & $\begin{array}{l}\text { - Specifications for thermocouple loggers } \\
\text { Internal Temperature Sensor } \\
\text { This sensor is also used to measure the } \\
\text { cold-junction temperature. The } \\
\text { thermocouple readings are compensated } \\
\text { in the logger regardless of whether this } \\
\text { channel is selected. } \\
\text { - Internal Range: } 0^{\circ} \mathrm{C} \text { to } 50^{\circ} \mathrm{C}\left(32^{\circ} \mathrm{F} \text { to }\right. \\
\left.122^{\circ} \mathrm{F}\right) \\
\text { - Internal Resolution: } 0.4^{\circ} \mathrm{C} @ 21^{\circ} \mathrm{C} \\
\left.\text { (0.7 } 7^{\circ} \mathrm{F} @ 70^{\circ} \mathrm{F}\right) \\
\text { - Internal Accuracy: } \pm 0.7^{\circ} \mathrm{C} @ 21^{\circ} \mathrm{C} \\
\left.\text { ( } \pm 1.3^{\circ} \mathrm{F} @ 70^{\circ} \mathrm{F}\right) \\
\text { - Capacity: } 32,530 \text { measurements total } \\
\text { - User-selectable sampling intervals: } 0.5 \\
\text { seconds to } 9 \text { hours, recording times up to } \\
1 \text { year } \\
\text { - Readout and relaunch with optional } \\
\text { HOBO Shuttle } \\
\text { - Drop-proof to } 5 \text {, } \\
\text { - Mounting kit included (hook/loop, } \\
\text { magnet, and tape) } \\
\text { - Programmable start time/date } \\
\text { - Memory modes: stop when full, wrap- } \\
\text { around when full } \\
\text { - Nonvolatile EEPROM memory retains } \\
\text { data even if battery fails } \\
\text { - Blinking LED confirms operation } \\
\text { - User-replaceable battery lasts } 1 \text { year } \\
\text { - Battery level indication at launch } \\
\text { - Operating range: } 0^{\circ} \mathrm{C} \text { to } 50^{\circ} \mathrm{C}\left(32^{\circ} \mathrm{F} \text { to }\right.\end{array}$ \\
\hline
\end{tabular}




\begin{tabular}{|c|c|c|}
\hline & & $\begin{array}{l}\left.122^{\circ} \mathrm{F}\right), 0 \text { to } 95 \% \text { relative humidity, non- } \\
\text { condensing, non-fogging } \\
\text { - Time accuracy: } \pm 1 \text { minute per week at } \\
20^{\circ} \mathrm{C}\left(68^{\circ} \mathrm{F}\right) \\
- \text { Size/Weight: } 6.1 \times 4.8 \times 2.0 \mathrm{~cm}(2.4 \times \\
\left.1.9 \times 0.8^{\prime \prime}\right) / \text { approx. } 26 \text { gms }(0.9 \mathrm{oz} .)\end{array}$ \\
\hline 24 & $\left.\begin{array}{c}\text { HOBO }{ }^{\circledR} \mathrm{H8} \text { Outdoor/Industrial } \\
\text { 4-Channel External Logger } \\
\text { outdoor/Industrial } \\
\text {-Channel External } \\
\text { onset } \\
\text { computer corporation }\end{array}\right)$ & $\begin{array}{l}\text { *Drop-proof to } 5 \text { ' } \\
\text { *Programmable start time/date } \\
\text { *Operating range: }-4^{\circ} \mathrm{F} \text { to }+158^{\circ} \mathrm{F}\left(-20^{\circ} \mathrm{C}\right. \\
\left.\text { to }+70^{\circ} \mathrm{C}\right) \\
\text { *Access port provides easy data offload } \\
\text { *Mounting hardware included ( } 4 \\
\text { mounting screws and washers) } \\
\text { *Size: } 14.0 \text { x } 13.7 \text { x } 3.2 \mathrm{~cm}\left(5.50^{\prime} \text { x }\right. \\
5.38^{\prime} \text { x } 1.25 \text { ") } \\
\text { Accepts external sensors and input cables for: } \\
\text { Temperature } \\
\text { AC Current } \\
4-20 \text { milliamps } \\
0 \text { to } 2.5 \text { Volts DC } \\
\text { CO2 } \\
\text { Specifications: } \\
\text { *Operating environment: weatherproof } \\
\text { case, tested to NEMA } 6 \\
\text { *Accepts external sensors and input } \\
\text { cables for temperature, AC current, } 0-2.5 \\
\text { Volt DC, } 4-20 \text { mA, and CO2 } \\
\text { *Capacity: } 32,520 \text { measurements total } \\
\text { *User-selectable sampling interval: } 0.5 \\
\text { seconds to } 9 \text { hours, recording times up to } \\
1 \text { year } \\
\text { *Readout and relaunch with optional } \\
\text { HOBO Shuttle } \\
\text { *Weight: approx. } 200 \text { grams ( } 7 \text { oz.) } \\
\text { *Memory modes: stop when full, wrap- } \\
\text { around when full } \\
\text { *Nonvolatile EEPROM memory retains } \\
\text { data even if battery fails } \\
\text { *Blinking LED light confirms operation } \\
\text { *User-replaceable battery lasts } 1 \text { year } \\
\text { *Battery level indication at launch } \\
\text { *Time accuracy: } \pm 1 \text { minute per week at } \\
+68^{\circ} \mathrm{F}\left(+20^{\circ} \mathrm{C}\right) \\
\end{array}$ \\
\hline
\end{tabular}




\begin{tabular}{|c|c|c|}
\hline 25 & 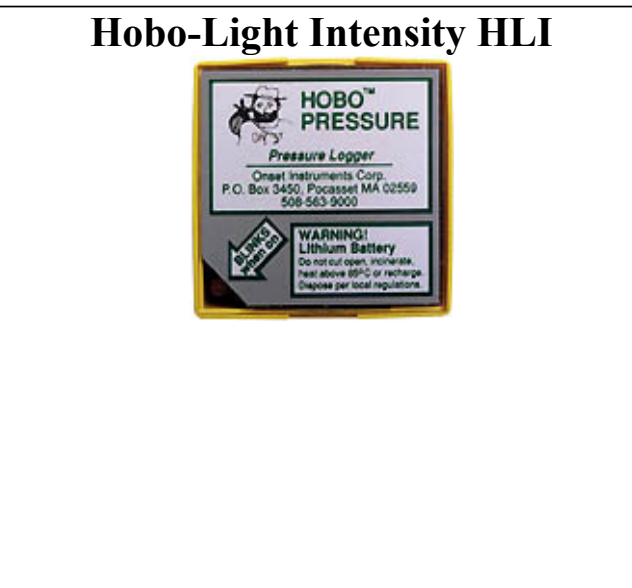 & $\begin{array}{l}\text { Features: } \\
\text { Single-channel model features available } \\
\text { with: } \\
\text { - Wider light intensity range } \\
\text { - Atmospheric pressure logging } \\
\text { - Blinking LED confirms operation } \\
\text { * Measurement range from less than } 0.01 \\
\text { lumens/square foot to over } 15,000 \\
\text { lumens/square foot } \\
\text { - Wide spectral response } \\
\text { - Wide dynamic range }\end{array}$ \\
\hline 26 & $\begin{array}{l}\text { Hobo Stainless Steel Temperature } \\
\text { Probe } \\
\end{array}$ & 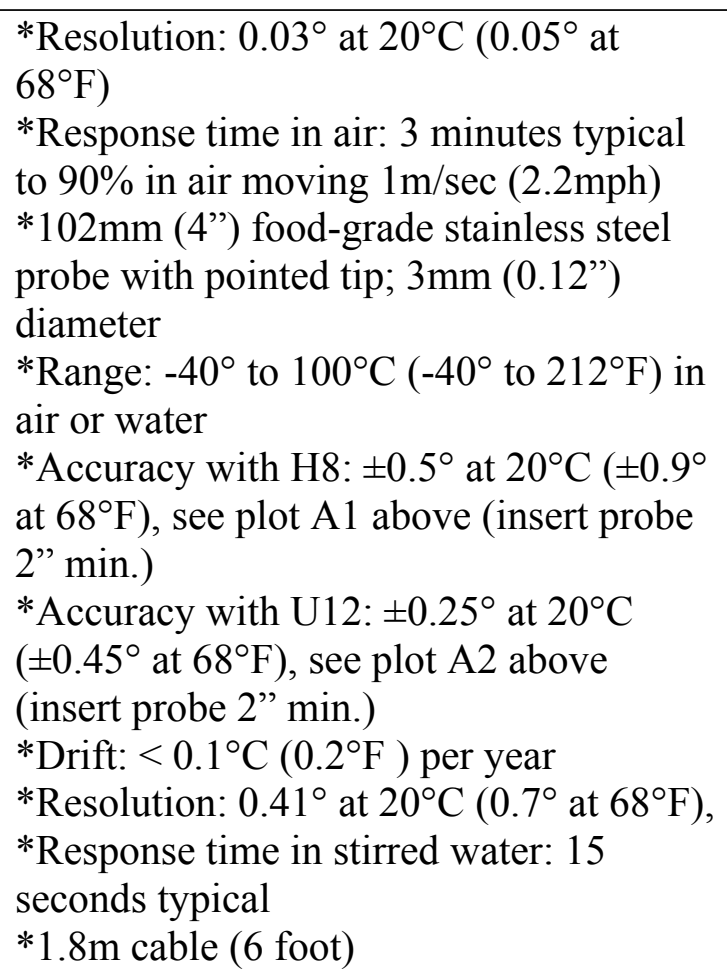 \\
\hline
\end{tabular}




\begin{tabular}{|c|c|c|}
\hline 27 & 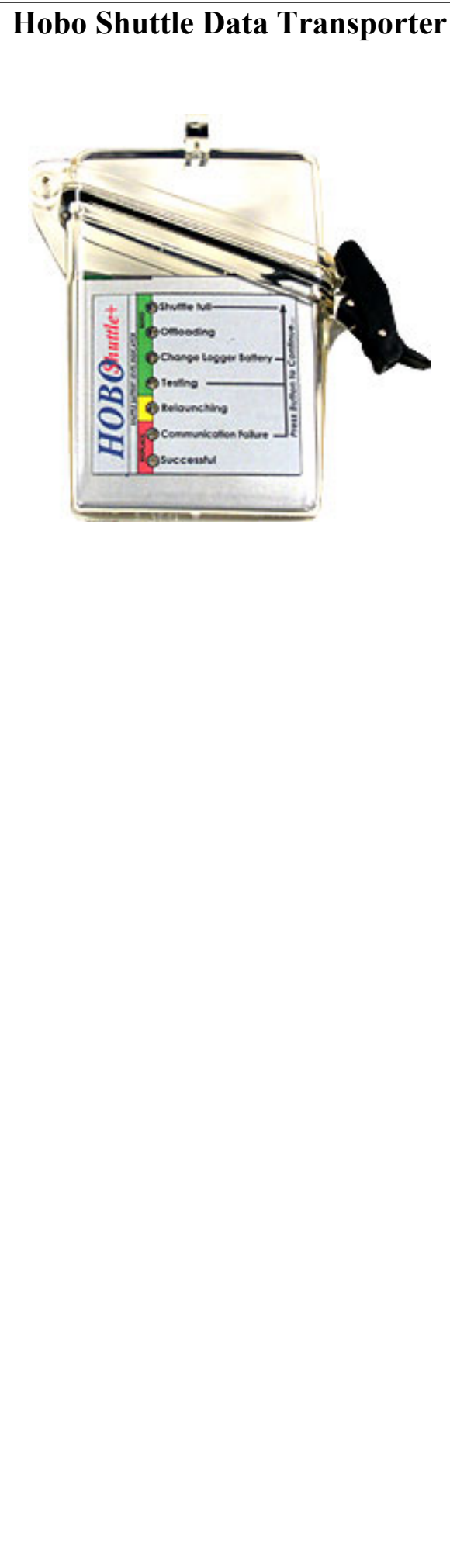 & $\begin{array}{l}\text { Case: weatherproof when closed; } \\
\text { made from clear styrene } \\
\text { - Size: } 12.1 \text { x } 8.9 \times 3.8 \mathrm{~cm}(4.75 \times 3.5 \\
\left.\text { x } 1.5^{\prime \prime}\right) \text {, adjustable cord attached } \\
\text { - Weight: approx. } 193.3 \text { grams ( } 6.82 \\
\text { oz.) } \\
\text { 468K capacity is enough for } 51 \text { full } \\
\text { 8K loggers or } 13 \text { full } 32 \mathrm{~K} \text { loggers or } \\
7 \text { full } 64 \mathrm{~K} \text { loggers } \\
\text { - Provides triggered start on location } \\
\text { - Verifies operation of HOBO H6 } \\
\text { Family and HOBO Event data } \\
\text { loggers } \\
\text { - Synchronizes HOBO data logger's } \\
\text { clock with the PC's clock } \\
\text { Resynchronized relaunch: sets the } \\
\text { HOBO's sample times to be } \\
\text { synchronized with the prior launch's } \\
\text { sample times } \\
\text { - Uploads the same data to a PC as if } \\
\text { the data were read out directly from } \\
\text { the logger } \\
\text { - User-replaceable batteries last } 1 \text { year } \\
\text { (typical) } \\
\text { Battery indication: HOBO Shuttle's } \\
\text { battery status can be displayed on } \\
\text { shuttle or displayed in percent by } \\
\text { BoxCar Pro software } \\
\text { - One-foot connector cable fits inside } \\
\text { case } \\
\text { Data offload time from logger: } 90 \\
\text { seconds typical from } 8 \mathrm{~K} \text { logger, } \\
\text { about } 6 \text { min from } 32 \mathrm{~K} \text { logger and } \\
\text { about } 1 \text { min from } 64 \mathrm{~K} \text { HOBO Pro } \\
\text { logger } \\
\text { Data readout time to PC: } 2 \text { minutes } \\
\text { typical for full shuttle } \\
\text { Time accuracy: } \pm 1 \text { minute per week } \\
\text { at }+68^{\circ} \mathrm{F} \text { (20ㄷ). The HOBO } \\
\text { Shuttle's clock is synchronized to the } \\
\text { computer clock when the HOBO } \\
\text { Shuttle is read out or launched }\end{array}$ \\
\hline
\end{tabular}




\begin{tabular}{|c|c|c|c|}
\hline 28 & $\begin{array}{c}\text { Battery Powered Digital Pressure } \\
\text { Gage }\end{array}$ & $\begin{array}{l}\text { Options: } \\
\text { Analog output (0-2 VDC output) } \\
\text { Zero adjust knob } \\
4-20 \text { mA output (loop powered) } \\
0-5 \text { VDC output (external power) } \\
\pm 0.1 \% \text { accuracy on selected ranges } \\
\text { *Self-powered by standard } 9 \text { V battery } \\
\text { Large,full } 4 \text { digit display with } 0.5 \text { in.characters } \\
\text { Microprocessor-based circuit has "TARE" } \\
\text { capability standard } \\
\text { Ranges vacuum to } 10,000 \text { psi } \\
\text { Direct reading to } 10,000 \text { psi }(9,999) \\
\text { On/off switch with optional auto-off circuit } \\
\text { Peak-hold and analog outputs available } \\
\pm 0.25 \% \text { of full-scale accuracy } \\
\text { Options: } \\
\text { *Metric units available at standard price. } \\
\text { Rear-facing pressure connection } \\
\text { Peak-hold }\end{array}$ & 3 \\
\hline 29 & Pressure Transducer & $\begin{array}{l}\text { *Interface 2' Cable } \\
\text { *Pressure Port } 1 / 4-18 \text { NPT } \\
\text { SENSOR 300PSIG STEEL 4-20MA } \\
\text { OUT } \\
\text { *Vendor } \\
\text { SenSym ICT } \\
\text { *Operating Pressure } \\
\text { 0-300 PSIG } \\
\text { *Voltage-Rated } \\
\text { 12V } \\
\text { *Output } \\
\text { 4-20mA } \\
\text { *Package / Case } \\
\text { N/A Gauge } \\
\text { *Pressure Type } \\
\text { Calibrated and Temperature } \\
\text { Compensated Steel }\end{array}$ & 20 \\
\hline
\end{tabular}




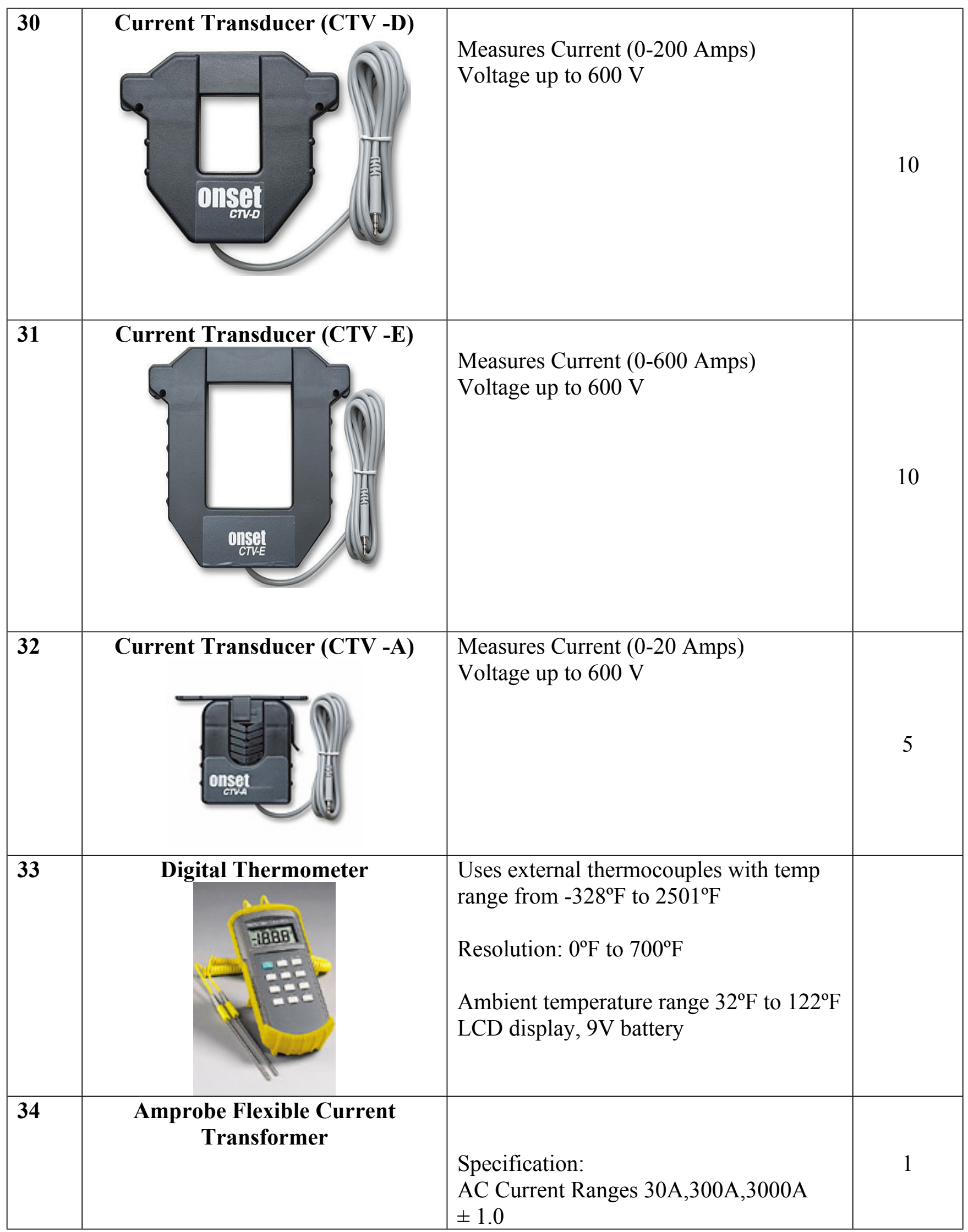




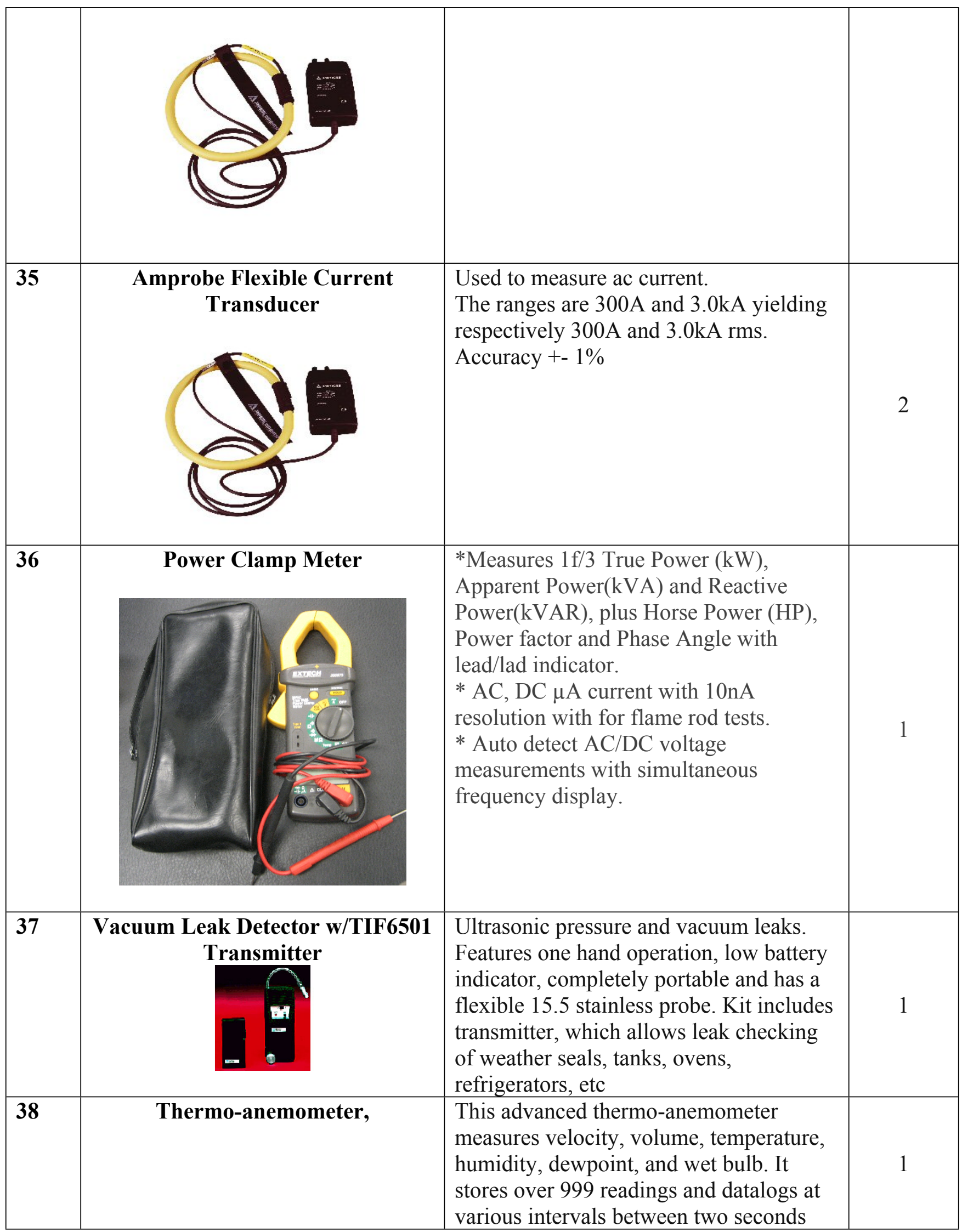




\begin{tabular}{|c|c|c|c|}
\hline & \& & $\begin{array}{l}\text { and one hour. The } 8585 \text { also has the } \\
\text { capability of printing in real-time to a } \\
\text { MicroPrinter or downloading stored data } \\
\text { to a computer. } \\
\text { Range: VELOCITY } 30-9999 \mathrm{fpm} \\
\text { VOLUME : } 0.2-2,600,000 \mathrm{cfm} \\
\text { TEMPERATURE: } 14-140 \mathrm{o} \mathrm{F} \\
\text { HUMIDITY: } 5-95 \% \\
\text { Resolution: VELOCITY } 1 \mathrm{fpm} \\
\text { TEMPERATURE }: 0.1 \mathrm{o} \text { F } \\
\text { HUMIDITY : } 0.1 \% \\
\text { Accuracy VELOCITY } \pm 3 \% \text { of reading } \\
\text { or } \pm 3 \text { fpm (whichever is greater) } \\
\text { VOLUME: } \pm 3 \% \text { of reading } \\
\text { TEMPERATURE }: \pm 0.5 \mathrm{o} \text { F } \\
\text { HUMIDITY : } \pm 3 \% \\
\text { Display A } 4.5 \text { digit LCD with backlight } \\
\text { Battery life A minimum } 24 \text { hours } \\
\text { continuous use }\end{array}$ & \\
\hline 39 & & $\begin{array}{l}1,000,000 \text { candlepower } \\
\text { Works from } 12 \text {-volt DC lighter plug or } \\
110 \text {-vold AC charger. }\end{array}$ & \\
\hline 40 & Digital Thermometer / Pyrometer & $\begin{array}{l}\text { Range: }-40^{\circ} \text { to } 1999^{\circ} \mathrm{F}\left(-40^{\circ} \text { to } 1100^{\circ} \mathrm{C}\right) \\
\text { Resolution: } 1^{\circ} \mathrm{F}\left(1^{\circ} \mathrm{C}\right) \\
\text { Accuracy: } \quad \pm 1 \%, \pm 1 \text { digit }\left(32^{\circ} \text { to }\right. \\
\left.212^{\circ} \mathrm{F}\right) \\
\text { Operating Temp: } \quad 32^{\circ} \text { to } 125^{\circ} \mathrm{F}\left(0^{\circ} \text { to }\right. \\
\left.52^{\circ} \mathrm{C}\right)\end{array}$ & 1 \\
\hline
\end{tabular}




\begin{tabular}{|l|l|l|}
\hline Power Supply: $19 \mathrm{~V}$ Battery \\
Response Time: 1 10 seconds \\
Probe Cord Length: 36" (91.4cm)
\end{tabular} \mid




\begin{tabular}{|c|c|c|c|}
\hline 43 & $\begin{array}{c}\text { PROElectronic Distance } \\
\text { Measuring Tool (Ultrasonic) }\end{array}$ & $\begin{array}{l}\text { Measures } 11 / 2 \text { to } 60 \text { Feet in Single Mode } \\
-11 / 2 \text { to } 250 \text { Feet in Dual Mode - } \\
\text { Accuracy } 99.5 \% \text { - For Indoor/Outdoor } \\
\text { Use }\end{array}$ & 1 \\
\hline 44 & Linemen's Rubber Gloves & $\begin{array}{l}\text { All high voltage and low voltage Gloves } \\
\text { feature straight cuffs and thick natural } \\
\text { rubber throughout. Class } 1,10 \mathrm{KV} \text { test } \\
\text { voltage with } 7500 \mathrm{AC} \text { maximum use } \\
\text { voltage. Class } 2,20 \mathrm{KV} \text { test voltage with } \\
17,000 \mathrm{AC} \text { maximum use voltage. Class } \\
3,30 \mathrm{KV} \text { test voltage with } 26,500 \mathrm{AC} \\
\text { maximum use voltage. Class } 0 \text {, lighter } \\
\text { weight, one-color low voltage gloves are } \\
\text { widely used in meter departments and } \\
\text { other low voltage applications. } 5 \mathrm{KV} \text {. } \\
1000 \mathrm{AC} \text { maximum use voltage. }\end{array}$ & 2 \\
\hline 45 & $\begin{array}{c}\text { Stroboscope, Ametek Digistrobe } \\
\text { III }\end{array}$ & $\begin{array}{l}\text { The AMETEK DIGISTROBE }{ }^{\circledR} \text { Series } \\
\text { are easy-to-use, multifunction digital } \\
\text { instruments that provide both stroboscope } \\
\text { and tachometer functionality in one unit. } \\
\text { With a flash rate of } 20.0 \text { to } 29,999 \text { FPM } \\
\text { and a tachometer range of } 120.0 \text { to } \\
99,999 \text { RPM, these instruments are ideal } \\
\text { for most speed measurement } \\
\text { applications. They have an accuracy of } \\
+0.01 \% \text { + LSD. The } \\
\text { DIGISTROBE } \\
\text { either magnetic or photoelectric pickups } \\
\text { (AMETEK does not manufacture these } \\
\text { pickups), may be manually adjusted to } \\
\text { the desired flash rate. }\end{array}$ & 2 \\
\hline
\end{tabular}




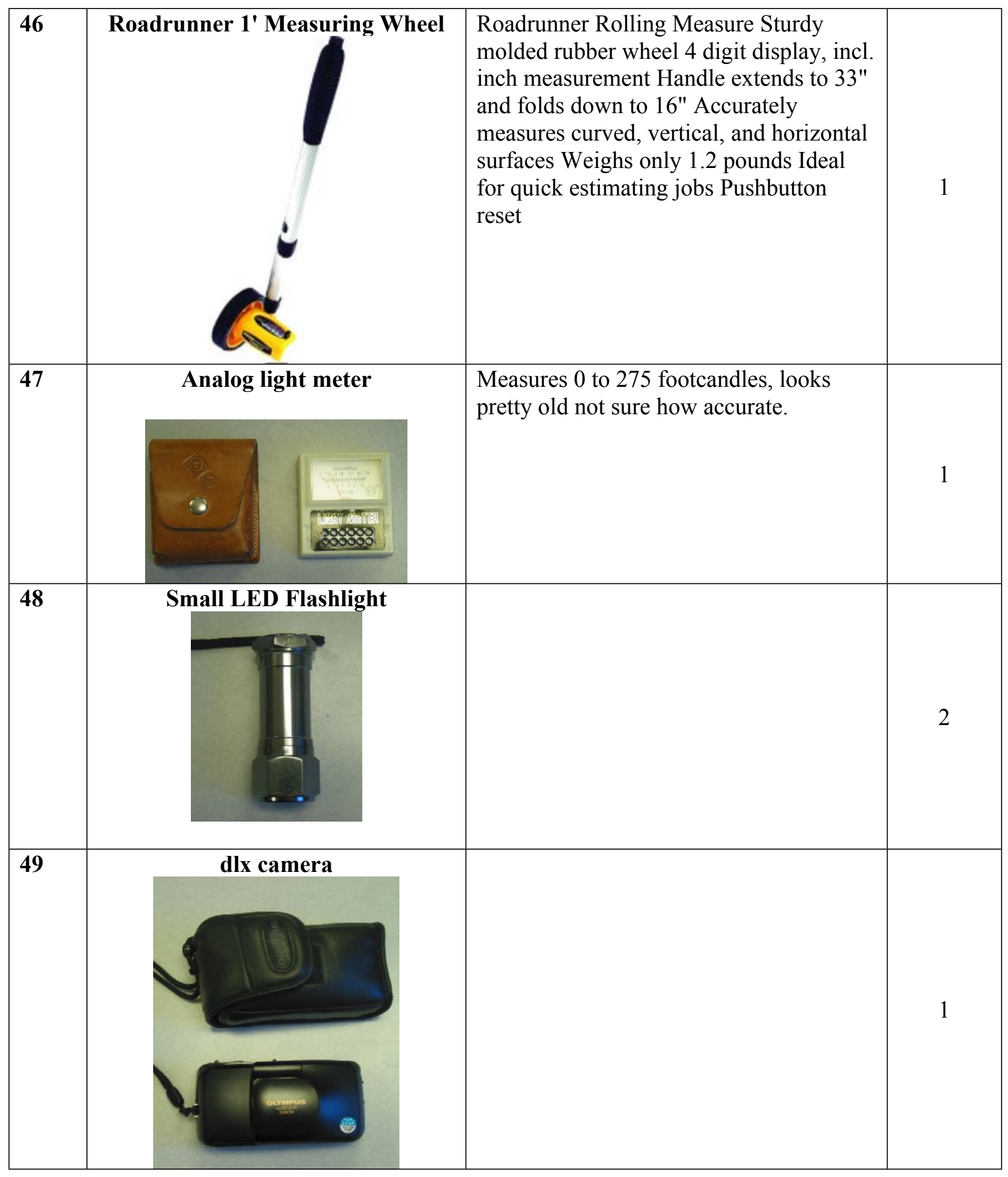




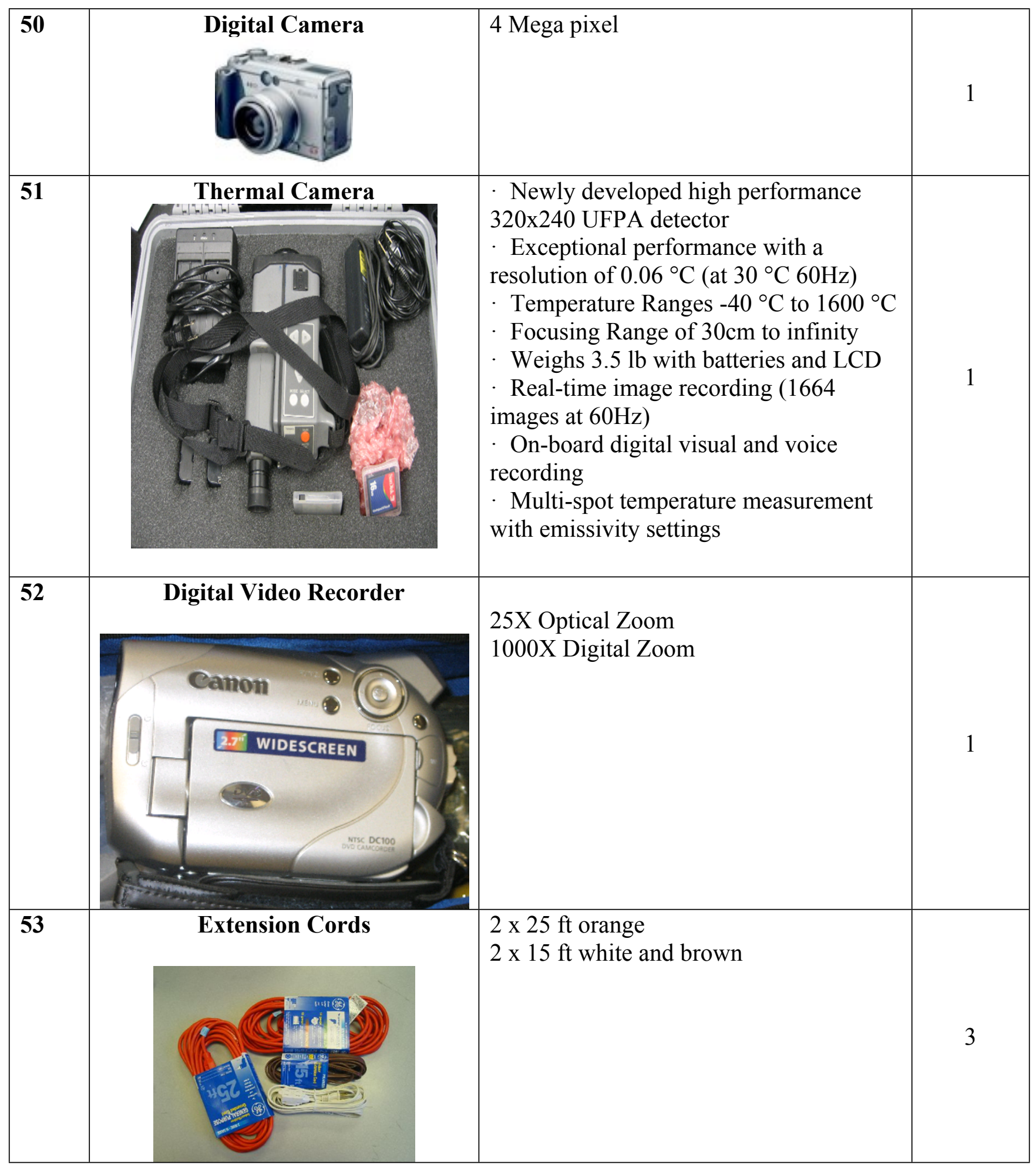




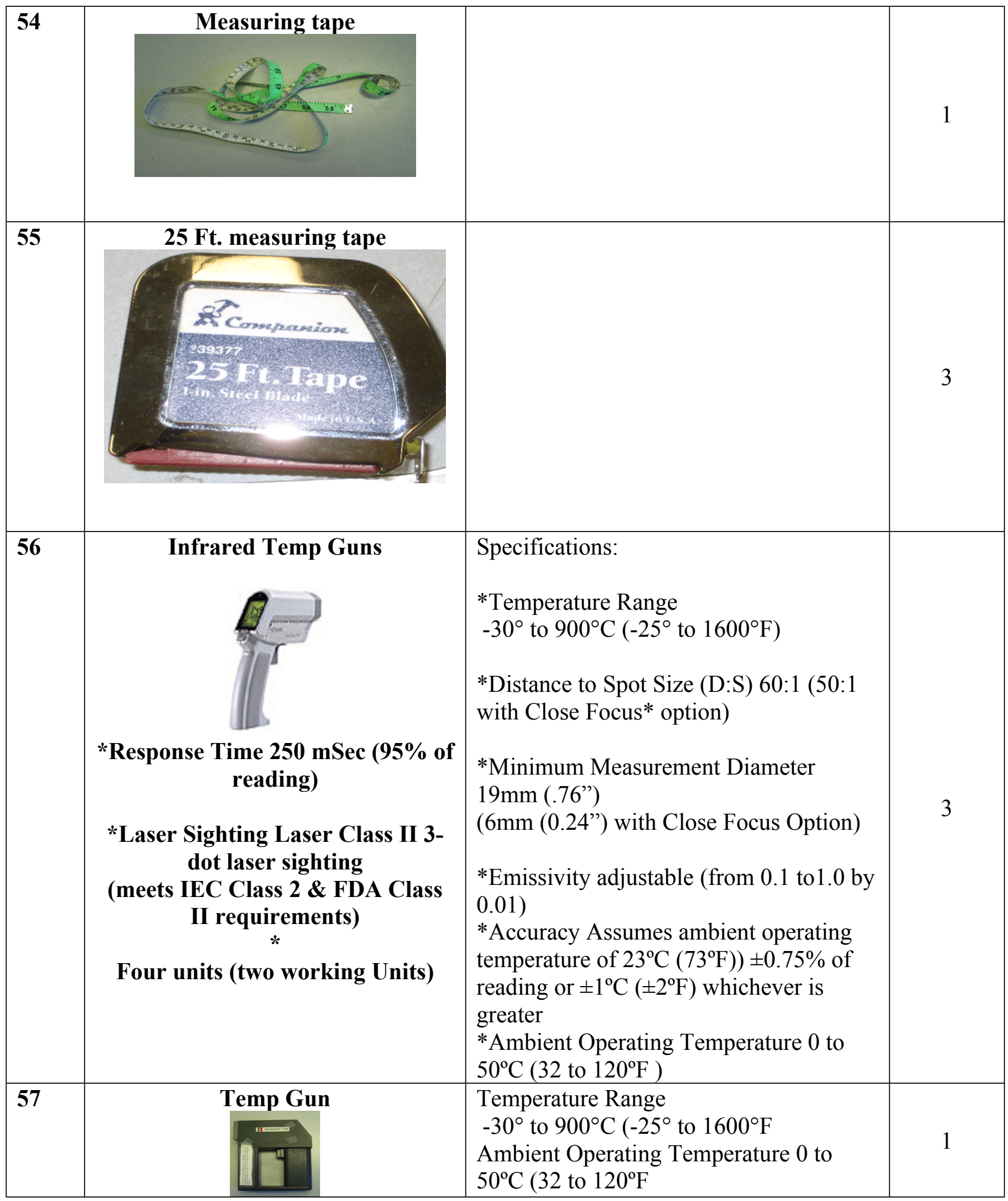




\begin{tabular}{|c|c|c|c|}
\hline 58 & Light Meter & $\begin{array}{l}\text { *\% displays differential from reference } \\
\text { point } \\
\text { *“ZERO” Re-Calibration } \\
\text { *Enhance accuracy by selecting lighting } \\
\text { type Tungsten/Daylight, Fluorescent, } \\
\text { Sodium, Mercury) } \\
\text { *Data Hold, Min/Max/Avg readings } \\
\text { *Built-in RS-232 PC serial interface } \\
\text { Part \#407026 }\end{array}$ & 1 \\
\hline 59 & $\begin{array}{l}\text { Multifunctional Instrument } \\
\text { Operation temperature } 0 \text { to }+50{ }^{\circ} \mathrm{C} \\
\left(32 \text { to }+122^{\circ} \mathrm{F}\right) \\
\text { short-term } 0 \text { to }+60^{\circ} \mathrm{C}(32 \text { to } \\
\left.+140^{\circ} \mathrm{F}\right)\end{array}$ & $\begin{array}{l}\text { Temperature Range }-200 \text { to }+800{ }^{\circ} \mathrm{C} \text { (- } \\
328 \text { to }+1472{ }^{\circ} \mathrm{F} \text { ) } \\
\text { System Accuracy up to } \pm 0.1^{\circ} \mathrm{C} / \pm 0.1^{\circ} \mathrm{F} \\
\text { (Class A, B) } \\
\text { Resolution } 0.01{ }^{\circ} \mathrm{C}\left(0.01{ }^{\circ} \mathrm{F}\right) \\
\text { Measuring Range } 0 \text { to } 100 \% \mathrm{RH} \\
\text { System Accuracy up to } \pm 1.0 \% \mathrm{RH} \\
\text { Pressure } \\
\text { Measuring Range } \pm 0.1 \mathrm{bar} \pm 0.01 \mathrm{bar} ; 2 \\
\text { bar } 10 \text { bar } 30 \text { bar } \\
\text { Velocity } \\
\text { Vane Measuring Range } 0 \text { to } 60 \mathrm{~m} / \mathrm{s}(0 \text { to } \\
12,000 \text { fpm) } \\
\text { Thermal Measuring Range } 0 \text { to } 20 \mathrm{~m} / \mathrm{s}(0 \\
\text { to } 4,000 \mathrm{fpm}) \\
\text { Pitot tube measuring range } 0 \text { to } 10 \mathrm{mbar} / \\
100 \mathrm{mbar} \\
0 \text { to } 40 \mathrm{~m} / \mathrm{s} / 100 \mathrm{~m} / \mathrm{s}(0 \text { to } 8,000 / 20,000 \\
\text { fpm) } \\
\text { Volume flow in } 1 / \mathrm{s}, \mathrm{m} 3 / \mathrm{min}, \mathrm{m} 3 / \mathrm{h} \\
\text { Measuring Range } 360.000 \mathrm{cfm} \text { (max. } \\
\text { calculated at } 1 \mathrm{~m} 2,20,000 \mathrm{fpm} \text { values) } \\
\text { CO } \\
\text { Measuring Range } 0 \text { to } 500 \mathrm{ppm} \\
\text { Accuracy } \pm 5 \mathrm{ppm} \\
\text { CO2 }\end{array}$ & 1 \\
\hline
\end{tabular}




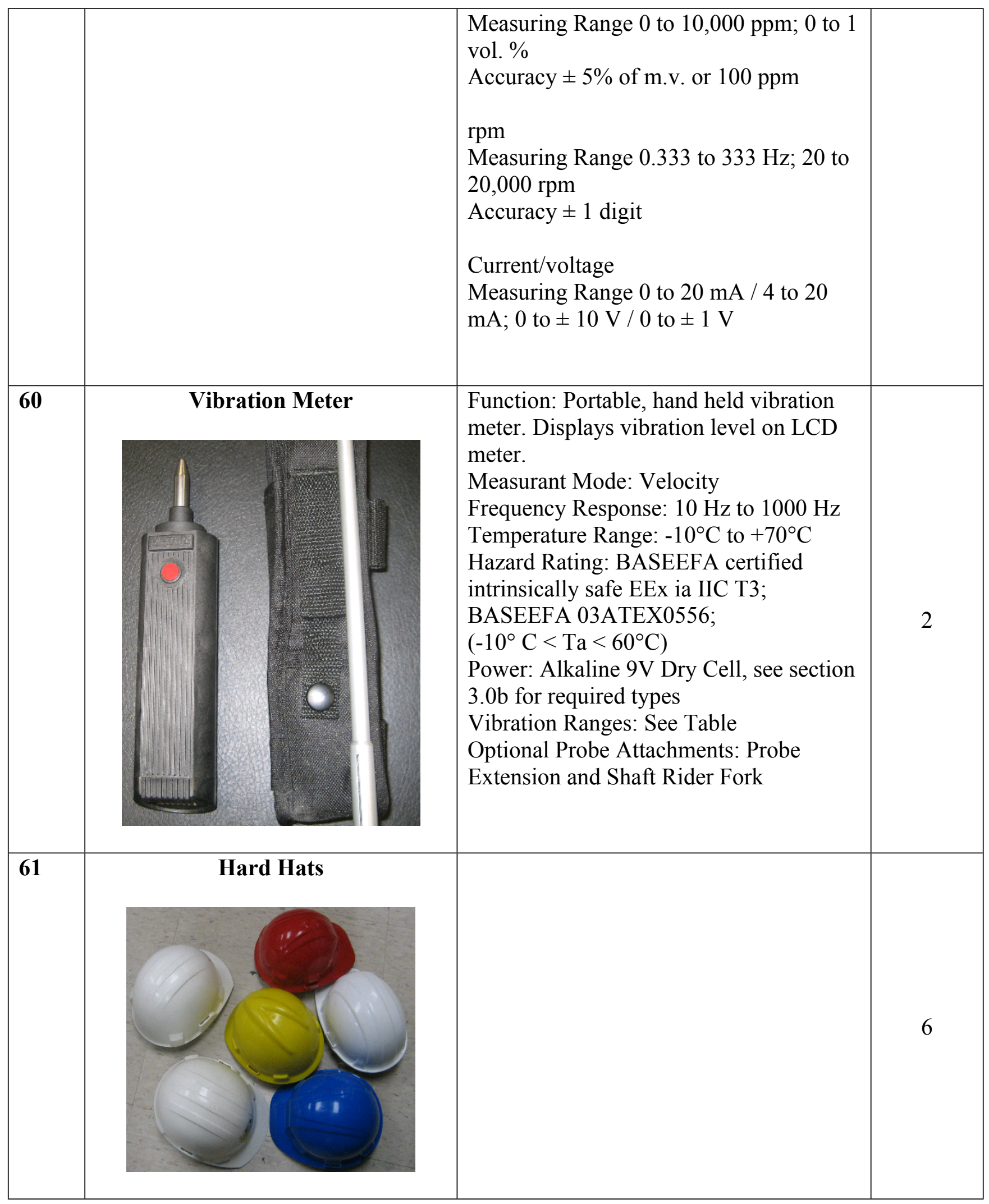




\begin{tabular}{|c|c|c|c|}
\hline 62 & Multi Tool Bit & & 1 \\
\hline 63 & Portable Digital Manometers & 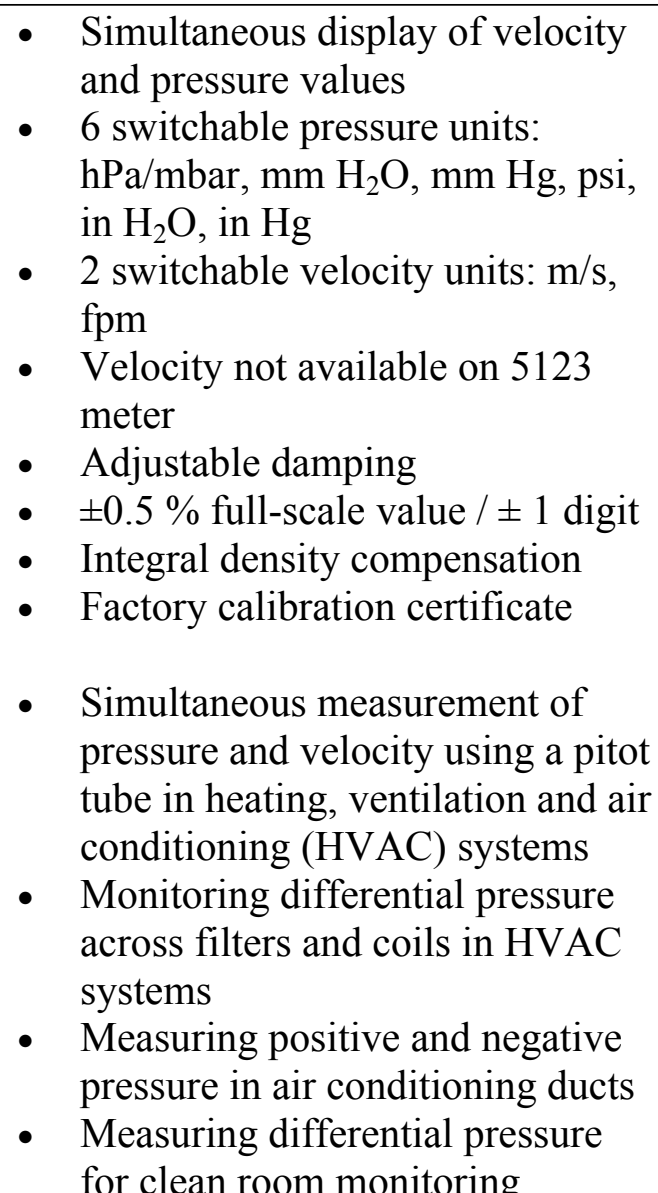 & 1 \\
\hline
\end{tabular}




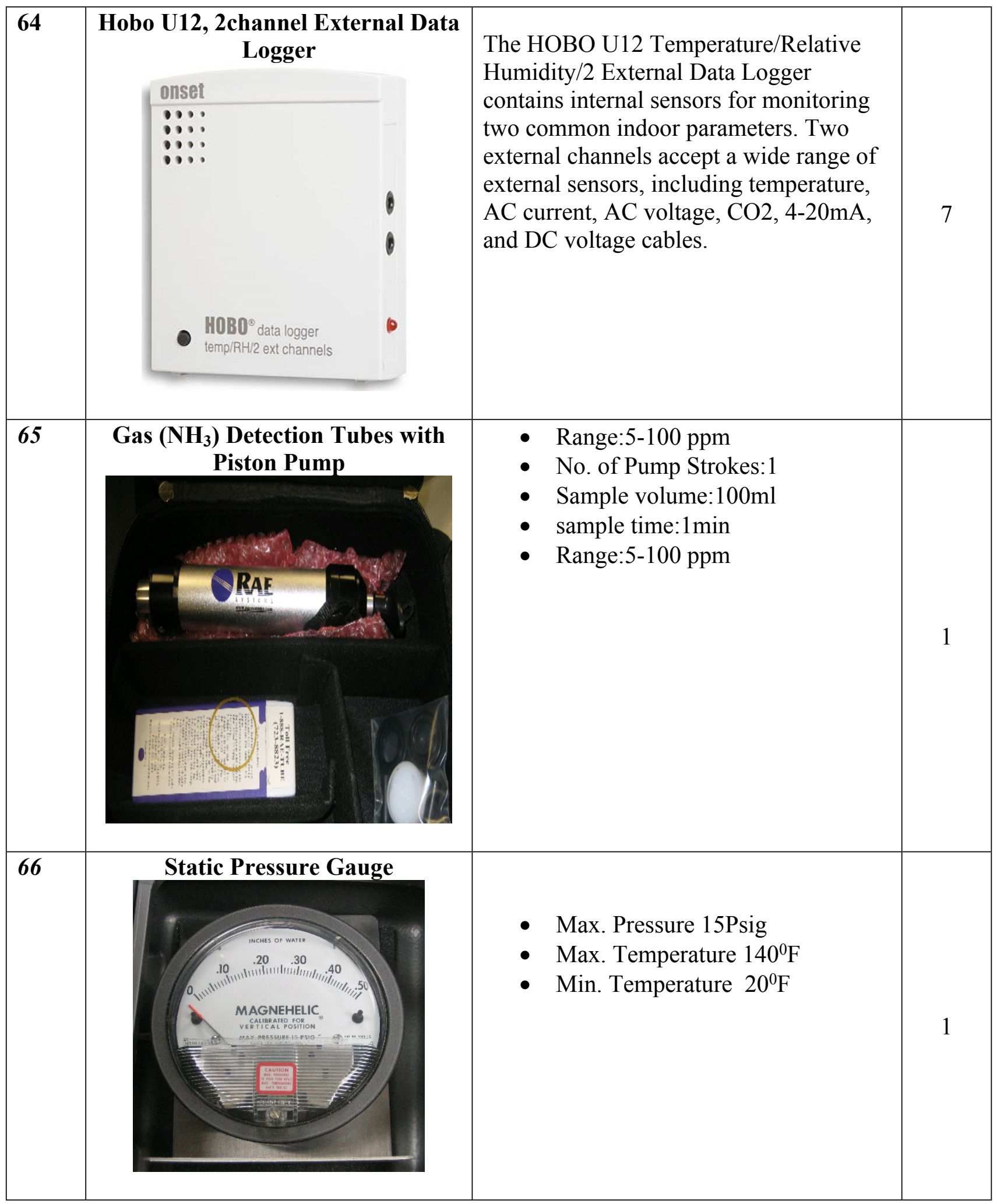




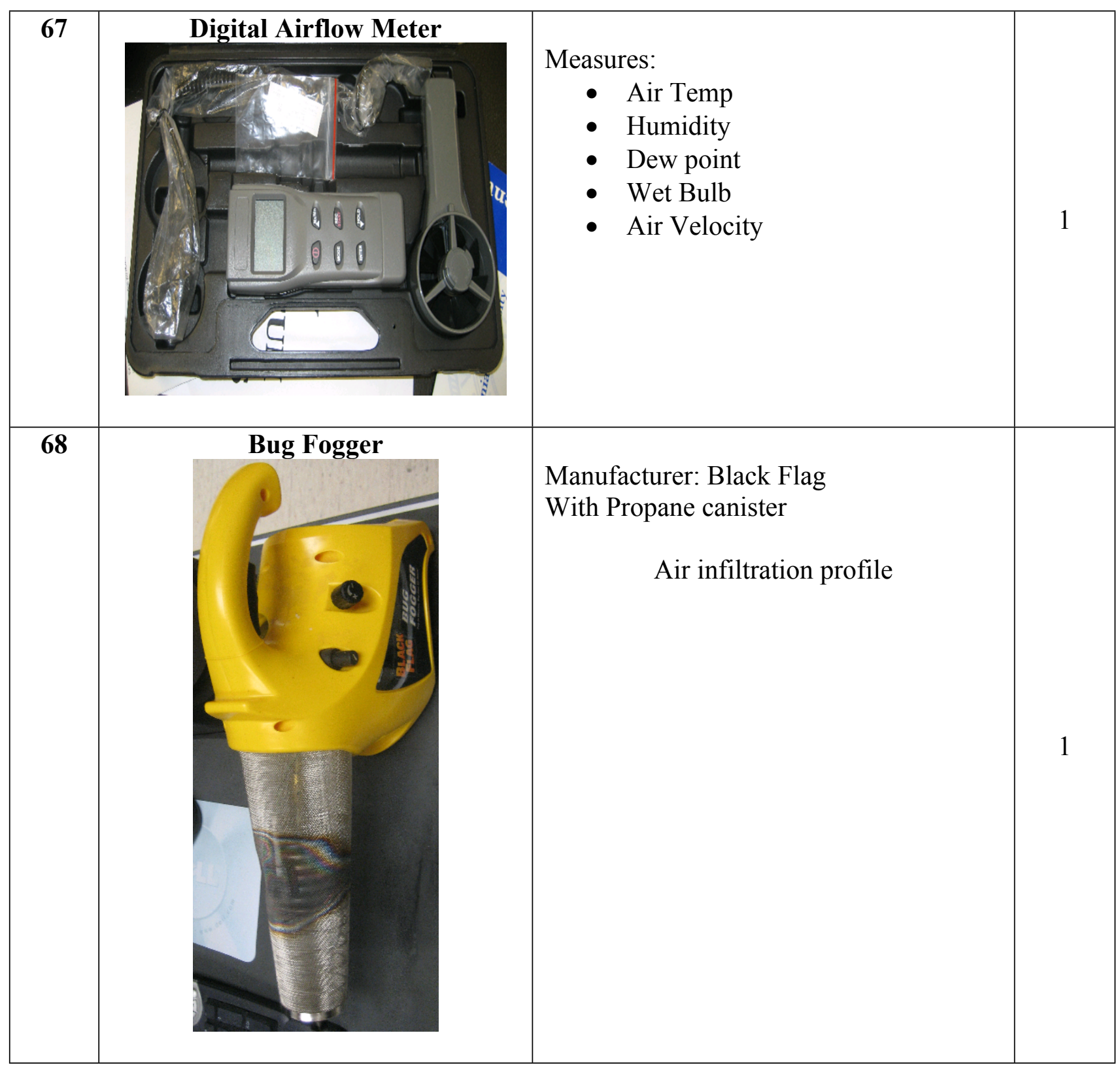




\section{Appendix II: Sample IAC Pre Assessment Questionnaire}

INDUSTRIAL ASSESSMENT CENTER

PLANT BACKGROUND INFORMATION

Plant Name

City

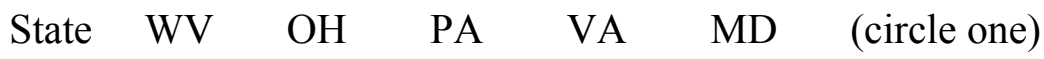

Contact Person

Number of Employees:

Number of salaried employees:

Principal Product:

Working Hours:
1. Office
From
A.M. to
P.M.

Number of days per week:

Number of weeks per year:

2. Production Area:

Number of hours per day:

Number of days per week:

Number of weeks per year:

Note down any special shutdowns, overtimes, different operating hours in different areas of

the plant. This information will affect the operating time calculations: 
Annual Sales: \$ million

Plant and Office Area: $\mathrm{ft}^{2} \quad$ (Ask for plant layout)

Were energy bills sent to IAC office: YES / NO

If 'YES', were they complete: YES / NO

Labor rate for in-house maintenance including fringe benefits: $\$$ per hour

Production Volume/ Amount of Material Consumed

\section{Building Construction}

Wall Material:

Insulation on wall: YES / NO

If 'YES', name of insulation material:

Insulation thickness: inches

Roof material:

Insulation on roof: YES / NO

If 'YES', name of insulation material:

Insulation thickness: inches

Major Energy Consuming Equipment: (add more lines as needed) $\underline{\text { Name }}$ Capacity/size Number of Units

1.

2. 
3.

4.

5.

Air conditioning:

Office cooling: (add more lines as needed)

Name / category / type of unit

Number of Units

Capacity/size

1.

2.

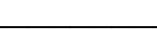

Plant cooling: (add more lines as needed)

Name / category / type of unit Number of Units

Capacity/size

1.

Office heating: (add more lines as needed)

Name / category / type of unit

Capacity/size

Number of Units

1.

Plant Heating: (add more lines as needed)

Name / category / type of unit

Number of Units

Capacity/size

1.

2.

Heating Setback Temperature:

${ }^{\circ} \mathrm{F}$ 
Cooling Setback Temperature: ${ }^{\circ} \mathrm{F}$

Boilers: (add more lines as needed)

Name / category / type of unit

Capacity/size

1.

2.

3.

Air Compressors: (add more lines as needed)

Name / category / type of unit

Capacity/size

Number of Units

1.

2.

3.

Chiller/Cooling Towers: (add more lines as needed)

Name / category / type of unit

Number of Units

Capacity/size

1.

2.

Any other pertinent equipment: (add more lines as needed)

Name / category / type of unit

Number of Units

\section{Capacity/size}

1. 
2.

3.

4.

5.

Raw Material Used in Manufacturing:

Brief Description of Manufacturing Process:

Waste Generation Information (specifically waste oil and lubricants): 


\section{Appendix III: Sample IAC Assessment Report}

Input from Mike Jr. Muller, Rutgers University 


\section{Appendix IV: Sample Implementation Survey}

Input from Mike Jr. Muller, Rutgers University 